\title{
Análise espacial da distribuição dos casos de dengue e a relação com fatores entomológicos, ambientais e socioeconômicos no município de São José do Rio Preto - SP - Brasil
}

\author{
Sirle Abdo Salloum Scandar
}

Tese apresentada ao Programa de PósGraduação em Saúde Pública da Faculdade de Saúde Pública da Universidade de São Paulo para obtenção do título de Doutor em Saúde Pública.

Área de concentração: Epidemiologia

Orientador: Prof ${ }^{a}$. Dr ${ }^{\mathrm{a}}$. Maria Anice M. Sallum

SÃO PAULO

2007 
Aos meus pais, Najla ( in memorian) e Halim, pelo empenho dedicado à educação de suas filhas e pelo incentivo para a realização deste trabalho. 
Ao meu marido Jorge pelo incentivo, carinho, compreensão e amor fundamentais a realização desse trabalho.

Aos meus filhos Joni, Dayane e Danyele a quem dedico esse trabalho, pelo incentivo, compreensão e carinho recebidos durante a realização desse trabalho. 


\section{AGRADECIMENTOS}

A prof ${ }^{a}$ Maria Anice M. Sallum, pela orientação, estímulo e apoio na construção desse trabalho e pela construção de uma grande amizade fruto do nosso convívio.

Ao amigo Pedro Vieira, pela colaboração na utilização da análise espacial e confecção dos mapas utilizados na tese.

Ao amigo Marcelo Papa, pela colaboração na coleta dos dados, construção de tabelas e gráficos utilizados na tese.

Ao amigo Rubens Pinto Cardoso pelo apoio recebido e pela ajuda e correção do trabalho.

Aos amigos Leila, Rosangela, Cristina e Gercilene do Serviço Regional 08 da SUCEN, pelo apoio e incentivo recebido durante a realização desse trabalho.

A Superintendência de Controle de Endemias - SUCEN - por ter viabilizado a realização do doutorado.

A Faculdade de Saúde Pública da USP pela acolhida durante o meu doutorado.

A Secretaria Municipal de Saúde do município de São José do Rio Preto, por ter cedido a base cartográfica do município, para a SUCEN e que foi de grande utilidade na elaboração da minha tese.

Aos professores, técnicos e funcionários do Departamento de Epidemiologia da Faculdade de Saúde Pública da USP, pelo apoio recebido. 
Aos funcionários da Seção de Pós-Graduação e da Biblioteca da Faculdade de Saúde Pública da USP pela gentileza sempre dedicada.

APqC Márcia M. Hokman da SUCEN pelos cálculos estatísticos aplicados na tese.

Ao meu filho Joni Salloum Scandar pela tradução do resumo da tese para a língua inglesa.

Ao Rubens Silva da SUCEN pela ajuda na revisão do trabalho 


\section{Resumo}

Scandar SAS. Análise espacial da distribuição dos casos de dengue e a relação com fatores entomológicos, ambientais e socioeconômicos no município de São José do Rio Preto - SP - Brasil [tese de doutorado]. São Paulo: Faculdade de Saúde Pública da USP; 2007.

Foram georreferenciados 14.554 casos de dengue. As maiores incidências observadas para o período, foram nas áreas 7 e 8 (regiões leste e centro respectivamente). Nessas áreas, a incidência variou de 381 a 432 casos por 100.000 habitantes. O índice de Moran estimado foi 0,2517 com a maioria dos aglomerados espaciais na região leste, seguido das regiões centro e norte. Observou-se que a região que apresentou o maior número de casos de dengue foi aquela com padrão de densidade demográfica, renda e grau de escolaridade médios. A incidência de dengue foi maior em indivíduos na faixa etária dos 15 aos 49 anos e 50 anos e mais, e menor na faixa etária de zero a 14 anos. Com relação à incidência por sexo, observa-se que houve variações pequenas, sendo ligeiramente maior no sexo feminino. Os resultados da análise de Correlação de Pearson para a incidência de dengue sugerem que a influência da precipitação

pluviométrica e da temperatura não foram estatisticamente significativas, mas o foram com relação ao índice predial. Analisando-se a distribuição das formas imaturas do mosquito Aedes aegypti em diferentes recipientes, observa-se que o vaso mereceu maior destaque, seguido de lata, pote e frasco. A distribuição espacial da dengue não apresentou padrão uniforme, pois a taxa de incidência variou nas 
diversas áreas. Altas incidências de dengue foram observadas tanto em áreas com elevado padrão socioeconômico como naquelas com padrão mais baixo. O nível de infestação larvário, estimado pelo Índice Predial foi maior no período chuvoso. Os resultados deste estudo, em relação ao vetor confirmam a característica de espécie oportunista que já foi registrada para o Aedes aegypti em outras regiões. As formas imaturas do inseto, apesar de serem mais freqüentes em alguns tipos de recipientes, por exemplo, os vasos, podem ocupar outros, dependendo da disponibilidade dos mesmos.

Descritores: Dengue; Georreferenciamento; Aedes aegypti; Habitats; Análise espacial; Variáveis socioeconômicas. 


\begin{abstract}
Scandar SAS. Análise espacial da distribuição dos casos de dengue e a relação com fatores entomológicos, ambientais e socioeconômicos no município de São José do Rio Preto - SP - Brasil./ Spatial analysis of the distribution of the cases of dengue and the relationship with entomologics, environmental and socioeconomics factors, in the municipal district of São José do Rio Preto - SP - Brazil [thesis]. São Paulo (BR): Faculdade de Saúde Pública da Universidade de São Paulo; 2007.
\end{abstract}

It was georeferenced 14.554 cases of dengue. The largest incidences in the period were observed in the areas 7 and 8 (east and center areas respectively). In these areas, the incidence varied from 381 to 432 for 100.000 inhabitants. The index of Moran estimated was of 0,2517 with most of the spatial agglomerates in the east area, followed by the center and north areas. It was observed that the area that presented the largest number of cases of dengue was that with medium demographic density, income and education degree pattern. The dengue incidence was larger in individuals in the age group of the 15 to the 49 years and 50 years and older, and smaller in the age group zero to 14 years. Regarding to incidence for sex, it was observed that there were small variations, being slightly higher in the female gender. The results of the analysis of Correlation of Pearson for dengue incidence suggest that the precipitation and temperature influence were not statistically significant, but they were in relation to the Building Index (Índice Predial). In the analysis of the distribution of the immature stages of the Aedes aegypti in different recipients, it was observed that the vase deserved larger prominence, followed by can, pot and flask. 
The spatial distribution of the dengue did not present uniform pattern, because the incidence rate varied in the several areas. Dengue high incidences were observed as much in areas with high socioeconomic pattern as in those with lower pattern. The larval infestation level, estimated by the Building Index it was larger in the rainy period. The results of this study, in relation to the vector, confirmed the characteristic of opportunist species that was already registered for the Aedes aegypti in other areas. The immature stages of the insect, in spite of they be more frequent in some types of recipients, for instance, in vases, they can occupy other, depending on the readiness of the same ones.

Descriptors: Dengue; Georeferencing; Aedes aegypti; Habitats; Spatial analysis; Socioeconomics variables. 


\section{ÍNDICE}

1 INTRODUÇÃ O........................................................ 19

2 OBJETIVOS ................................................................. 36

2.1 Objetivos Gerais........................................................................... 36

2.2 Objetivos Específicos …………………………………………... 36

3 MATERIAL E MÉTODOS........................................... 37

3.1 ÁREA DE ESTUDO............................................................. 37

3.2 DELINEAMENTO DO ESTUDO.......................................... 38

3.3 CASOS DE DENGUE......................................................... 39

3.4 ANÁLISE ESPACIAL............................................................. 40

3.5 IDENTIFICAÇÃO DE AGLOMERADOS ESPACIAIS......... 42

3.6 INFESTAÇÃO DO VETOR....................................................

3.7 FATORES SOCIOECONÔMICOS.......................................... 47

3.8 FATORES CLIMÁTICOS..................................................... 49

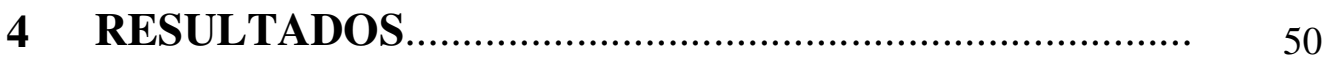

4.1 INCIDÊNCIA DE DENGUE NO MUNICÍPIO DE SÃO JOSÉ DO RIO PRETO NO PERÍODO DE 1990 A 1994....... 50

4.2 INCIDÊNCIA DE DENGUE NO MUNICÍPIO DE SÃO JOSÉ DO RIO PRETO NO PERÍODO DE 1995 A 2005..... 53

4.3 INCIDÊNCIA EM RELAÇÃO À IDADE................................. 82 
4.4 INCIDÊNCIA EM RELAÇÃO AO SEXO............................ 83

4.5 FATORES CLIMÁTICOS................................................. 84

4.6 INFESTAÇÃO DO VETOR - TIPOS DE RECIPIENTES..... 94

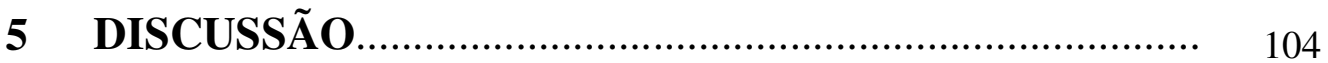

6 CONCLUSÕES ................................................... 121

7 RECOMENDAÇÕES................................................. 124

8 REFERÊNCIAS BIBLIOGRÁFICAS........................... 126 ANEXOS

Anexo 1 - Casos de dengue........................................................... 136

Anexo 2 - Coeficiente geral de Correlação de Pearson............................ 137

Anexo 3 - Variáveis socioeconômicas e ambientais - IBGE - 2000..... 138 


\section{Lista de Figuras}

Figura 1 Localização do município de São José do Rio Preto - Estado de São Paulo

Figura 2 Mapa da área urbana do município de São José do Rio Preto Estado de São Paulo, Brasil, segundo as áreas de controle de vetores definidas pela Secretaria Municipal de Saúde e Superintendência de Controle de Endemias (SUCEN)....................... 4

Figura 3 Diagrama de espalhamento de Moran............................................... 44

Figura 4 Distribuição espacial da incidência de dengue por 100.000 habitantes, nas áreas de controle de vetores do município de São José do Rio Preto - Estado de São Paulo, no período de 1990 a 1994.

Figura 5 Distribuição de dengue por aglomerados espaciais no município de São José do Rio Preto - Estado de São Paulo, no período de 1990 a 1994

Figura 6 Distribuição espacial da incidência de dengue por 100.000 habitantes, nas áreas de controle de vetores do município de São José do Rio Preto - Estado de São Paulo, no período de 1995............

Figura 7 Distribuição de dengue por aglomerados espaciais no município de São José do Rio Preto - Estado de São Paulo, no período de 1995....

Figura 8 Distribuição espacial da incidência de dengue por 100.000 habitantes, nas áreas de controle de vetores do município de São José do Rio Preto - Estado de São Paulo, no período de 1996.

Figura 9 Distribuição de dengue por aglomerados espaciais no município de São José do Rio Preto - Estado de São Paulo, no período de 1996....

Figura 10 Distribuição espacial da incidência de dengue por 100.000 habitantes, nas áreas de controle de vetores do município de São José do Rio Preto - Estado de São Paulo, no período de 1997.

Figura 11 Distribuição de dengue por aglomerados espaciais no município de São José do Rio Preto - Estado de São Paulo, no período de 1997.... 
Figura 12 Distribuição espacial da incidência de dengue por 100.000 habitantes, nas áreas de controle de vetores do município de São José do Rio Preto - Estado de São Paulo, no período de 1998............

Figura 13 Distribuição de dengue por aglomerados espaciais no município de São José do Rio Preto - Estado de São Paulo, no período de 1998....

Figura 14 Distribuição espacial da incidência de dengue por 100.000 habitantes, nas áreas de controle de vetores do município de São José do Rio Preto - Estado de São Paulo, no período de 1999............

Figura 15 Distribuição de dengue por aglomerados espaciais no município de São José do Rio Preto - Estado de São Paulo, no período de 1999....

Figura 16 Distribuição espacial da incidência de dengue por 100.000 habitantes, nas áreas de controle de vetores do município de São José do Rio Preto - Estado de São Paulo, no período de 2000...........

Figura 17 Distribuição de dengue por aglomerados espaciais no município de São José do Rio Preto - Estado de São Paulo, no período de 2000....

Figura 18 Distribuição espacial da incidência de dengue por 100.000 habitantes, nas áreas de controle de vetores do município de São José do Rio Preto - Estado de São Paulo, no período de 2001...........

Figura 19 Distribuição de dengue por aglomerados espaciais no município de São José do Rio Preto - Estado de São Paulo, no período de 2001....

Figura 20 Distribuição espacial da incidência de dengue por 100.000 habitantes, nas áreas de controle de vetores do município de São José do Rio Preto - Estado de São Paulo, no período de 2002............

Figura 21 Distribuição de dengue por aglomerados espaciais no município de São José do Rio Preto - Estado de São Paulo, no período de 2002....

Figura 22 Distribuição espacial da incidência de dengue por 100.000 habitantes, nas áreas de controle de vetores do município de São José do Rio Preto - Estado de São Paulo, no período de 2003............

Figura 23 Distribuição de dengue por aglomerados espaciais no município de São José do Rio Preto - Estado de São Paulo, no período de 2003.... 
Figura 24 Distribuição espacial da incidência de dengue por 100.000 habitantes, nas áreas de controle de vetores do município de São José do Rio Preto - Estado de São Paulo, no período de 2004............

Figura 25 Distribuição de dengue por aglomerados espaciais no município de São José do Rio Preto - Estado de São Paulo, no período de 2004....

Figura 26 Distribuição espacial da incidência de dengue por 100.000 habitantes, nas áreas de controle de vetores do município de São José do Rio Preto - Estado de São Paulo, no período de 2005............

Figura 27 Distribuição de dengue por aglomerados espaciais no município de São José do Rio Preto - Estado de São Paulo, no período de 2005.... 75

Figura 28 Distribuição espacial da incidência de dengue por 100.000 habitantes, nas áreas de controle de vetores do município de São José do Rio Preto - Estado de São Paulo, no período de 1990 a 2005 .

Figura 29 Distribuição de dengue por aglomerados espaciais no município de São José do Rio Preto - Estado de São Paulo, no período de 1990 a 2005.

Figura 30 Distribuição espacial da incidência de dengue por 100.000 habitantes, nas áreas de controle de vetores associado à variável renda média dos responsáveis pelas famílias no município de São José do Rio Preto - Estado de São Paulo, no período de 1990 a 2005 .

Figura 31 Distribuição espacial da incidência de dengue por 100.000 habitantes, nas áreas de controle de vetores associado à variável grau de escolaridade no município de São José do Rio Preto Estado de São Paulo, no período de 1990 a 2005.

Figura 32 Distribuição espacial da incidência de dengue por 100.000 habitantes, nas áreas de controle de vetores associado à variável de cobertura de serviços, abastecimento e coleta no município de São José do Rio Preto - Estado de São Paulo, no período de 1990 a 2005 . 
Figura 33 Distribuição espacial da incidência de dengue por 100.000 habitantes, nas áreas de controle de vetores associado à variável densidade demográfica no município de São José do Rio Preto Estado de São Paulo, no período de 1990 a 2005.

Figura 34 Índice predial, temperatura, índice pluviométrico e incidência de casos de dengue por mês, no município de São José do Rio Preto Estado de São Paulo, no ano de 1990

Figura 35 Índice predial, temperatura, índice pluviométrico e incidência de casos de dengue por mês, no município de São José do Rio Preto Estado de São Paulo, no ano de 1991.

Figura 36 Índice predial, temperatura, índice pluviométrico e incidência de casos de dengue por mês, no município de São José do Rio Preto Estado de São Paulo, no ano de 1993.

Figura 37 Índice predial, temperatura, índice pluviométrico e incidência de casos de dengue por mês, no município de São José do Rio Preto Estado de São Paulo, no ano de 1994.

Figura 38 Índice predial, temperatura, índice pluviométrico e incidência de casos de dengue por mês, no município de São José do Rio Preto Estado de São Paulo, no ano de 1995.

Figura 39 Índice predial, temperatura, índice pluviométrico e incidência de casos de dengue por mês, no município de São José do Rio Preto Estado de São Paulo, no ano de 1996.

Figura 40 Índice predial, temperatura, índice pluviométrico e incidência de casos de dengue por mês, no município de São José do Rio Preto Estado de São Paulo, no ano de 1997.

Figura 41 Índice predial, temperatura, índice pluviométrico e incidência de casos de dengue por mês, no município de São José do Rio Preto Estado de São Paulo, no ano de 1998.

Figura 42 Índice predial, temperatura, índice pluviométrico e incidência de casos de dengue por mês, no município de São José do Rio Preto Estado de São Paulo, no ano de 1999. 
Figura 43 Índice predial, temperatura, índice pluviométrico e incidência de casos de dengue por mês, no município de São José do Rio Preto Estado de São Paulo, no ano de 2000.

Figura 44 Índice predial, temperatura, índice pluviométrico e incidência de casos de dengue por mês, no município de São José do Rio Preto Estado de São Paulo, no ano de 2001.

Figura 45 Índice predial, temperatura, índice pluviométrico e incidência de casos de dengue por mês, no município de São José do Rio Preto Estado de São Paulo, no ano de 2002.

Figura 46 Índice predial, temperatura, índice pluviométrico e incidência de casos de dengue por mês, no município de São José do Rio Preto Estado de São Paulo, no ano de 2003.

Figura 47 Índice predial, temperatura, índice pluviométrico e incidência de casos de dengue por mês, no município de São José do Rio Preto Estado de São Paulo, no ano de 2004.

Figura 48 Índice predial, temperatura, índice pluviométrico e incidência de casos de dengue por mês, no município de São José do Rio Preto Estado de São Paulo, no ano de 2005.

Figura 49 Tipos de recipientes positivos por ano, no município de São José do Rio Preto - Estado de São Paulo, no período de 1990 a 2005

Figura 50 Mapa de incidência de dengue por 100.000 habitantes e índice de recipientes, por área de controle de vetores, no município de São José do Rio Preto - Estado de São Paulo, para o ano de 1995.

Figura 51 Mapa de incidência de dengue por 100.000 habitantes e índice de recipientes, por área de controle de vetores, município de São José do Rio Preto - Estado de São Paulo SP, para o ano de 1996.

Figura 52 Mapa de incidência de dengue por 100.000 habitantes e índice de recipientes, por área de controle de vetores, município de São José do Rio Preto - Estado de São Paulo SP, para o ano de 1997 
Figura 53 Mapa de incidência de dengue por 100.000 habitantes e índice de recipientes, por área de controle de vetores, município de São José do Rio Preto - Estado de São Paulo SP, para o ano de 1999.

Figura 54 Mapa de incidência de dengue por 100.000 habitantes e índice de recipientes, por área de controle de vetores, município de São José do Rio Preto - Estado de São Paulo SP, para o ano de 2001...............

Figura 55 Mapa de incidência de dengue por 100.000 habitantes e índice de recipientes, por área de controle de vetores, município de São José do Rio Preto - Estado de São Paulo SP, para o ano de 2002...............

Figura 56 Mapa de incidência de dengue por 100.000 habitantes e índice de recipientes, por área de controle de vetores, município de São José do Rio Preto - Estado de São Paulo SP, para o ano de 2003..............

Figura 57 Mapa de incidência de dengue por 100.000 habitantes e índice de recipientes, por área de controle de vetores, município de São José do Rio Preto - Estado de São Paulo SP, para o ano de 2004..

Figura 58 Mapa de incidência de dengue por 100.000 habitantes e índice de recipientes, por área de controle de vetores, município de São José do Rio Preto - Estado de São Paulo SP, para o ano de 2005. 


\section{LISTA DE TABELAS}

Tabela 1 - Incidência de dengue por área de controle de vetores, nos anos de 1990 a 1994, São José do Rio Preto - Estado de São

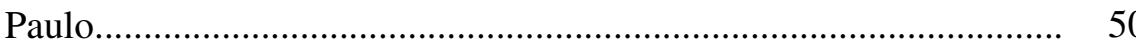

Tabela 2 - Incidência de dengue por área de controle de vetores, nos anos de 1995 a 2005, São José do Rio Preto - São

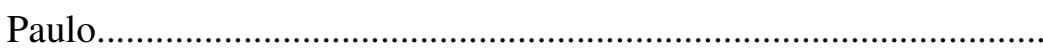

Tabela 3 - Incidência de dengue por 100.000 habitantes em São José do Rio Preto - Estado de São Paulo, segundo a faixa etária, de 1990 a 2005

Tabela 4 - Incidência de casos de dengue por 100.000 habitantes em São José do Rio Preto - Estado de São Paulo, segundo sexo, de 1990 a 2005

Tabela 5 - Coeficiente de correlação (r) e valores de (p) para incidência de dengue (IC) e índice de infestação predial (IP), comparados a chuva e temperatura, São José do Rio Preto - Estado de São Paulo, de 1990 a 2005. 


\section{INTRODUÇÃO}

A dengue é um dos problemas de saúde pública, de maior relevância no mundo. A Organização Mundial de Saúde estima que 80 milhões de pessoas se infectam anualmente, em 100 países, de todos os continentes, exceto a Europa. Cerca de 550 mil doentes necessitam de hospitalização e 20 mil morrem em consequiência da enfermidade (OMS, 2001; GUBLER, 2002).

A dengue é uma das doenças de maior incidência nas regiões intertropicais de todos os continentes. Dengue é fenômeno da segunda metade do século XX, sendo que nas duas últimas décadas houve crescimento do número de casos e dos países acometidos (BARRERA et al., 2000; GUBLER, 2001).

Tanto a forma clássica como a hemorrágica da dengue são causadas por vírus da família Flaviviridae, gênero Flavivirus. Atualmente são conhecidos 4 sorotipos, de vírus Dengue (DEN-1, DEN-2, DEN-3 e DEN-4) (GUBLER, 2001; SCANDAR et al., 2003).

Nas Américas, África, Ásia e Austrália, foram registradas pandemias e epidemias isoladas de dengue, principalmente nos três últimos séculos (TEIXEIRA et al., 1999). Nas Américas, após as primeiras décadas do século XX, ocorreu diminuição ou mesmo interrupção da transmissão do vírus dengue. Mas, a partir de meados da década de 1960, foram registradas epidemias de dengue clássico em vários países. Na década de 1990, o quadro epidemiológico da dengue nas Américas e no Caribe agravou-se e, freqüentemente, tem-se observado epidemias em vários centros urbanos, muitas delas associadas à ocorrência de casos hemorrágicos 
(TEIXEIRA et al., 1999, DOMINGOS, 2005). Em 1981, ocorreu em Cuba, a primeira epidemia de dengue hemorrágico das Américas, quando foram registrados mais de 10.000 casos graves, relacionados ao sorotipo DEN-2. Entre 1981 e 1996, foram notificados 42.171 casos hemorrágicos em 25 países latino-americanos, sendo mais da metade procedentes de Cuba e Venezuela (PINHEIRO, 1996; KOURI et al., 1998). É importante salientar que, diferentemente do padrão de distribuição etária dos casos de Febre Hemorrágica de Dengue (FHD) / Síndrome do Choque de Dengue (SCD) registrados no sudeste Asiático e em Cuba, que atingiram principalmente os indivíduos com idade inferior a 15 anos, na América do Sul, a incidência de dengue é maior nas faixas etárias acima de 15 anos de idade (THEME FILHA e BARAN, 1992).

No Brasil, os primeiros casos de dengue foram registrados em meados do século XIX (TEIXEIRA et al., 1999; SANTOS et al., 2002). No entanto, as primeiras referências na literatura datam de 1916 e de 1923 (SANTOS et al., 2002). No início da segunda metade do século XX foi observada soropositividade para dengue na Amazônia (CAUSEY e THEILER, 1958; SANTOS et al., 2002; SANTOS OO, 2003), mas a primeira epidemia, causada pelos sorotipos DEN-1 e DEN-4, foi registrada em 1982, em Boa Vista (Estado de Roraima). Nos anos de 1986 e 1987 ocorreram surtos de dengue nos Estados do Rio de Janeiro, Alagoas, Ceará, Pernambuco, São Paulo, Bahia e Minas Gerais (TEIXEIRA et al., 1999; SANTOS et al., 2002). A partir de 1990, observou-se ampliação das áreas de transmissão, com aumento da circulação do DEN-1 e a introdução do DEN-2 (TEIXEIRA et al., 1999). Nos anos seguintes, foi registrada de maneira contínua a ocorrência de dengue. Vale assinalar que o maior número de casos se concentra no período de chuvas, época em 
que as condições ambientais são propícias para o desenvolvimento e proliferação do vetor (SILVEIRA, 1998; THU et al., 1998; CALADO e SILVA, 2002). A partir de 1994, o número de pessoas infectadas pelo vírus DEN aumentou e conseqüentemente a incidência da doença atingiu proporções epidêmicas, geralmente associadas com a introdução de novos sorotipos (BRASIL, 2002a; FIGUEIREDO, 2003). As epidemias de dengue, tanto no Brasil como no Estado de São Paulo, apresentaram comportamento cíclico, intercalando anos com incidências mais altas e anos com incidências mais baixas. Atualmente, tem-se registro de casos de dengue em quase todos os Estados brasileiros (BRASIL, 2002c).

No Brasil, os primeiros casos de dengue hemorrágica apareceram no Rio de Janeiro em 1990, com a introdução do sorotipo DEN-2. Com a disseminação desse sorotipo para outras regiões do país, infectando pessoas que já haviam contraído a doença anteriormente, foram surgindo casos de dengue hemorrágica em outros Estados (Ceará, Espírito Santo, Rio Grande do Norte, Pernambuco e Rio de Janeiro) (VASCONCELOS et al., 1999).

Algumas teorias têm sido desenvolvidas para explicar a ocorrência das formas hemorrágicas da dengue. A primeira, denominada teoria imunológica de HALSTEAD (1980, 1981), associa a ocorrência destas formas a duas infecções seqüenciais, por diferentes sorotipos, após ter transcorrido tempo mínimo entre elas de, aproximadamente, três anos, a resposta imunológica do indivíduo sensibilizado seria amplificada pela segunda infecção, em função da existência prévia de anticorpo heterotípico (ADE). A segunda defendida por ROSEN (1977, 1986), relaciona as formas graves a maior virulência de determinadas cepas dos vírus. A terceira teoria reconhece que as duas primeiras não explicam de forma isolada os eventos 
epidemiológicos que vêm ocorrendo no mundo e propõe uma teoria integral de multicausalidade, segundo a qual se aliam vários fatores de risco: individuais idade, sexo, raça, estado nutricional, pré-existência de enfermidades crônicas, presença de anticorpos, intensidade da resposta imunológica a infecções anteriores (ADE); fatores virais - virulência da cepa circulante, sorotipo viral; e os fatores epidemiológicos - imunidade de grupo, competência vetorial, densidade vetorial, intervalo de tempo entre as infecções e intensidade da circulação viral (PANG, 1987; KOURI et al., 1987).

O principal vetor do vírus dengue é o mosquito Aedes (Stegomyia) aegypti, Linnaeus, 1762 (BARRERA et al., 2000; MCCONNELL e GUBLER, 2003). Este inseto tem conseguido explorar o ambiente antrópico, que fornece condições adequadas de sobrevivência do adulto e enorme variedade de habitats para os estádios imaturos, favorecendo o aumento da densidade e a dispersão ativa e passiva do vetor (FORATTINI, 1962, DONALISIO, 1999; WINCH et al., 2002; SANTOS OO, 2003). A situação agrava-se pelas condições precárias de saneamento ambiental, e pela utilização intensa de recipientes descartáveis e não biodegradáveis como os de plástico e de vidro (MOORE, 1990; FOCKS et al., 1995; MAZINE et al., 1996; DONALISIO, 1999). Vale considerar as alterações climáticas e os movimentos migratórios do homem que fornecem condições ideais para o desenvolvimento do mosquito, para a circulação do vírus em diversas áreas e para o desenvolvimento do vírus dentro do organismo do vetor (MARZOCHI, 1994; DAL FABBRO, 1997). Dessa maneira, o Aedes aegypti dispersou-se por áreas onde vivem cerca de 3,5 bilhões de pessoas em todo o mundo. Nas Américas, está presente desde os Estados 
Unidos até o Uruguai, com exceção do Canadá, por razões climáticas e de altitude (BRASIL, 2002 a).

Como o Aedes aegypti é inseto sinantrópico, as medidas adotadas para o controle são bastante complexas. Obviamente, a interrupção da transmissão da dengue depende, até o momento, do controle do vetor, dado que não existe vacina eficaz que possibilite a imunização da população humana para os quatro sorotipos (BARRERA et al., 1995; DAL FABBRO, 1997; SANTOS, 1999; TAUIL, 2001).

Desde o final da década de 1980, os Estados e municípios brasileiros vêm somando esforços para o controle da dengue, encontrando grandes dificuldades devido à escassez de recursos no Setor Saúde. Em 1988, no Estado de São Paulo, passaram a ser assinados termos de adesão ao Convênio SUDS - Sistema Único e Descentralizado de Saúde, cujos planos municipais de saúde incluíam as atividades de controle do vetor, marcando o início de seu processo de municipalização. A partir de 1991, com a publicação da Norma Operacional Básica de Saúde (NOB), pelo Ministério da Saúde, os municípios passaram a assumir a responsabilidade pelas ações de saúde, porém, as ações de controle de vetores ficaram sem financiamento. Desta forma, a Secretaria de Estado da Saúde de São Paulo iniciou o repasse de recursos para certos municípios, em períodos de maior risco de transmissão, para a execução de ações de controle vetorial, como a realização de visitas a todos os imóveis urbanos para a remoção ou tratamento dos criadouros de mosquitos, além da orientação aos moradores (BEPA, 2006). O quadro epidemiológico da dengue levou técnicos e autoridades sanitárias, por iniciativa do Ministério da Saúde, a analisar cuidadosamente a situação e propor estratégias com vistas à erradicação do Aedes aegypti, respeitando as diretrizes básicas do Sistema Único de Saúde. 
Em 1996, a Organização Mundial da Saúde (OMS) apresentou o Plano Diretor de Erradicação do Aedes aegypti - PEAa (BRASIL, 1996). Esse plano foi implantado em 1997, por meio de celebrações de convênios com os municípios, alcançando o total de 3701 municípios no ano de 1999. Cada estado criou a própria Comissão Executiva Estadual e Secretaria Executiva Estadual, o mesmo ocorrendo nos municípios, tendo aquelas como atribuições principais, a elaboração e execução dos planos de erradicação no âmbito dos respectivos estados e municípios.

O Plano Nacional de Erradicação do Aedes aegypti - PEAa consistia de ações governamentais nos três níveis de governo que procuravam integrar efetivamente a sociedade civil organizada e a população para a criação de uma consciência sanitária e participação ativa neste processo, com vistas a eliminar as causas que favorecessem a sobrevivência e a dispersão do vetor, além de efetivar o seu combate direto (BRASIL, 2002a).

As ações previstas no Plano iriam muito além da redução de casos de dengue e do vetor transmissor, tais como: a melhoria da qualidade de vida da população através de ações de saneamento; de formação de uma estrutura permanente de vigilância entomológica, epidemiológica e ambiental em todos os municípios; melhoria, em caráter permanente, da vigilância sanitária em portos, aeroportos e fronteiras e a estratégia de cooperação técnica permanente entre os países do continente. Mas infelizmente, os únicos componentes que avançaram foram as operações de campo de combate ao vetor e a área de educação (informação, educação, comunicação - IEC).

A proposta de erradicação do Aedes aegypti estava alicerçada em várias justificativas, tais como: gravidade da situação de dengue e potencial de epidemias 
de febre hemorrágica de dengue; risco de reurbanização da febre amarela; pouca eficácia dos programas de combate ao mosquito; fortalecimento do turismo e do comércio; melhoria da qualidade de vida da população através das ações de saneamento dos centros urbanos e fortalecimento de estruturas administrativas e de controle social do Sistema Único de Saúde (BRASIL, 2002a).

O Plano foi elaborado como um projeto do Governo Brasileiro, envolvendo as esferas federal, estadual e municipal e a sociedade que recomendava a atuação integrada de três grupos de ações, na luta contra o Aedes aegypti:

- saneamento e vigilância sanitária;

- educação em saúde pública;

- operações de controle ao vetor realizadas em todos os imóveis incluindo ações de educação / vigilância epidemiológica e medidas de controle mecânico, químico e biológico.

O PEAa previa que as Secretarias Municipais de Saúde - (SMS) executassem todas as atividades rotineiras de vigilância e combate ao Aedes aegypti, incluindo as ações educativas, de importância fundamental para a participação da sociedade no combate a esse mosquito. No Estado de São Paulo, a SUCEN, como órgão da Secretaria de Estado da Saúde, tinha como atribuição realizar treinamento de pessoal das SMSs, acompanhar, supervisionar e avaliar o trabalho de vigilância e combate ao Aedes aegypti, realizado, e desenvolver pesquisa científica sobre o assunto. Além disso, quando fossem detectados casos de dengue, equipes de campo da SUCEN atuariam na área de ocorrência, juntamente com equipes das SMSs, com medidas especiais de combate ao mosquito (BRASIL, 2002a). 
Em 1998, dos 645 municípios paulistas, 638 elaboraram planos de erradicação do Aedes aegypti - PEAa, seguindo as diretrizes do plano diretor estadual, o qual por sua vez seguiu as diretrizes do plano nacional. O custo inicial desses planos foi de 73 milhões de reais para 12 meses, sendo 49,8 milhões do tesouro nacional e 23,3 milhões de recursos municipais. A este valor foram acrescidos 18 milhões do convênio firmado entre Fundação Nacional de Saúde, do Ministério da Saúde, e a Secretaria de Estado da Saúde. Além disso, o Governo do Estado de São Paulo disponibilizou recursos da ordem de 17 milhões no orçamento da SUCEN para fazer frente ao problema (SANTOS LS, 2003; dados não publicados da SUCEN).

Ao longo do processo de implantação desse programa observou-se a inviabilidade técnica de erradicação do mosquito a curto e médio prazo. O PEAa, mesmo não atingindo seus objetivos, teve méritos ao propor a necessidade de atuação multissetorial e prever um modelo descentralizado de combate à doença, com a participação dos governos, Federal, Estadual e Municipal. A implantação do PEAa resultou em fortalecimento das ações de combate ao vetor, com aumento significativo dos recursos utilizados para essas atividades, mas ainda com as ações de prevenção centradas quase que exclusivamente nas atividades de campo de combate ao Aedes aegypti com o uso de inseticidas. Essa estratégia, comum aos programas de controle de doenças transmitidas por vetor em todo o mundo, não foram eficientes para reduzir a população do vetor a níveis adequados para que a infecção deixasse de ocorrer.

O Plano de Intensificação das Ações de Controle da Dengue (PIACD), reformulou em 2000, o Programa de Erradicação do Aedes aegypti (PEAa), que tinha 
como proposta de erradicação do vetor, em curto prazo. Nesse mesmo ano, houve mudança no repasse de recursos, optando-se pela sistemática de financiamento fundo a fundo, para o município, para a área de epidemiologia e controle de doenças, com a correspondente divisão de responsabilidade para cada instância de governo. Deu-se inicio à Programação Pactuada Integrada - Epidemiologia e Controle de Doenças (PPI-ECD), com o objetivo de descentralizar as ações referentes à epidemiologia e ao controle de doenças (BRASIL, 2002a).

Esse plano selecionou 657 municípios prioritários no país, sendo 69 municípios em São Paulo, com o objetivo de intensificar ações e adotar iniciativas capazes de utilizar com melhor eficácia, os pontos positivos criados anteriormente, a saber: a grande infra-estrutura para controle de vetores nos estados e municípios (veículos, equipamentos de pulverização, microscópios e computadores); cerca de 60.000 agentes, em mais de 3.500 municípios capacitados para o controle de vetores; a existência de um conjunto de rotinas e normas técnicas padronizadas nacionalmente para o controle de vetores.

No entanto, o Programa de Controle da Dengue manteve a mesma característica verticalizada quando da sua concepção. As ações de controle continuaram sendo prioritariamente, voltadas para o controle químico do vetor.

Em 2002, em função da introdução do sorotipo DEN - 3, foi apresentado o Plano Nacional de Controle da Dengue (PNCD). Nesse plano ressalta-se a característica de um programa permanente de controle da doença, que visa aumentar ainda mais a responsabilidade do indivíduo em seu ambiente doméstico, regulamentar o componente de legislação com a utilização de instrumentos legais, denominado de Amparo Legal à Execução das Ações de Campo - dando ao poder 
público a possibilidade de ingresso forçado em imóveis particulares (BRASIL, 2002b). Este plano procura incorporar as lições das experiências nacionais e internacionais de controle da dengue, enfatizando a necessidade de mudanças nos modelos anteriores, fundamentalmente em alguns aspectos essenciais, tais como:

1. a elaboração de programas permanentes, uma vez que não existe qualquer evidência técnica de que erradicação do mosquito seja possível, em curto prazo;

2. o desenvolvimento de campanhas de informação e de mobilização das pessoas, de maneira a se criar uma maior responsabilidade de cada família na manutenção de seu ambiente doméstico livre de potenciais criadouros do vetor;

3. o fortalecimento da vigilância epidemiológica e entomológica para ampliar a capacidade de predição e de detecção precoce de surtos da doença;

4. a melhoria da qualidade do trabalho de campo de combate ao vetor;

5. a integração das ações de controle da dengue na atenção básica, com a mobilização do Programa de Agentes Comunitários de Saúde (PACS) e Programa de Saúde da Família (PFS);

6. a utilização de instrumentos legais que facilitem o trabalho do poder público na eliminação de criadouros em imóveis comerciais, casas abandonadas, etc;

7. a atuação multissetorial por meio do fomento à destinação adequada de resíduos sólidos e a utilização de recipientes seguros para armazenamento de água; 
8. o desenvolvimento de instrumentos mais eficazes de acompanhamento e supervisão das ações desenvolvidas pelo Ministério da Saúde, estados e municípios (BRASIL, 2002a).

Os objetivos do PNCD são:

- reduzir a infestação pelo Aedes aegypti;

- reduzir a incidência de dengue;

- reduzir a letalidade por febre hemorrágica de dengue.

O Estado de São Paulo, através da SUCEN implantou o PNCD, onde em um primeiro momento foram priorizados 69 municípios, mantendo também nos demais os trabalhos de vigilância e controle. Atualmente, houve reestruturação no plano, que passou a ter 57 municípios prioritários.

No período de 1990 a 2005, foram confirmados, no Brasil, aproximadamente 3.714.626 casos de dengue, sendo 4.911 casos de dengue hemorrágica. Nesse período, o número de óbitos registrados foi aproximadamente 319 (BRASIL, 2006).

No Estado de São Paulo, os primeiros casos com transmissão autóctone foram registrados no ano de 1987, nos municípios de Guararapes e Araçatuba. No verão de 1990/1991 foi registrada epidemia de dengue clássica de grandes proporções, com início em Ribeirão Preto, que rapidamente se expandiu para os municípios vizinhos e outras regiões. Desde aquela época, as epidemias de dengue têm sido constantes e a transmissão do vírus foi registrada em aproximadamente $50 \%$ dos municípios do estado de São Paulo (FIGUEIREDO et al., 1992; GLASSER e GOMES, 2002; SCANDAR, 1998). As incidências mais elevadas ocorreram no verão de 1999 e de 2001 quando foram registrados casos em 102 e 191 municípios, respectivamente. O aumento da incidência de dengue está relacionado à dispersão do mosquito vetor, o 
Aedes aegypti, que era registrado em 21,0\% em 1999, passou a infestar 39,6\% dos municípios do Estado de São Paulo em 2001 (BRASIL, 2002a). Em 2006, a infestação atinge 508 municípios $(78,7 \%)$ sendo que apenas as regiões do Vale do Paraíba e do Vale do Ribeira apresentaram municípios considerados sem infestação. Com relação ao vírus, observa-se até o presente a circulação dos sorotipos DEN-1, 2 e 3 (BEPA, 2006).

Apesar da incidência da dengue ser mais elevada nos meses de verão, tem-se observado a ocorrência de casos ao longo do ano. Dessa maneira, pode-se considerar que a dengue tornou-se endêmica em vários municípios do Estado de São Paulo. Em 2001, a transmissão teve inicio na região da Grande São Paulo, mantendo-se nas regiões atingidas anteriormente. A partir de 1996, observou-se a circulação dos sorotipos DEN-1 e DEN-2 no Estado de São Paulo. No ano de 2002, ocorreu à introdução do sorotipo DEN-3 em território paulista e na região de São José do Rio Preto registrou-se a circulação do vírus em 2003, aumentando o risco de transmissão hiperendêmica e conseqüentemente, o risco do aparecimento de casos hemorrágicos (BRASIL, 2002a). No Estado de São Paulo, o primeiro caso da forma hemorrágica ocorreu em 1999, no município de Riolândia. Em 2000 ocorreram dois casos, em 2001, cinco casos, em 2002, 31 casos e em 2003, 20 casos (CVE, 2006).

O aumento acentuado do número de casos de dengue é resultado de vários fatores, que facilitam a introdução, a transmissão e a dispersão do vírus, tais como: a utilização de meios de transportes cada vez mais rápidos, o incremento do processo de migração humana e da urbanização desordenada, aumento do uso de recipientes descartáveis e a falta de estrutura de saneamento ambiental (SCANDAR, 1998). Nesse sentido, a falta de investimentos nos serviços de infra-estrutura social, a 
existência de rede irregular ou mesmo inexistente de abastecimento de água, os serviços insuficientes de coleta de lixo, o baixo envolvimento da população e a presença de recipientes artificiais expostos tem favorecido a proliferação do mosquito vetor e dificultado a tomada de medidas de controle eficientes (MARZOCHI, 1994: LAPORTA, 2004). Programas essencialmente centrados no combate químico, com baixíssima ou mesmo nenhuma participação da comunidade, sem integração intersetorial e com pequena utilização do instrumental epidemiológico mostraram-se incapazes de conter a dispersão do vetor (BRASIL, 2002a).

Há muito que se conhecer sobre os hábitos das populações humanas e suas necessidades, para facilitar a motivação dos indivíduos e dessa forma obter maior participação e co-responsabilidade na prevenção de epidemias. Identificar potenciais criadouros e estudar alternativas para eliminá-los é parte das tarefas de pesquisadores, particularmente em investigações vinculadas aos programas de controle. Por outro lado, é necessário manter permanente vigilância em relação à capacidade do vetor de explorar diversos tipos de recipientes, à medida que se diminui a oferta dos criadouros inicialmente utilizados pelas populações do inseto (GLUBER, 1988; MARZOCHI, 1994; GÓMEZ-DANTÉS et al., 1995).

Apesar das campanhas de controle do vetor terem sido intensas e contínuas, o resultado não tem sido o desejado. Ou seja, a transmissão da dengue é epidêmica e o vetor Aedes aegypti se dispersou para todos os Estados brasileiros. Obviamente, as medidas adotadas não foram adequadas, o que evidencia a necessidade de se conhecer melhor os hábitos e o comportamento das populações de mosquitos e os fatores socioambientais que levam a sua dispersão e proliferação (MORRISON et al., 
1999; HARRINGTON et al., 2001; DONALÍSIO e GLASSER, 2002; LAPORTA, 2004; BARCELLOS et al., 2005). Dessa maneira, poderão ser desenhadas medidas de controle mais efetivas.

Informações espaciais são usadas desde as civilizações antigas para auxiliar a navegação e também para fins militares. No século XVIII, os governos europeus faziam o planejamento do uso de suas terras construindo mapas com o registro da topografia, geologia, geomorfologia, tipo de solo, vegetação e ocupação (ARONOFF, 1989). No século XX, com o desenvolvimento da tecnologia, houve um aumento na demanda de informações espaciais. Os avanços na computação, cartografia e fotogrametria exigiam um sistema que pudesse registrar, trabalhar e analisar os dados com maior rapidez para processar as informações e conseqüentemente o planejamento (STAR e ESTES, 1990).

O SIG, Sistema de Informação Geográfica, foi introduzido no Brasil, na década de 1980, pela comunidade de usuários de sensoriamento remoto (MENEGUETTE, et al., 1997). Nos anos 90, houve maior interesse pela utilização dos SIGs, já que aumentou a oferta de software e hardware no mercado e com preços mais acessível (RODRIGUES, 1995).

O geoprocessamento possibilita detectar áreas vulneráveis, nas quais os problemas de saúde ocorrem com maior freqüência e gravidade, e que, portanto, merecem maior atenção por parte dos serviços de saúde (BARRETO, 1995; CHIESA, et al., 2002).

Por permitir a identificação de variáveis sociais, econômicas e ambientais, a que está submetida a população, o geoprocessamento é instrumento que poderá 
contribuir para a pesquisa em saúde, pois possibilita a análise da relação entre as mesmas e os riscos relacionados à saúde (BARCELLOS e BASTOS, 1996).

Fatores culturais, sociais, comportamentais, ambientais e biológicos, a que estão submetidos os indivíduos, podem influenciar na incidência de doenças e mortalidade, porque o homem e o meio ambiente interagem. Portanto, nos estudos epidemiológicos a análise espacial é de fundamental importância (MAYER, 1983; CHIESA, et al, 2002).

Associada à noção atual de que muitos tipos de informação contêm componentes de localização espacial, observa-se crescente utilização de dados geograficamente referenciados. Estima-se que entre $75 \%$ e $90 \%$ das informações utilizadas diariamente por diversas organizações sejam georreferenciadas. (MEDRONHO e PEREZ, 2002).

Atualmente, um dos problemas que se discute em saúde pública refere-se ao tipo de instrumento que pode ser usado como método de avaliação rápido, confiável e cientificamente adequado. Nesse sentido, objetiva-se auxiliar a avaliação de programas de prevenção e controle das doenças. Novas técnicas devem capacitar as autoridades públicas a avaliarem as conseqüências das decisões relacionadas ao investimento em saúde pública, e tornar possível rever situações para as quais novos desenvolvimentos deverão ser propostos. Por suas características, as técnicas de geoprocessamento, em especial o Sistema de Informação Geográfica - SIG - podem ser instrumentos poderosos para o planejamento, monitoramento e avaliação dos programas de saúde. A utilização dos SIGs em epidemiologia poderá contribuir para melhorar as possibilidades da descrição espacial da situação de um evento de saúde. Dessa maneira, propiciará a identificação das áreas de maior risco ambiental, 
contribuirá para a análise de padrões ou diferenças nas situações de saúde em diferentes níveis de agregação. Nesse sentido, permitirá a identificação de grupos de alto risco e áreas críticas ao facilitar o processamento e a análise de múltiplas variáveis de forma simultânea. Os SIGs podem ser utilizados como ferramenta de apoio à vigilância e monitoramento da saúde pública e para o planejamento de ações de prevenção e controle das doenças, (MEDRONHO, 1995; SOUZA-SANTOS e CARVALHO, 2000; BRASIL, 2002a; SKABA, et al., 2004).

A principal característica do SIG é focalizar o relacionamento de determinado fenômeno da realidade com sua localização espacial. Por conseguinte, podem-se estudar outros aspectos mais complexos como os de vizinhança e contigüidade envolvendo áreas externas. Além disso, fenômenos distintos podem ser representados em sua interação e evolução, abrangendo-se toda a complexidade do sistema, inclusive a dimensão temporal (TEIXEIRA et al., 1999: BARCELLOS e BASTOS, 1996).

Uma vez que as características da distribuição geográfica das doenças sejam descritas, questões poderão ser levantadas sobre as razões de distribuição geográfica particular. Nesse sentido, mapas podem prover indicação das áreas nas quais seria importante incrementar as pesquisas. Os SIGs são instrumentos úteis para a avaliação das relações da doença com variáveis ambientais, sociais, econômicas e paisagísticas. Conforme já mencionado, embora o número de aplicações de um SIG esteja em franco crescimento na pesquisa em saúde, constitui ferramenta pouco familiar para os profissionais de saúde pública (MEDRONHO, 1993).

O município de São José do Rio Preto foi reinfestado pelo mosquito Aedes aegypti em 1985, ocupando os mais variados tipos de recipientes ao longo do tempo. 
Apesar das atividades de controle, a infestação permanece em níveis elevados e a transmissão de dengue registrou-se de maneira contínua. Essa infestação não ocorre de maneira homogênea nas distintas áreas que compõem a cidade e nem nos domicílios, havendo locais com maiores riscos da presença do mosquito vetor. Estes riscos estão associados às características entomológicas, ambientais, socioeconômicos, demográficos e das atividades de controle realizadas no município (CHIARAVALLOTI NETO, 1999).

A proposta de utilizar análise espacial na avaliação da ocorrência da dengue no município de São José do Rio Preto no período de 1990 a 2005 visa obter informações sobre os condicionantes da doença. Desse modo pretende-se compreender a dinâmica espacial da dengue, através do mapeamento dos casos e das medidas de infestação do vetor. Tanto os casos de dengue como as medidas de infestação serão avaliadas em relação aos fatores entomológicos, ambientais e socioeconômicos. Nesse contexto, procurar-se-á contribuir para o planejamento de ações de vigilância e controle eficientes para a prevenção da doença. Assim será possível adotar abordagens distintas e ações diferenciadas nas áreas com maiores riscos da ocorrência de dengue em relação ao controle do vetor. 


\section{OBJETIVOS}

\section{OBJETIVOS GERAIS}

Caracterizar a distribuição espacial dos casos de dengue no Município de São José do Rio Preto, Estado de São Paulo, no período de 1990 a 2005.

\section{OBJETIVOS ESPECÍFICOS}

Relacionar a distribuição espacial da incidência da dengue com variáveis demográficas, socioeconômicas e ambientais.

Descrever a relação entre a incidência da dengue, variáveis climatológicas e índices larvários do Aedes aegypti.

Identificar áreas com incidências alta e baixa de dengue.

Comparar as variáveis socioeconômicas das áreas com maior e menor incidência de dengue.

Descrever a relação entre incidência de dengue e disponibilidade de criadouros. 


\section{MATERIAL E MÉTODOS}

\section{1 ÁREA DE ESTUDO}

A cidade de São José do Rio Preto (SJRP) situa-se na região noroeste do Estado de São Paulo, nas coordenadas $20^{\circ} 49^{\prime} 11^{\prime}$ 'de latitude Sul e $49^{\circ} 22^{\prime} 46^{\prime \prime}$ de longitude oeste. Apresenta área de $434 \mathrm{Km}^{2}$ e população estimada em 2005 de 385.181 habitantes (IBGE, 2006). Está a uma altitude de 489 m acima do nível do mar, a 452 km de São Paulo, Estado de São Paulo, e situa-se numa região de clima quente com transição para subquente (NIMER, 1972), com temperatura média anual de $25^{\circ} \mathrm{C}$ e pluviosidade anual em torno de $1400 \mathrm{~mm}$. Possui relevo pouco ondulado, com espigões duplos e de modesta altitude. O solo é arenoso e a vegetação é composta por cerrado, cerradinho e capoeira (SJRP, 2006). São José do Rio Preto é sede de região que reúne 101 municípios que pertencem a Divisão Regional de Saúde XXII (DIR XXII) e ao Serviço Regional 08 da SUCEN (SR-08) na estrutura da Secretaria de Estado da Saúde (Figura 1). 


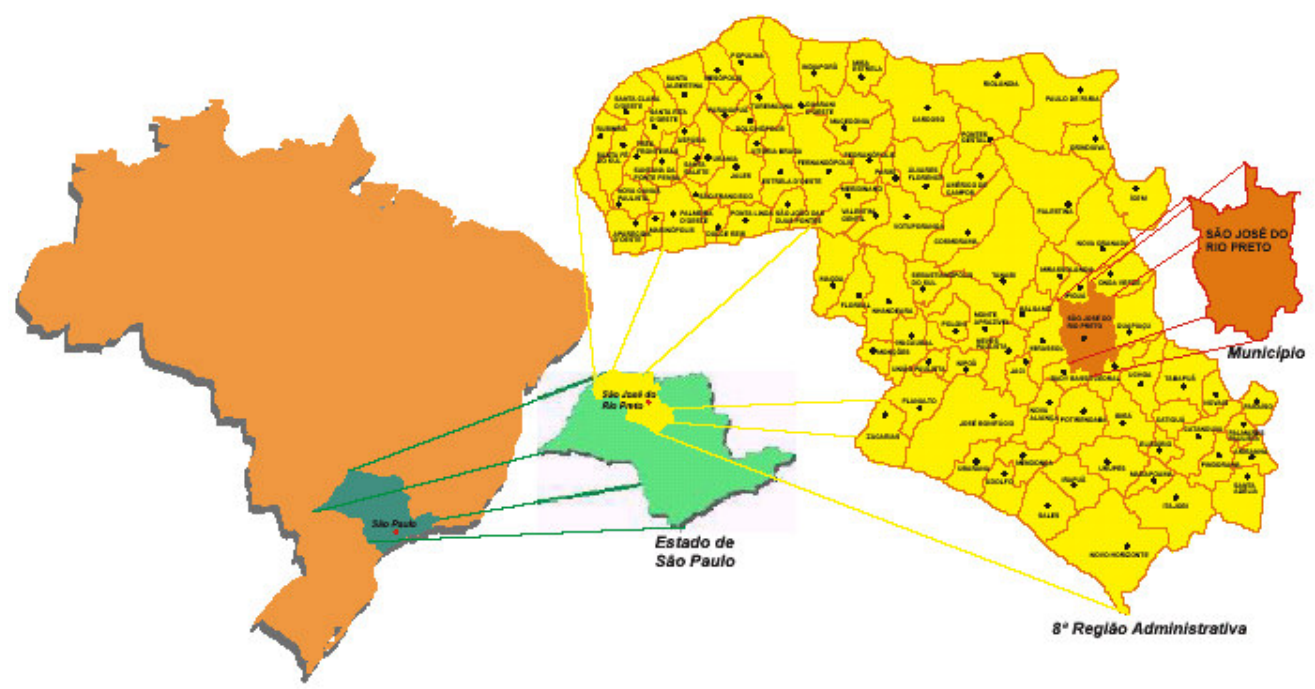

Figura 1 - Localização município de São José do Rio Preto - Estado de São Paulo. Fonte: Secretaria Municipal de Planejamento e Gestão Estratégica de São José do Rio Preto - SP. (SJRP, 2006).

\subsection{DELINEAMENTO DO ESTUDO}

Apresenta-se estudo descritivo que utiliza dados secundários de casos de dengue e entomológicos, relativo ao período de 1990 a 2005, disponíveis no Serviço Regional da SUCEN de São José do Rio Preto.

Para atender aos objetivos do estudo, levou-se em conta a distribuição espacial dos casos de dengue no Município de São José do Rio Preto no período de 1990 a 2005. Os casos foram relacionados com variáveis entomológicas, ambientais e socioeconômicas consideradas relevantes para a ocorrência da doença. 


\subsection{CASOS DE DENGUE}

No estudo, foram utilizados os casos de dengue notificados à Divisão Regional de Saúde - DIR - XXII e confirmados laboratorialmente pelo Instituto Adolfo Lutz. Foi construído banco de dados, utilizando a estrutura do programa Microsoft Excel. O banco de dados incorpora as seguintes informações: nome do paciente, sexo, idade, endereço, data de notificação, data de início de sintomas, data da coleta de sangue e resultado positivo ou negativo para dengue. A data do caso foi definida como aquela de início de sintomas. Inicialmente, foram digitados todos os casos de dengue para verificação da integridade dos dados e realização da importação do banco pelo programa MapInfo, versão 7.0. Em seguida, foi realizado o georreferenciamento segundo os setores censitários e depois agrupados segundo as áreas de trabalho designadas pela SUCEN e pela Secretaria Municipal de Saúde de São José do Rio Preto. No período de 1990 a 1994, o município não era dividido por áreas. De 1995 a 1998 o município foi dividido em 10 áreas e a partir de 1999 foram adotadas 14 áreas. Essa divisão é utilizada apenas pela Secretaria da Saúde do Município e pela SUCEN. Utilizou-se as informações sobre a infestação do Aedes aegypti disponíveis no sistema de avaliação e controle usados pela SUCEN.

Para estimar a incidência de dengue no período de 1990 a 1994, optou-se por somar todos os casos positivos que foram notificados naqueles anos. Não foram calculados índices para cada ano, pois o número de casos foi pequeno. Assim, o número total de casos foi dividido pela soma da população do período, multiplicando-se por 100.000 e distribuídas no mapa segundo escalas de incidências 
geradas pelo programa Natural Break do MapInfo. Da mesma forma, estimou-se a incidência de dengue no período de 1990 a 2005. Para o cálculo do coeficiente de incidência anual, foi considerando o período de janeiro a dezembro, dividindo-se o total de casos de dengue de cada período pela estimativa de população naquele ano, multiplicando-se os resultados por 100.000 e distribuídos no mapa conforme relatado anteriormente. Dessa maneira, foi possível obter a série histórica de incidências anuais, que forneceu informações sobre a evolução da transmissão de dengue.

O coeficiente de incidência de dengue, por faixa etária, foi calculado dividindo-se o número de casos de cada ano, pela respectiva estimativa de população naquela faixa etária, multiplicando-se os resultados por 100.000. O coeficiente de incidência para variável sexo foi calculado da mesma forma que para a faixa etária. As estimativas anuais de população foram obtidas no DATASUS (2006).

\subsection{ANÁLISE ESPACIAL}

Os casos de dengue ocorridos na área urbana do município entre dezembro de 1990 e dezembro de 2005 foram georreferenciados, através do Programa MapInfo, versão 7.0, utilizando-se a Base Cartográfica de São José do Rio Preto (em projeção UTM - Universal Transverse Mercator) contendo os eixos das ruas. A base cartográfica, de propriedade da Prefeitura Municipal, foi cedida à SUCEN pela Secretaria Municipal de Saúde. Foram confirmados por exames de laboratório, 15.238 casos de dengue no período. Desses, 14.554 casos foram georreferenciados. A inexistência de endereços, a inadequação dos mesmos dentro da zona urbana ou 
endereços de áreas rurais ou distritos foram os responsáveis pela perda de 684 casos $(4,5 \%)$.

Os casos foram agrupados anualmente segundo os setores censitários da área urbana do município, disponibilizados pelo Instituto Brasileiro de Geografia e Estatística (IBGE, 2002) e a seguir por áreas de trabalho utilizadas para o controle de vetores. Foram utilizados os setores censitários do censo de 2000, por que estes estavam georreferenciados e não interferiram na localização dos casos que foram analisados pelo endereço (arruamento) e distribuídos pelas 14 áreas (Figura 2).

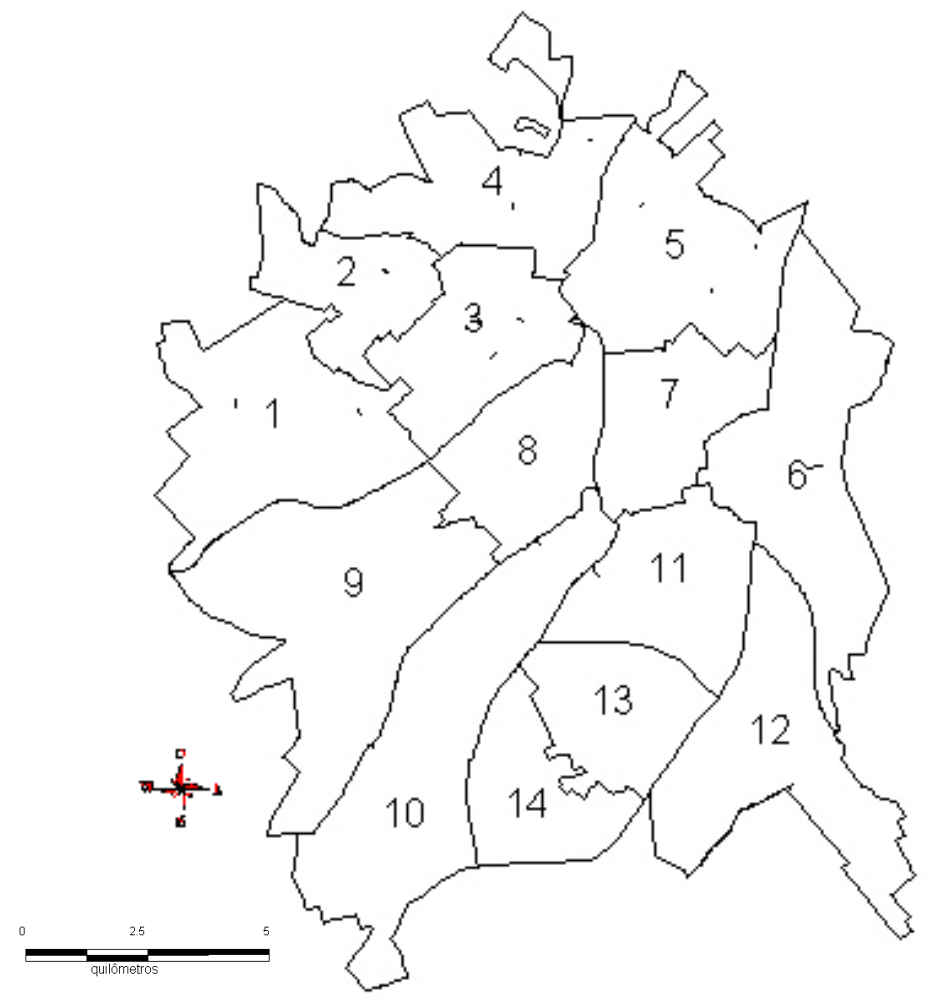

Figura 2 - Mapa da área urbana do município de São José do Rio Preto - Estado de São Paulo, Brasil, segundo as áreas de controle de vetores definidas pela Secretaria Municipal de Saúde e Superintendência de Controle de Endemias (SUCEN). 


\subsection{IDENTIFICAÇÃO DE AGLOMERADOS ESPACIAIS}

A identificação de aglomerados espaciais de São José do Rio Preto considerou a malha de setores censitários do município que é composta por 432 setores. O cálculo dos índices de autocorrelação espacial foi realizado utilizando o programa GEODA desenvolvido pela University of Illinois at Urbana-Champaign (GEODA, 2006) que permite identificar se existe ou não relação espacial entre dados univariados, além de determinar se a distribuição espacial da variável considerada é aleatória ou se é devida a fator espacial determinado. Empregou-se na análise dos padrões de distribuição espacial, o Índice de Moran (I Moran), buscando similaridade entre o coeficiente de correlação usual e a covariância entre regiões vizinhas. Para os dados com distribuição espacial aleatória, o I Moran é próximo a zero e para aqueles que apresentam padrão espacial, os valores são positivos. O limite superior igual a 1 significa agrupamento extremo (OPAS, 2002). O I Moran pode ser global, para toda a região estudada ou local. Para a realização do teste considerou-se a construção de hipóteses, sendo $\mathrm{H}_{0}$ : Distribuição aleatória dos casos e $\mathrm{H}_{1}$ : Distribuição não aleatória dos casos. Ou seja, para $\mathrm{H}_{1}$, espera-se a ocorrência de padrão espacial de distribuição de casos.

O primeiro passo para a análise de autocorrelação espacial foi a construção de matriz de vizinhança, para a qual se estabeleceu por contigüidade a relação entre vizinhos. Para os vizinhos que possuíam fronteiras (setor censitário) comuns atribuise o valor 1 e para aquele que não, o valor 0 . Construiu-se uma variável de intensidade espacial (Lagged Spatially Variables) ou de ponderadores da matriz de vizinhança, que correspondeu à soma dos pesos espaciais multiplicado pelo valor 
observado pela localização de vizinhança. A matriz foi essencial para realizar a análise de autocorrelação.

A estatística do I Moran é definida como:

$$
I=\frac{n}{W}\left(\frac{\sum_{i} \sum_{j} w_{i j} z_{i} z_{j}}{\sum_{i} z_{i}^{2}}\right) \operatorname{para} \mathrm{i} \neq \mathrm{j}
$$

Onde:

$\mathrm{n}=$ número de casos

$\mathrm{w}=$ elemento da matriz de vizinhança para o par $\mathrm{i} j$

W é a soma dos ponderadores da matriz

zi e zj são desvios em relação à média (zi-z) e (zj-z)

z é a média

A validade estatística do I Moran foi avaliada por teste de pseudosignificância (p-value) que foi gerado por diferentes permutações de valores dos atributos associados, que produziram arranjo espacial. Como apenas um arranjo corresponde à situação observada, pode-se construir distribuição empírica do índice. Se o valor medido correspondeu a um extremo da distribuição simulada, tratou-se de valor com significação estatística. Os dados puderam ser apresentados segundo diagrama de espalhamento de Moran. 


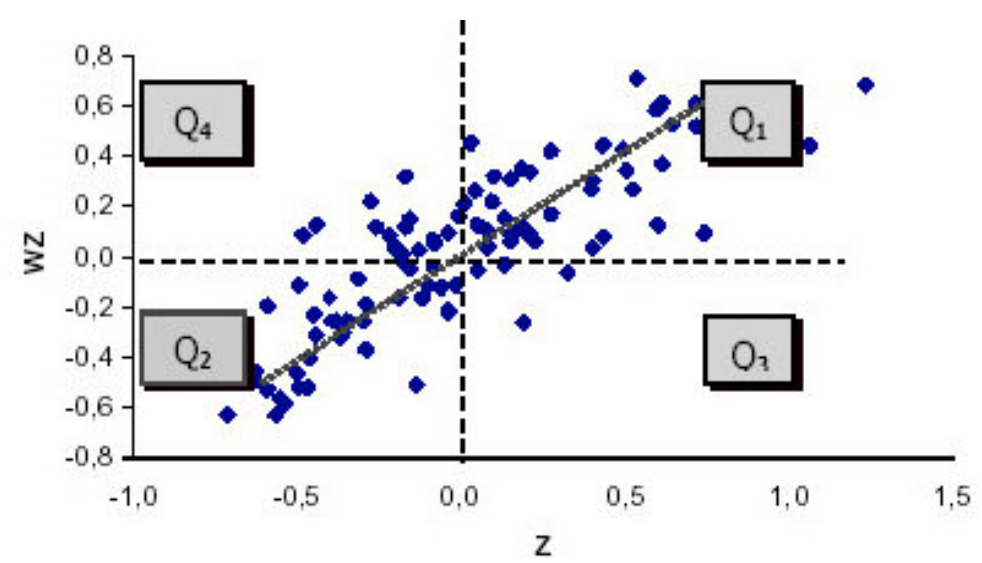

Figura 3 - Diagrama de espalhamento de Moran Fonte: INPE - DPI

Este diagrama relata espacialmente o relacionamento entre os valores do vetor de desvios $Z$ (zi-z) e os valores das médias locais $W Z$, indicando diferentes regimes espaciais presentes nos dados.

Os quadrantes indicam:

Q1 (valores positivos e médias positivas) e Q2 (valores negativos e médias negativas) indicam associações espaciais positivas no sentido de que uma localização espacial possui vizinhos com valores semelhantes; Q3 (valores positivos e médias negativas) e Q4 (valores negativos e médias positivas) indicam pontos de associação espacial negativa no sentido de que uma área possui vizinhos com valores distintos. São considerados pontos de transição entre diferentes padrões espaciais (INPE, 2006).

O I Moran refere-se aos aglomerados espaciais e relaciona o número de casos de dengue e a vizinhança. Assim, geram-se quatro situações:

Alto - alto: alto número de casos - alta vizinhança.

Baixo - baixo: baixo número de casos - baixa vizinhança.

Alto - baixo: alto número de casos - baixa vizinhança. 
Baixo - alto: baixo número de casos - alta vizinhança.

O I Moran foi estimado, utilizando-se os setores censitários para aprofundar a análise e dar sentido à identificação dos aglomerados espaciais. O mapa da distribuição das taxas de incidências foi criado utilizando-se as áreas de trabalho da Secretaria de Saúde do Município e da SUCEN. Para facilitar o entendimento, as áreas da SUCEN foram agrupadas em regiões maiores, a saber: Região central (área 8), Região norte (áreas 2, 3, 4 e 5), Região sul (áreas 10, 13 e 14), Região leste (áreas 6, 7, 11 e 12) e Região oeste (áreas 1 e 9).

\subsection{INFESTAÇÃO DO VETOR}

A distribuição do Aedes aegypti na cidade foi analisada através dos dados de levantamentos larvários realizados pelo Serviço Regional de São José do Rio Preto da SUCEN e lançados em boletim de avaliação de densidade larvária (ADL), do período estudado. Nos anos de 1990 a 1994 foram calculadas as médias dos índices de infestação do período de verão, pois nesses anos, a SUCEN fez vários levantamentos larvários. No entanto, a partir de 1995, com o agravamento da situação epidemiológica na região, os levantamentos foram feitos uma vez ao ano. No ano de 1998 não foi realizado levantamento, e no ano de 2000 foi realizado apenas nas áreas de 9 a 14.

A partir das informações registradas nos boletins da SUCEN foram calculados o Índice Predial (IP) e Índice de Recipientes (IR), conforme metodologia descrita por ALVES e ALMEIDA (1991). O IP é dado pelo número de casas com larvas de Aedes aegypti multiplicado por 100 e dividido pelo número de casas 
pesquisadas, e o IR é o número de recipientes com larvas de Aedes aegypti multiplicado por 100 e dividido pelo número de recipientes pesquisados, considerando recipiente pesquisado aquele contendo água no momento da pesquisa.

Para a análise dos tipos de recipientes foram utilizados os dados da ADL de 1990 a 1993 e de 1995 a 2005. O ano de 1994 não foi incluído porque nos boletins utilizados constavam apenas os recipientes intra e peridomiciliares, não especificando o tipo e, portanto, não havendo possibilidade de análise dos tipos de recipientes. Nos anos de 1995 a 1997, foi utilizado o mapa dividido em 10 áreas, porque as informações sobre a infestação do Aedes aegypti eram condensadas por 10 áreas e a partir de 1999 até 2005, em 14 áreas. Com relação à incidência não houve problemas, pois como já dito anteriormente, os casos de dengue foram georreferenciados por endereço. Os cálculos da incidência foram realizados da mesma forma relatada anteriormente, respeitando as divisões das 10 áreas para os anos de 1995 a 1997 e 14 áreas para os anos de 1999 a 2005.

Os recipientes constantes dos boletins de campo estavam em forma de código numérico de 1 a 8 , conforme especificações abaixo:

1- pneu;

2- vaso ou prato de planta;

3- lata, pote, frasco;

4- tambor, tanque, barril;

5- caixa d'água;

6- garrafa;

7- recipientes removíveis;

8- recipientes não removíveis. 
Dentre os recipientes removíveis constavam brinquedos, balde, peças de carro, vaso sanitário, sacolas plásticas, piscinas plásticas, bebedouros de animais e outros, enquanto os não removíveis incluíam piscinas, lajes, ralos, calhas, fontes d'água, bebedouros fixos de animais e outros.

A partir de 2004 houve mudança no boletim, que passou a abranger maior número de recipientes, os quais foram agrupados a estes citados anteriormente. No recipiente vaso foram agrupados, vasos de planta, pratos de vasos e bromélias em ambiente domiciliar; na caixa d'água foram agrupados, caixas ligadas à rede e depósito de água não ligado a rede; no recipiente lata, pote e frasco foi agrupado, bebedouros; no recipiente outros não removíveis foram agrupados, calha, ralo pluvial, ralo comum, outros fixos e recipientes naturais; e no recipiente outros removíveis foram agrupados, outros e material inservível.

As bromélias, nesse caso, como foram utilizadas no ambiente doméstico, plantadas em vasos e jardineiras de forma decorativa, foram incluídas no recipiente vaso.

\subsection{FATORES SOCIOECONÔMICOS}

Foram utilizadas as variáveis de nível socioeconômicos e ambientais para caracterização da cidade. Os dados foram obtidos junto ao IBGE (2002) e referiramse ao censo demográfico de 2000. As unidades de coletas dos mesmos foram os setores censitários, compostos por número variável de quadras, com cerca de 300 domicílios cada e localizadas em território contínuo. Os setores censitários foram agrupados por áreas de trabalho para o controle de vetores. O setor censitário foi 
escolhido por ser o grau máximo de desagregação das variáveis socioeconômicas utilizadas, permitindo bom detalhamento. As variáveis utilizadas foram:

- população;

- idade;

- sexo;

- densidade demográfica;

- porcentagem de domicílios com água encanada;

- porcentagem de domicílios com ligação de esgoto;

- porcentagem de domicílios com coleta de lixo;

- porcentagem de pessoas com 1 a 7 anos de instrução (fundamental incompleto);

- porcentagem de pessoas com 8 anos de instrução (fundamental completo);

- porcentagem de pessoas com 9 a 10 anos de instrução (segundo grau incompleto);

- porcentagem de pessoas com 12 anos de instrução (segundo grau completo);

- porcentagem de pessoas com mais de 15 anos de instrução (superior completo);

- porcentagem de famílias com renda média de até 1 salário mínimo;

- porcentagem de famílias com renda média de 1 a 3 salários mínimos;

- porcentagem de famílias com renda média de 3 a 5 salários mínimos;

- porcentagem de famílias com renda média de 5 a 10 salários mínimos;

- porcentagem de famílias com renda média de 10 a 15 salários mínimos;

- porcentagem de famílias com renda média maior que 15 salários mínimos; 
Considerou-se as informações do censo de 2000 (Anexo 3), apesar da série histórica compreender 1990 a 2005, pois o município não alterou sua estrutura socioeconômica em uma década. As regiões pobres continuaram pobres e as regiões ricas continuaram ricas na apropriação do território (SJRP, 2006).

\subsection{VARIÁVEIS CLIMÁTICAS}

As variáveis climáticas como temperatura e precipitação pluviométrica foram selecionadas para verificar a existência de correlação com a infestação do mosquito. Esses dados foram obtidos do Banco de Dados da Secretaria de Agricultura e Abastecimento - Coordenadoria de Assistência Técnica Integral - CATI Departamento de Sementes, Mudas e Matrizes - Núcleo de Produção de Sementes de São José do Rio Preto (CATI, 2006). Os dados de temperatura utilizados foram: as médias mensais em graus Celsius, para os anos estudados. Os dados de precipitação pluviométrica foram: precipitação total mensal $(\mathrm{mm})$, para os anos estudados. Com esses dados foi criado banco de dados Excel. Utilizou-se os valores diários de precipitação para permitir melhor visualização gráfica, estes foram calculados pelo total de milímetros de chuva do mês e dividido pelo número de dias do mês, obtendo-se assim, valores diários de chuva.

As associações entre as variáveis meteorológicas mencionadas, o índice de infestação (IP) e a incidência de casos de dengue foram examinadas utilizando-se o coeficiente de Correlação de Pearson (r). 


\section{RESULTADOS}

\subsection{INCIDÊNCIA DE DENGUE NO MUNICÍPIO DE SÃO JOSÉ DO RIO PRETO NO PERÍODO DE 1990 A 1994.}

No município de São José do Rio Preto, os primeiros casos de dengue ocorreram em dezembro de 1990 e continuaram durante os primeiros meses de 1991. Em 1992 não foram registrados casos de dengue. A partir de 1993, os casos de dengue passaram a ocorrer todos os anos, com incidência variável. Nos anos de 1990 a 1994, a incidência de dengue nas áreas e no município foi baixa (Tabela 1). De acordo com a Tabela 1 pode-se observar que para o ano de 1990, não ocorreram casos nas áreas 2, 3, 4, 5, 6, 8, 9, 10, 12 e 14, em 1991 nas áreas 3, 4, 10, em 1992 em todas as áreas. No ano de 1993, não ocorreram casos nas áreas 5, 6, 11, 12 e 14, e em 1994, somente as áreas 1 e 12 não tiveram transmissão do vírus.

Tabela 1 - Incidência de dengue por 100.000 habitantes, por área de controle de vetores, no município de São José do Rio Preto - Estado de São Paulo, no período de 1990 a 1994.

\begin{tabular}{lccccccccccccccc} 
ANO & \multicolumn{110}{c|}{ ÁREA } \\
\hline & $\mathbf{1}$ & $\mathbf{2}$ & $\mathbf{3}$ & $\mathbf{4}$ & $\mathbf{5}$ & $\mathbf{6}$ & $\mathbf{7}$ & $\mathbf{8}$ & $\mathbf{9}$ & $\mathbf{1 0}$ & $\mathbf{1 1}$ & $\mathbf{1 2}$ & $\mathbf{1 3}$ & $\mathbf{1 4}$ & TOTAL \\
$\mathbf{9 0}$ & 5,2 & 0,0 & 0,0 & 0,0 & 0,0 & 0,0 & 4,8 & 0,0 & 0,0 & 0,0 & 23,7 & 0,0 & 5,7 & 0,0 & 2,5 \\
$\mathbf{9 1}$ & 10,3 & 27,1 & 0,0 & 0,0 & 11,9 & 17,2 & 28,2 & 22,5 & 13,2 & 0,0 & 46,6 & 8,4 & 16,7 & 8,1 & 13,7 \\
$\mathbf{9 2}$ & 0,0 & 0,0 & 0,0 & 0,0 & 0,0 & 0,0 & 0,0 & 0,0 & 0,0 & 0,0 & 0,0 & 0,0 & 0,0 & 0,0 & 0,0 \\
$\mathbf{9 3}$ & 4,9 & 168,5 & 40,3 & 3,3 & 0,0 & 0,0 & 4,4 & 8,5 & 6,2 & 4,3 & 0,0 & 0,0 & 10,6 & 0,0 & 21,7 \\
$\mathbf{9 4}$ & 0,0 & 67,9 & 4,4 & 22,7 & 7,3 & 15,8 & 30,3 & 174,9 & 18,2 & 4,2 & 118,4 & 0,0 & 46,4 & 14,9 & 38,4 \\
\hline
\end{tabular}


Devido à baixa incidência, os casos de dengue (Anexo 1) que ocorreram nesses cinco anos, foram somados, calculando-se a incidência do período e distribuídas no mapa como estão representados na Figura 4. Verificou-se que a maior incidência ocorreu na área 2 (região norte), com 43,0 a 61,0 casos por 100.000 habitantes. Nas áreas 8, 11 e 13 a incidência variou entre 13,7 e 43,0 casos, nas áreas 3, 7 e 9 entre 6,7 e 13,7 casos, nas áreas 4, 6 e 14 entre 3,9 a 6,7 e nas áreas 1, 5, 10 e 12 foi 1,6 a 3,9 casos por 100.000 habitantes.

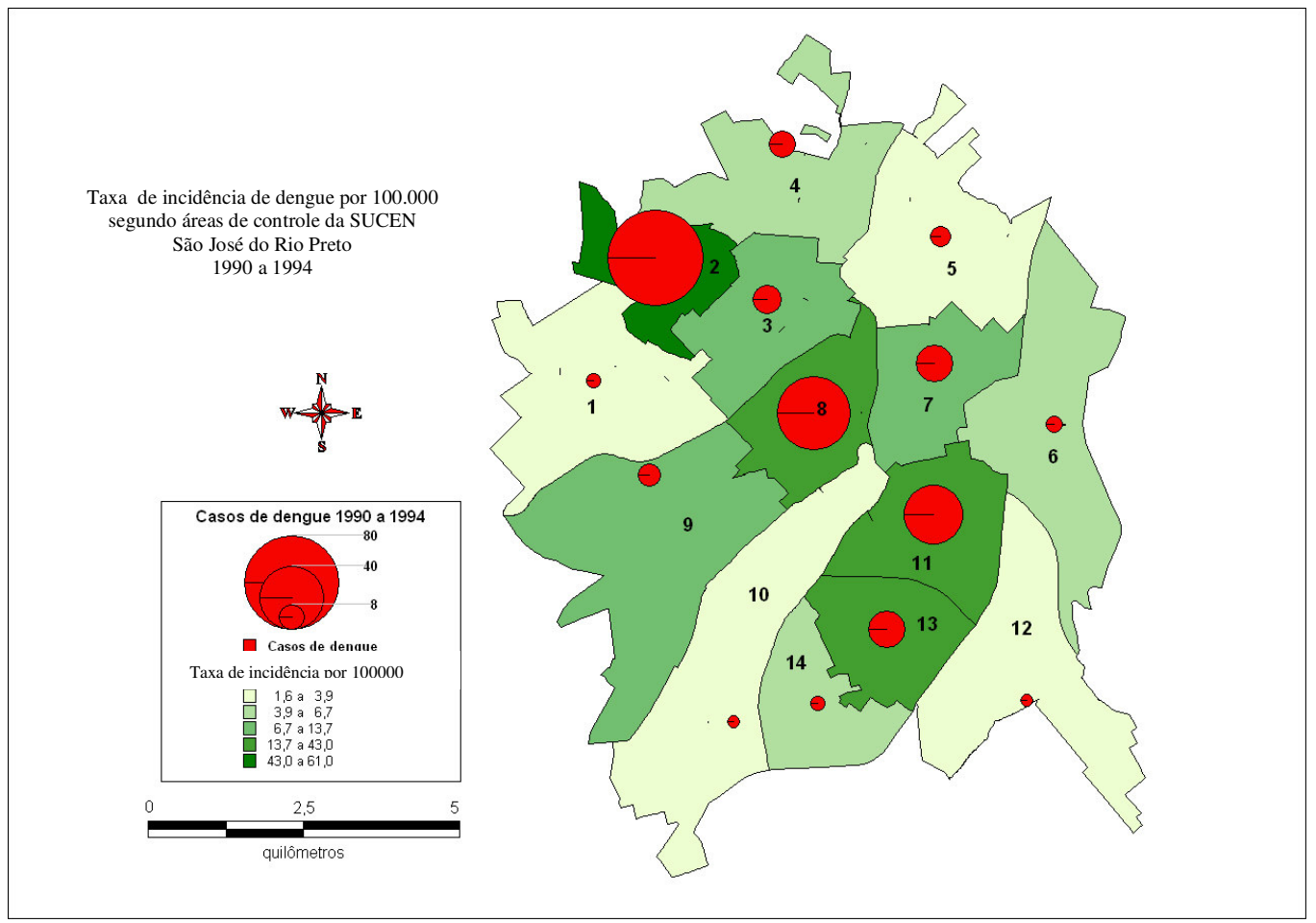

Figura 4 - Distribuição espacial da incidência de dengue por 100.000 habitantes, nas áreas de controle de vetores do município de São José do Rio Preto - Estado de São Paulo, no período de 1990 a 1994. 
A Figura 5 representa o coeficiente de auto-correlação espacial, ou I Moran dos casos de dengue de 1990 a 1994. O gráfico do diagrama de espalhamento aponta o nível de auto-correlação espacial, cujo valor foi de 0,0766 e o gráfico de barras aponta o nível de significância estatística com um p-value de 0,0020, indicando a ocorrência de baixa dependência espacial. As regiões norte (área 2), centro (área 8) e leste (área 11) apresentaram alguns aglomerados espaciais com maior número de casos, assim como no mapa da Figura 4, essas regiões apresentaram áreas com as maiores incidências do período.
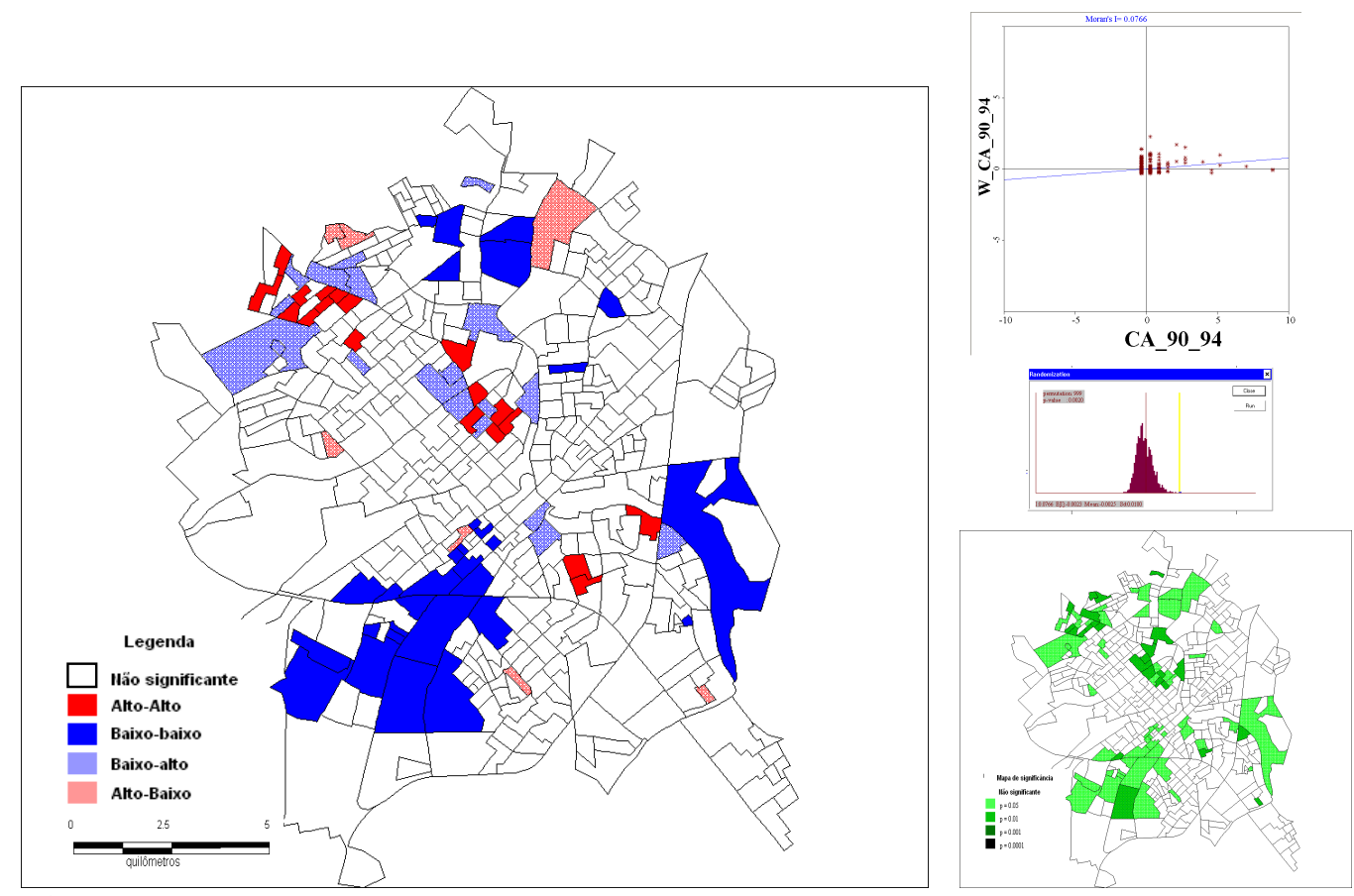

Figura 5 - Distribuição de dengue por setores censitários, evidenciando os aglomerados espaciais; gráfico do diagrama de espalhamento; gráfico de barras e mapa de significância no município de São José do Rio Preto - Estado de São Paulo, no período de 1990 a 1994. 


\subsection{INCIDÊNCIA DE DENGUE NO MUNICÍPIO DE SÃO JOSÉ DO RIO PRETO NO PERÍODO DE 1995 A 2005.}

No ano de 1995, ocorreu a primeira importante transmissão do vírus dengue no município de São José do Rio Preto. A Figura 6 representa as áreas com maior concentração de casos, destacando-se a área 2, com incidência entre 594 e 795 casos por 100.000 habitantes, as áreas 3, 4, 7 e 8 com incidência entre 450 e 594 casos. Nas áreas 5, 12 e 13 a incidência variou entre 305 e 450 casos, as áreas 1 e 14 entre 195 e 305 casos e finalmente as áreas 6, 9, 10 e 11 com incidência entre 136 e 195 casos por 100.000 habitantes.

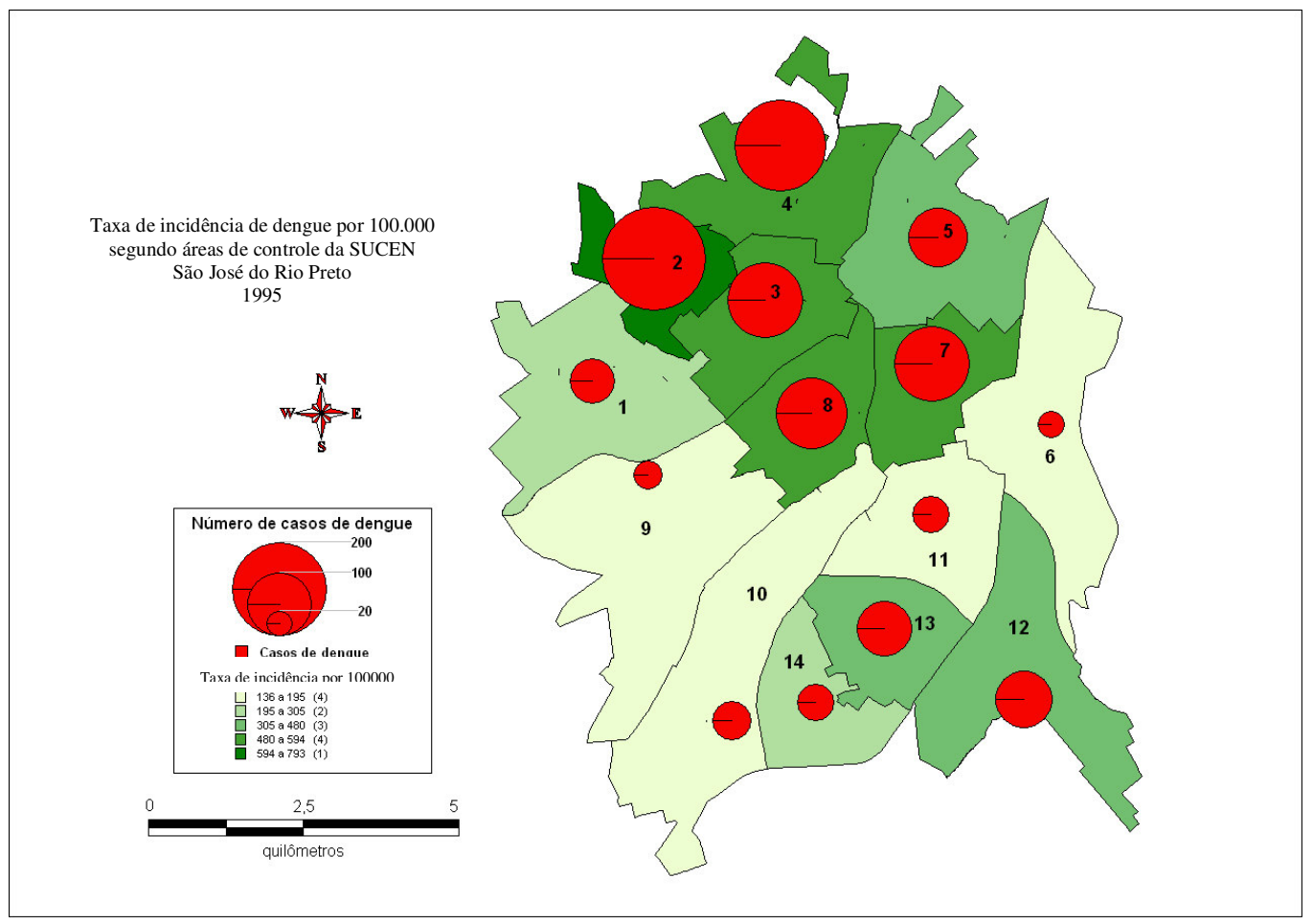

Figura 6 - Distribuição espacial da incidência de dengue por 100.000 habitantes, nas áreas de controle de vetores do município de São José do Rio Preto - Estado de São Paulo, no ano de 1995. 
Observando-se a Tabela 2, nota-se que ocorreram casos de dengue em todas as áreas da cidade durante este período. Assim, a primeira importante transmissão de dengue ocorreu em áreas situadas na região norte da cidade (Figura 6).

Tabela 2 - Incidência de dengue por 100.000 habitantes, por área de controle de vetores, no município de São José do Rio Preto - Estado de São Paulo, no período de 1995 a 2005.

\begin{tabular}{|c|c|c|c|c|c|c|c|c|c|c|c|c|c|c|c|}
\hline \multirow{2}{*}{ ANO. } & \multicolumn{15}{|c|}{ ÁREA } \\
\hline & 1 & 2 & 3 & 4 & 5 & 6 & 7 & 8 & 9 & 10 & 11 & 12 & 13 & 14 & TOT \\
\hline 1995 & 300,9 & 793,0 & 551,1 & 577,4 & 315,7 & 154,8 & 559,0 & 480,3 & 136,7 & 162,5 & 194,6 & 304,8 & 377,7 & 276,6 & 411,8 \\
\hline 1996 & 431,7 & 617,7 & 332,1 & 52,4 & 205,7 & 52,6 & 267,5 & 399,4 & 127,1 & 118,4 & 40,9 & 62,9 & 97,9 & 56,6 & 225,3 \\
\hline 1997 & 43,6 & 49,3 & 197,0 & 9,0 & 30,4 & 0,0 & 63,8 & 176,2 & 173,4 & 38,2 & 0,0 & 10,8 & 66,3 & 54,8 & 65,2 \\
\hline 1998 & 229,1 & 176,1 & 219,3 & 142,5 & 506,5 & 361,8 & 120,3 & 205,2 & 158,0 & 67,0 & 255,4 & 132,7 & 193,9 & 86,7 & 217,5 \\
\hline 1999 & 893,2 & 1223,4 & 813,2 & 867,4 & 878,3 & 615,4 & 1070,8 & 712,7 & 621,4 & 377,4 & 653,0 & 428,9 & 301,5 & 637,3 & 774,6 \\
\hline 2000 & 129,9 & 88,8 & 116,1 & 94,6 & 66,1 & 20,4 & 163,4 & 242,6 & 213,7 & 110,4 & 83,0 & 36,7 & 393,0 & 165,9 & 136,4 \\
\hline 2001 & 998,5 & 879,4 & 1756,1 & 2002,1 & 2199,6 & 1491,0 & 3600,3 & 2387,1 & 2071,6 & 963,2 & 2232,9 & 1497,2 & 1405,8 & 1346,0 & 1884,0 \\
\hline 2002 & 423,3 & 647,8 & 294,0 & 191,7 & 117,4 & 84,4 & 199,0 & 396,2 & 299,3 & 122,7 & 180,9 & 143,8 & 266,2 & 91,6 & 263,9 \\
\hline 2003 & 68,5 & 60,3 & 193,3 & 83,5 & 64,9 & 70,0 & 132,4 & 532,3 & 68,4 & 66,8 & 116,8 & 12,5 & 37,3 & 35,9 & 116,7 \\
\hline 2004 & 3,7 & 2,8 & 6,7 & 0,0 & 2,8 & 6,1 & 6,7 & 9,6 & 9,4 & 3,2 & 4,2 & 3,0 & 127,3 & 51,7 & 14,3 \\
\hline 2005 & 87,0 & 34,1 & 129,9 & 36,1 & 192,8 & 76,4 & 284,3 & 57,4 & 141,5 & 58,0 & 26,0 & 15,6 & 12,4 & 18,0 & 91,9 \\
\hline
\end{tabular}

Fonte: SUCEN 
Na Figura 7, pode-se observar que o I Moran para o ano de 1995 foi 0,2329 com nível de significância p-value de 0,0010 . Este valor indica a ocorrência de dependência espacial. Novamente, os aglomerados espaciais com maior número de casos de dengue ocorreram na região norte (área 2 e 3).
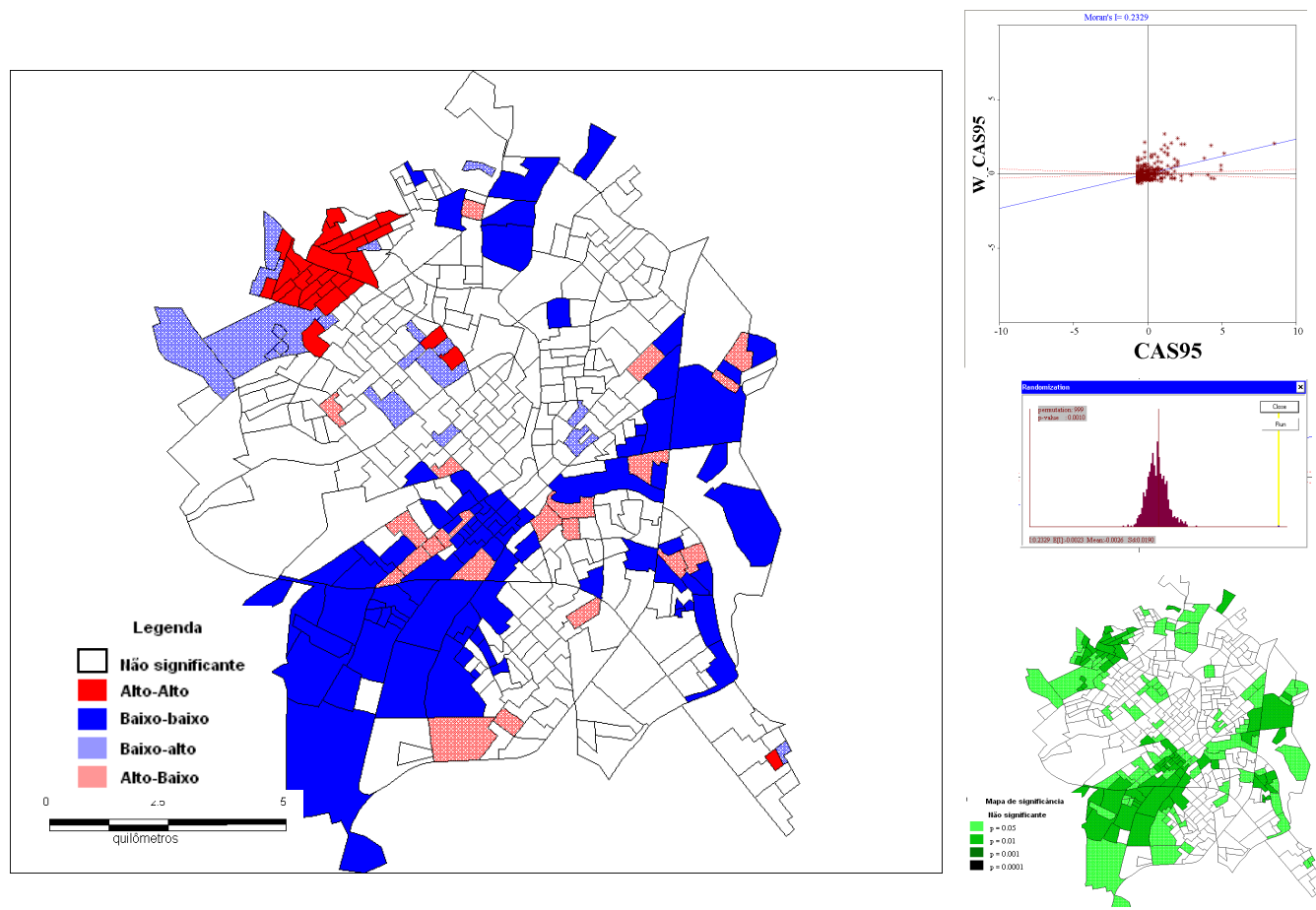

Figura 7 - Distribuição de dengue por setores censitários, evidenciando os aglomerados espaciais; gráfico do diagrama de espalhamento; gráfico de barras e mapa de significância no município de São José do Rio Preto - Estado de São Paulo, no período de 1995. 
No ano de 1996, a área 2 foi a mais atingida, com incidência variando entre 408 e 618 casos por 100.000 habitantes, as áreas 1 e 8 com incidência entre 267 e 408 casos, áreas 3, 5 e 7 com incidências entre 118 e 267 casos, áreas 9 e 10 com incidência entre 57 e 118 casos e finalmente pelas áreas 4, 6, 11, 12 e 14 com incidência entre 40 e 57 casos por 100.000 habitantes (Figura 8). Assim como a área 2 (região norte), a 8 (região central) veio se mantendo com destaque na transmissão. Nesse ano, todas as áreas tiveram ocorrência de casos de dengue (Tabela 2).

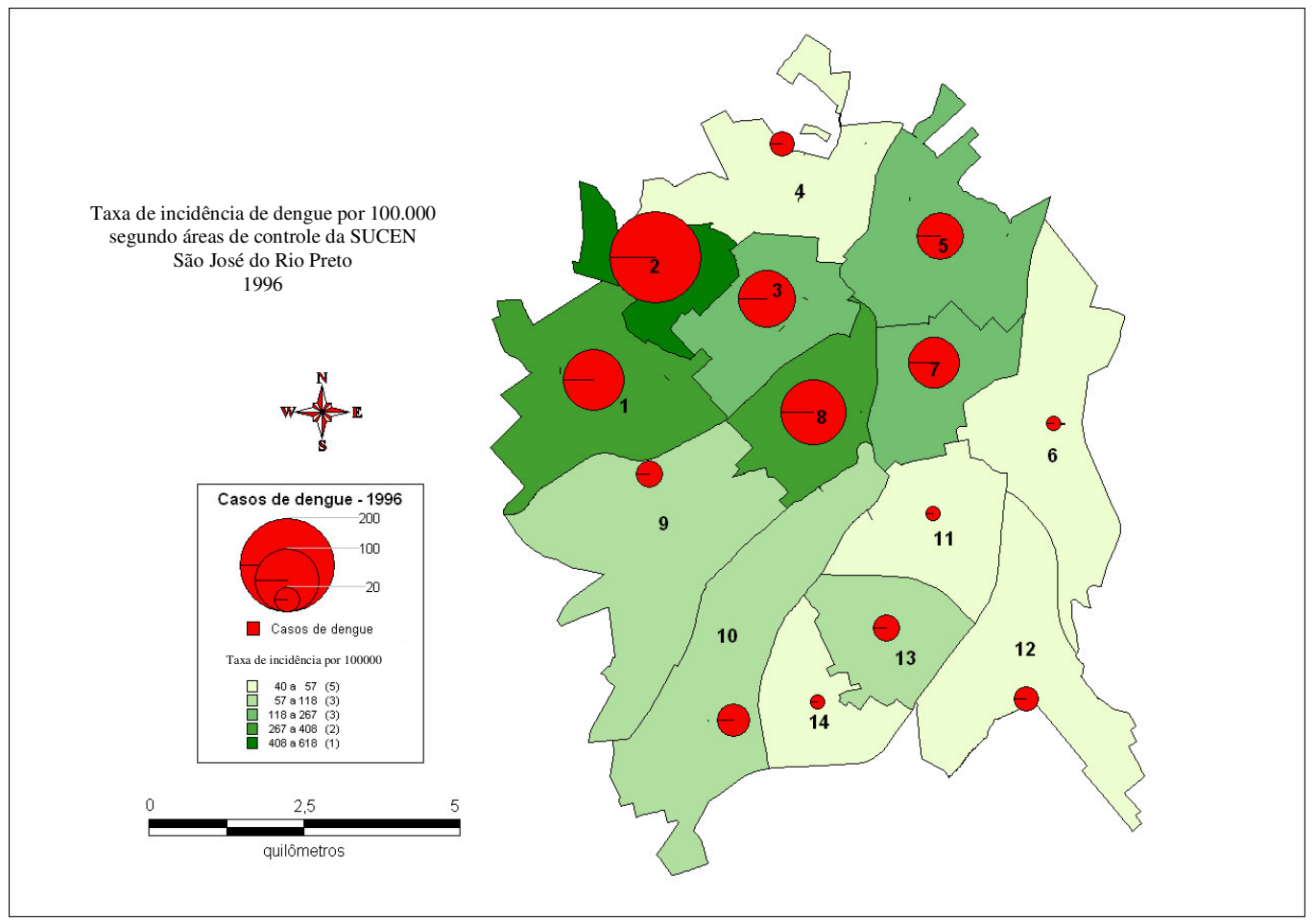

Figura 8 - Distribuição espacial da incidência de dengue por 100.000 habitantes, nas áreas de controle de vetores do município de São José do Rio Preto - Estado de São Paulo, no ano de 1996. 
No ano de 1996, as regiões norte (áreas 2 e 3), centro (área 8), oeste (área 1) e leste (área 7), apresentaram aglomerados espaciais significativos com I Moran de 0,1868, e com nível de significância estatística de p-value 0.0010. Essas regiões também apresentaram altas incidências de dengue. A região norte (área 5), apesar de apresentar incidência de 205 casos por 100.000 habitantes, não houve aglomerado espacial, como apresenta a Figura 9.
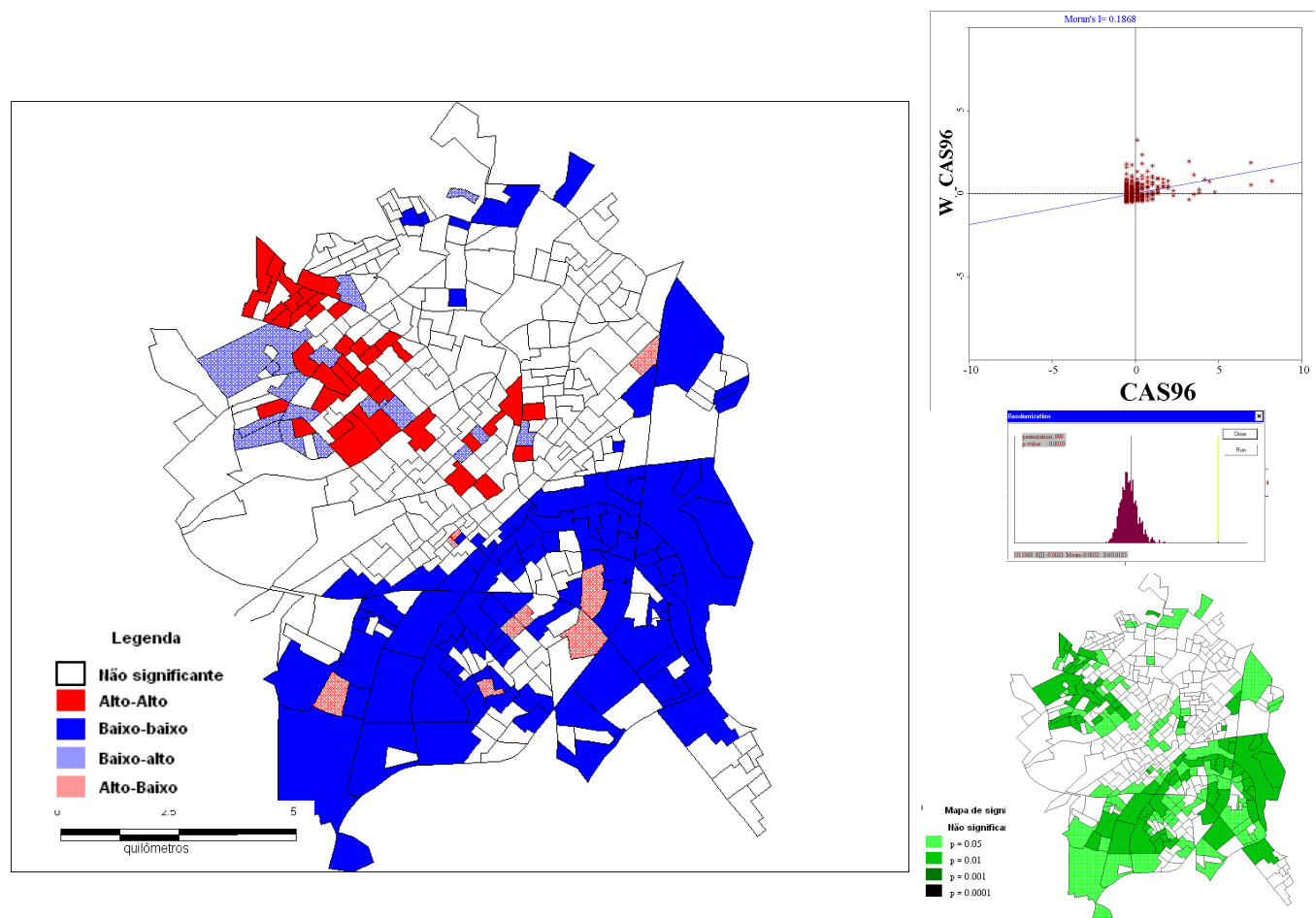

Figura 9 - Distribuição de dengue por setores censitários, evidenciando os aglomerados espaciais; gráfico do diagrama de espalhamento; gráfico de barras e mapa de significância no município de São José do Rio Preto - Estado de São Paulo, no período de 1996. 
No ano de 1997, a área mais atingida foi a 3, com incidência entre 197 e 190 casos por 100.000 habitantes, as áreas 8 e 9 com incidência variando entre 173 e 197 casos, áreas 2, 7, 13, e 14 entre 49 e 173 casos, áreas 1,5 e 10 com incidência entre 30 e 49 casos e as áreas 4, 6, 11 e 12 entre 0 e 30 casos por 100.000 habitantes (Figura 10). Em 1997, houve queda no número de casos de dengue, apresentando incidência menor e as áreas mais atingidas foram às regiões norte, centro e oeste da cidade.

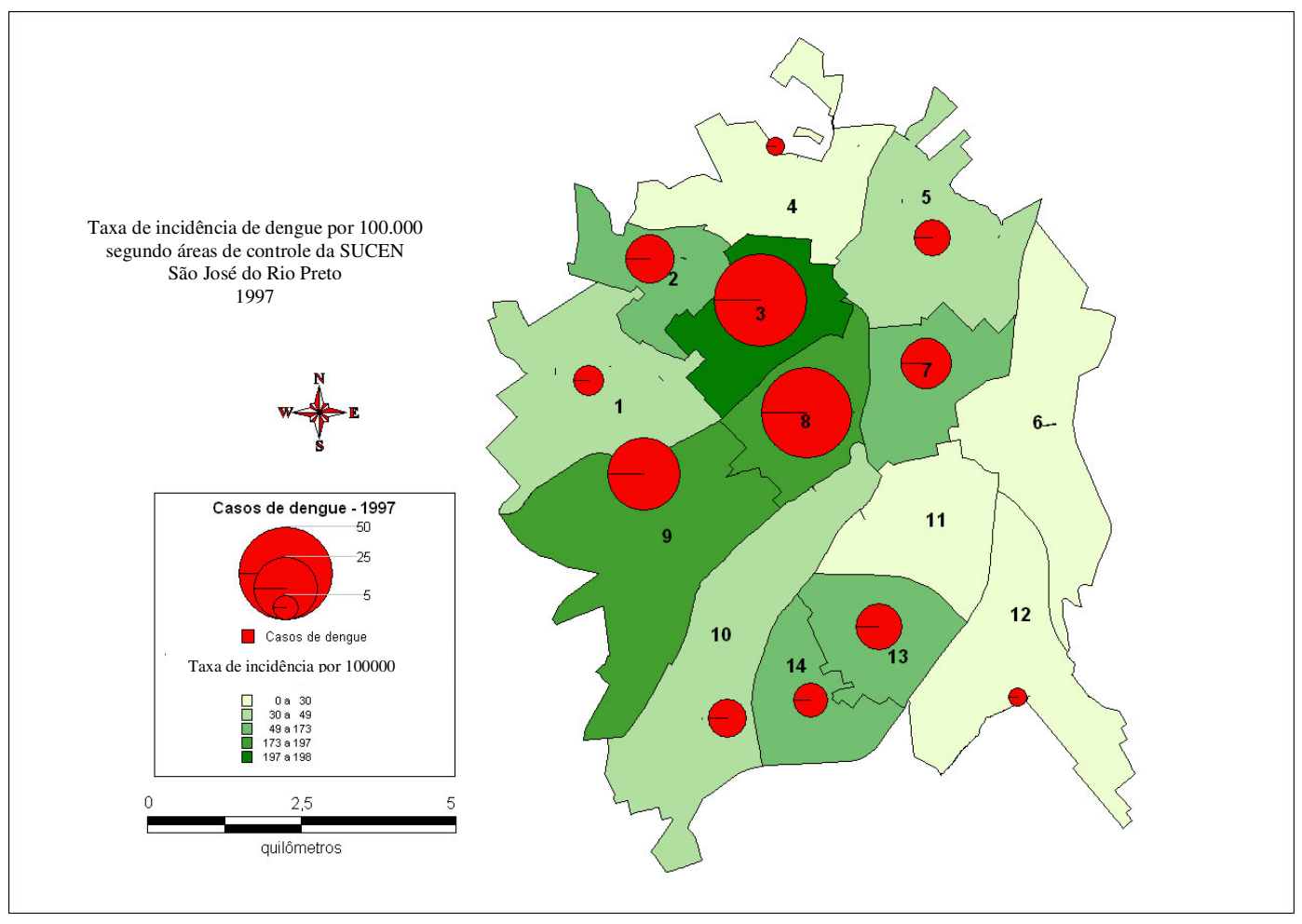

Figura 10 - Distribuição espacial da incidência de dengue por 100.000 habitantes, nas áreas de controle de vetores do município de São José do Rio Preto - Estado de São Paulo, no ano de 1997. 
No ano de 1997, o I Moran foi de 0,1162 com nível de significância estatística de p-value de 0,0020, e os aglomerados espaciais com maior número de casos de dengue ocorreram nas regiões norte (área 3), centro (área 8) e oeste (áreas 9 e 1). As 3 primeiras áreas correspondem as maiores incidências de dengue nesse ano, e a área 1 apesar de apresentar incidência baixa (entre 30 e 49 casos), também apresentou aglomerado espacial significativo (alto - alto), indicando que houve número alto de casos de dengue com alta vizinhança (Figura 11).
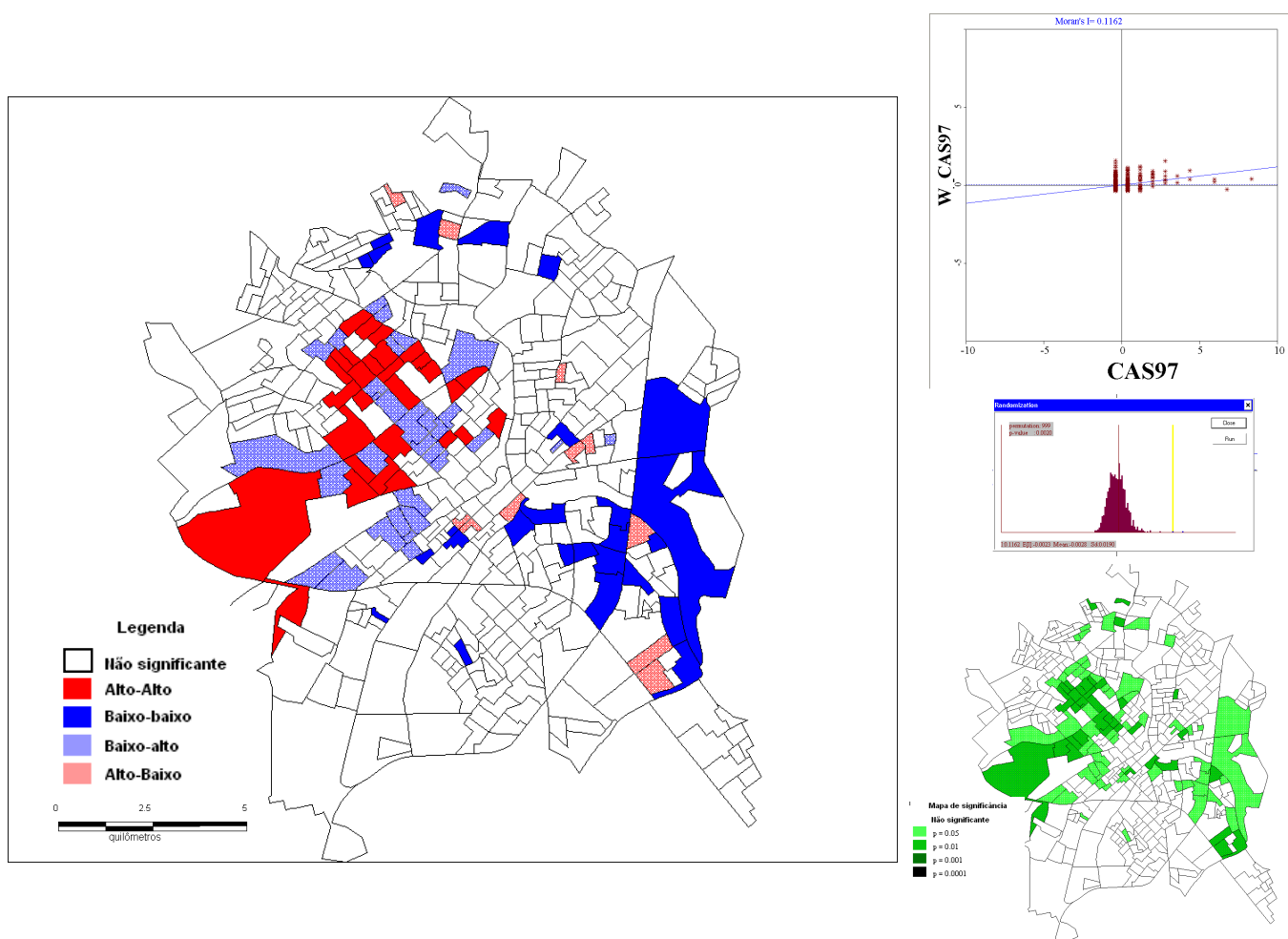

Figura 11 - Distribuição de dengue por setores censitários, evidenciando os aglomerados espaciais; gráfico do diagrama de espalhamento; gráfico de barras e mapa de significância no município de São José do Rio Preto - Estado de São Paulo, no período de 1997. 
Em 1998, o número de casos voltou a crescer, e a área 5 foi a que apresentou maior concentração de casos com incidência variando em torno de 507 casos por 100.000 habitantes, a área 6 com incidência entre 361 e 506 casos, áreas 1, 2, 3, 8, 11 e 13 entre 175 e 361 casos, áreas 4, 7, 9 e 12 com incidências entre 120 e 175 casos e por último as áreas 10 e 14 entre 67 e 120 casos por 100.000 habitantes. As regiões mais atingidas foram a norte, leste, centro e sul da cidade (Figura 12).

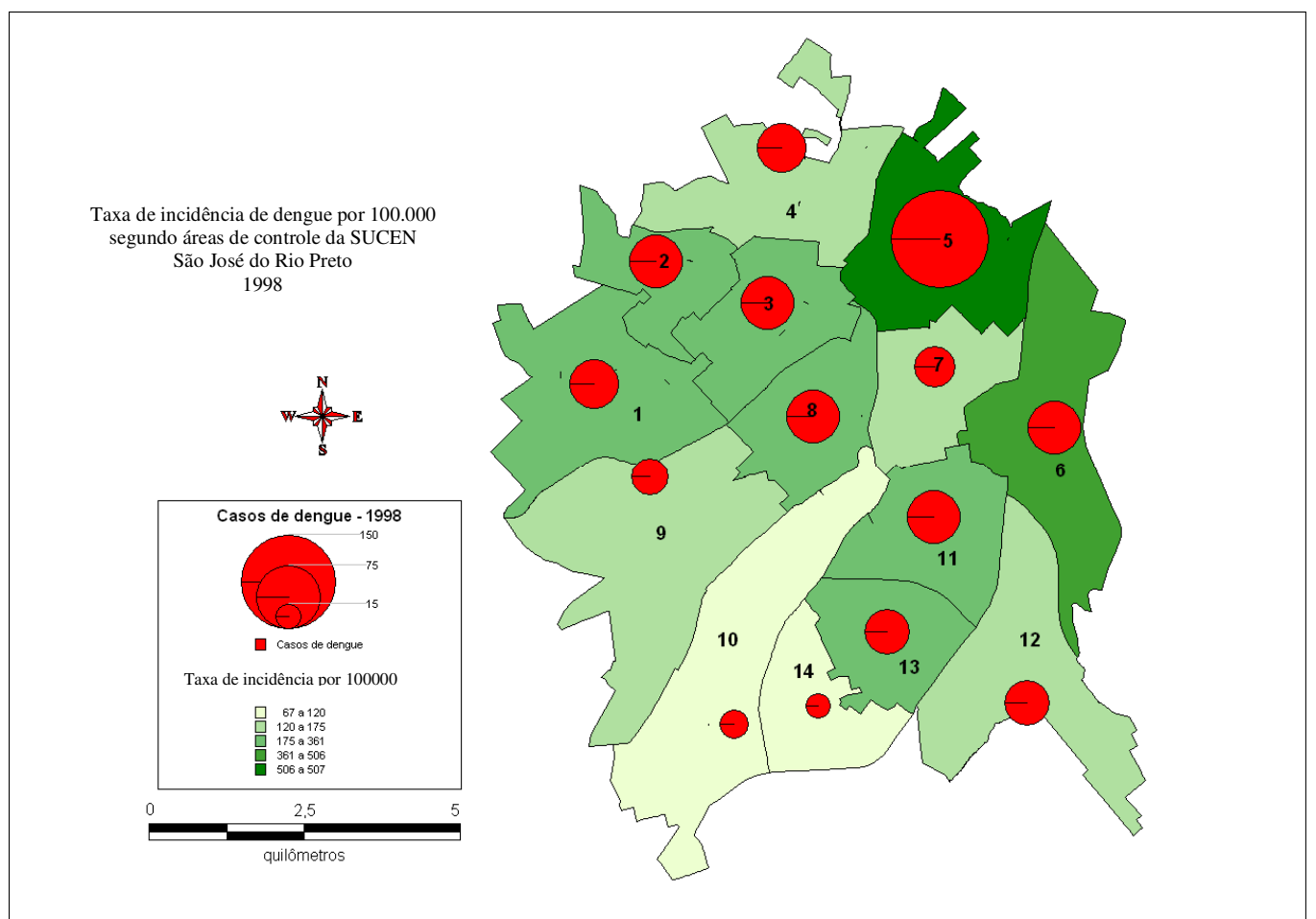

Figura 12 - Distribuição espacial da incidência de dengue por 100.000 habitantes, nas áreas de controle de vetores do município de São José do Rio Preto - Estado de São Paulo, no ano de 1998. 
Nesse ano de 1998, o I Moran foi de 0,1193 com nível de significância estatística p-value de 0,0010. Na região norte da cidade (área 5) ocorreu concentração de aglomerados espaciais classificados como alto-alto. A região leste (área 6) e oeste (área 1) apresentaram poucos aglomerados espaciais altos (Figura 13).

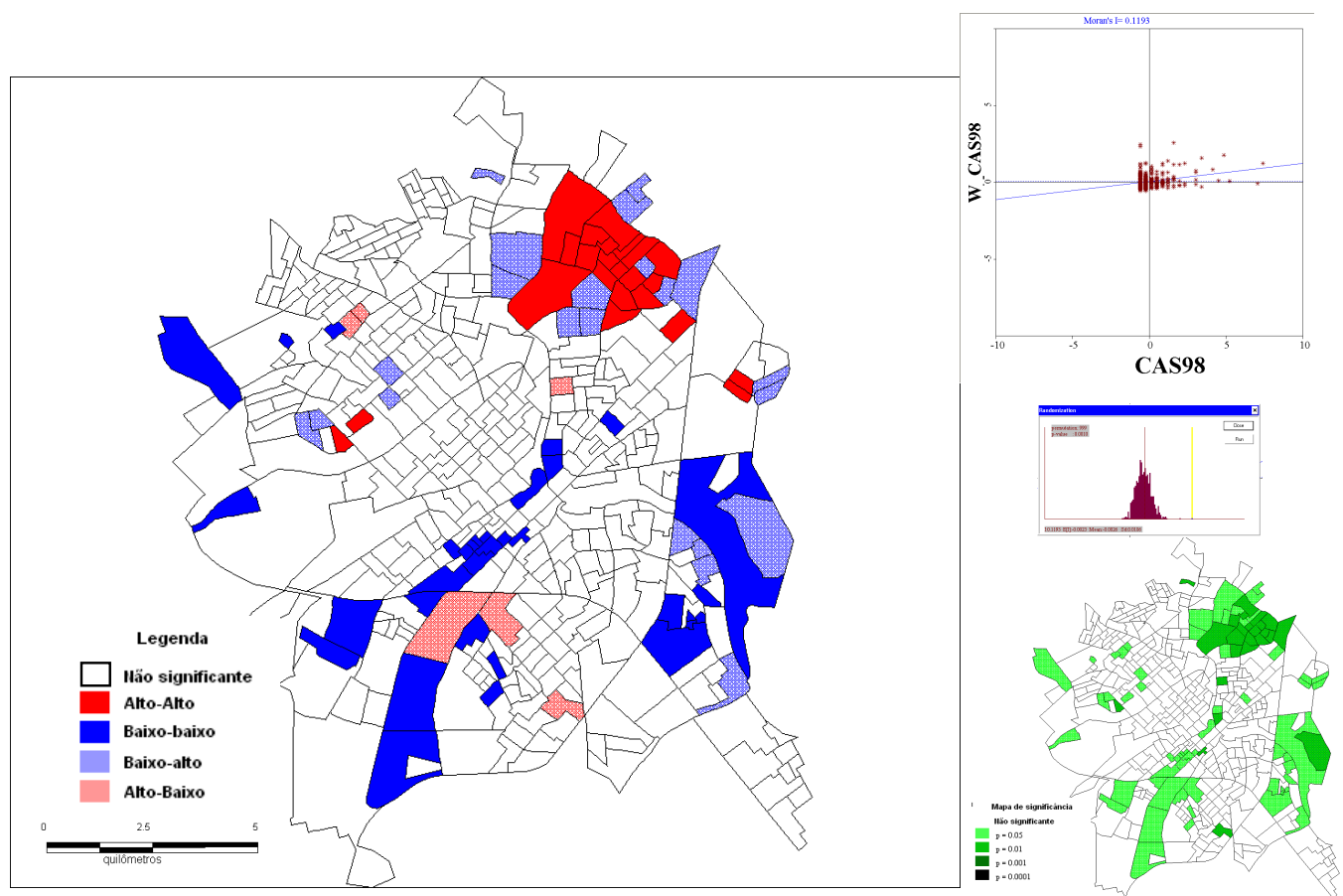

Figura 13 - Distribuição de dengue por setores censitários, evidenciando os aglomerados espaciais; gráfico do diagrama de espalhamento; gráfico de barras e mapa de significância no município de São José do Rio Preto - Estado de São Paulo, no período de 1998. 
Em 1999 ocorreu outra transmissão do vírus com proporções maiores do que a de 1995 e as áreas mais atingidas voltaram a ser a 2 e 7 com incidências variando entre 1.070 e 1.223 casos por 100.000 habitantes, as áreas 4 e 5 com incidências entre 878 e 1.070 casos, áreas 1 e 3 entre 796 e 878 casos, áreas 6, 8, 9, 11 e 14 com incidência entre 615 e 795 casos e finalmente pelas áreas 10, 12 e 13 entre 301 e 615 casos por 100.000 habitantes. Nesse ano a transmissão ocorreu em todas as áreas, mesmo assim, as maiores incidências ocorreram na região norte da cidade (Figura 14).

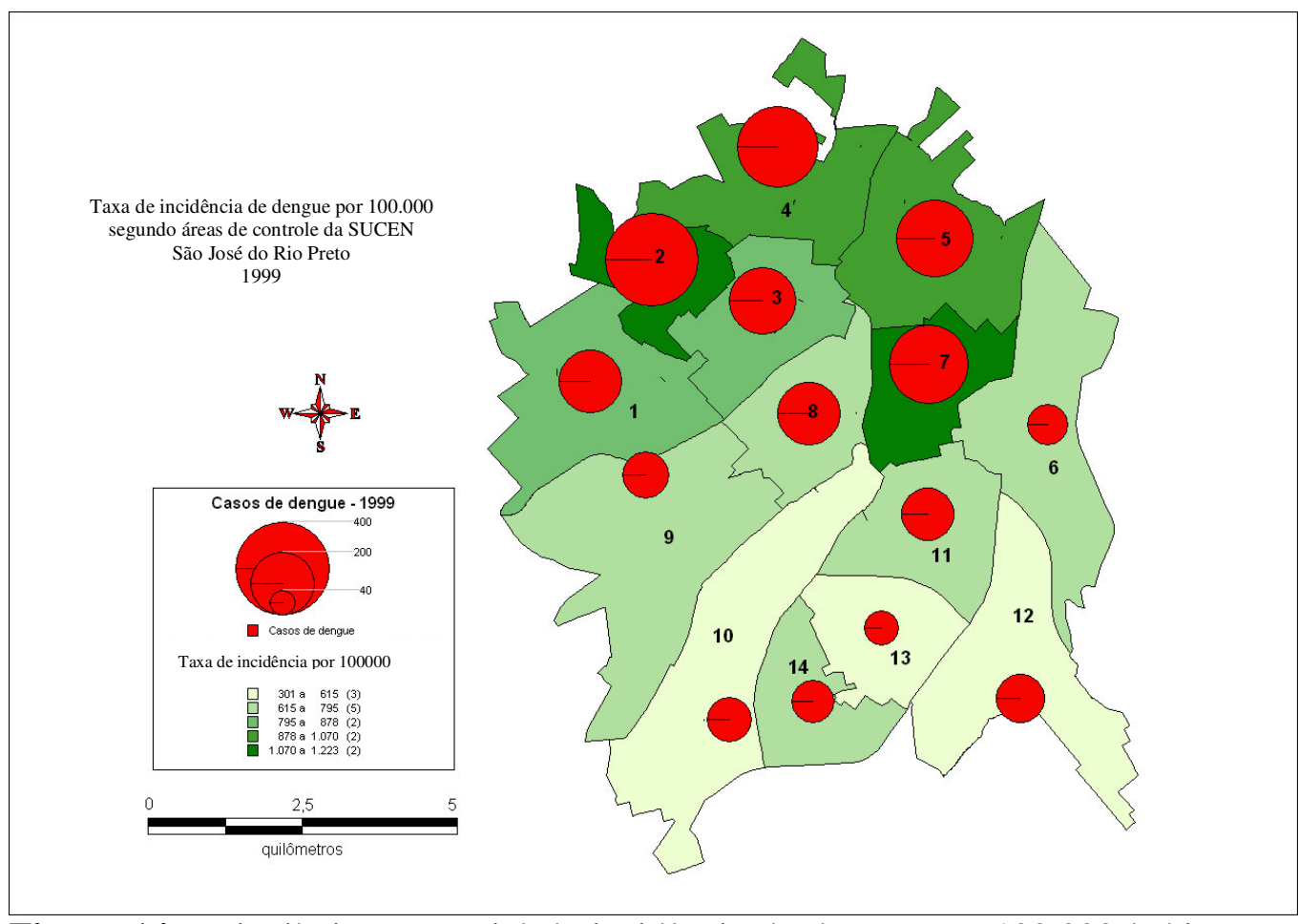

Figura 14 - Distribuição espacial da incidência de dengue por 100.000 habitantes, nas áreas de controle de vetores do município de São José do Rio Preto - Estado de São Paulo, no ano de 1999. 
No ano de 1999, o I Moran foi de 0,2045 com nível de significância estatística p-value de 0,0010 . Os aglomerados espaciais classificados como alto-alto se concentraram na região norte (áreas 2, 3, 4 e 5), leste (área 7) e oeste (área 1 e 9) (Figura 15).
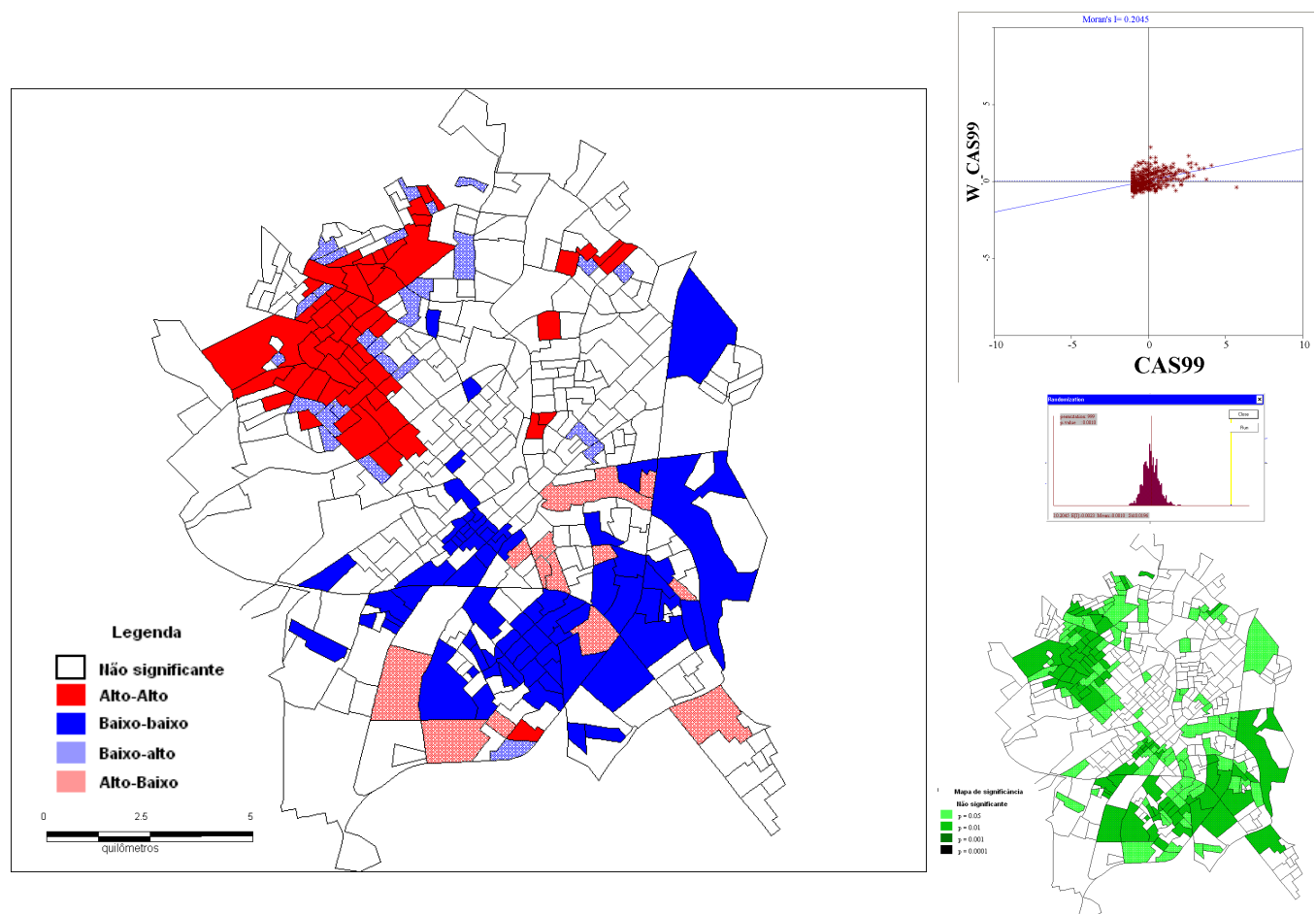

Figura 15 - Distribuição de dengue por setores censitários, evidenciando os aglomerados espaciais; gráfico do diagrama de espalhamento; gráfico de barras e mapa de significância no município de São José do Rio Preto - Estado de São Paulo, no período de 1999. 
No ano de 2000, a transmissão foi menor e a área que apresentou maior número de casos foi a 13 com incidência variando entre 392 e 393 casos por 100.000 habitantes, as áreas 7, 8, 9 e 14 com incidência entre 163 e 392 casos, áreas 1, 3 e10 entre 110 e 163 casos, áreas 2, 4, 5 e 11 com incidência entre 66 e 110 casos, e finalmente pelas áreas 6 e 12 com incidência entre 20 e 66 casos por 100.000 habitantes. A transmissão nesse ano concentrou-se nas regiões sul, centro, leste e oeste da cidade (Figura 16).

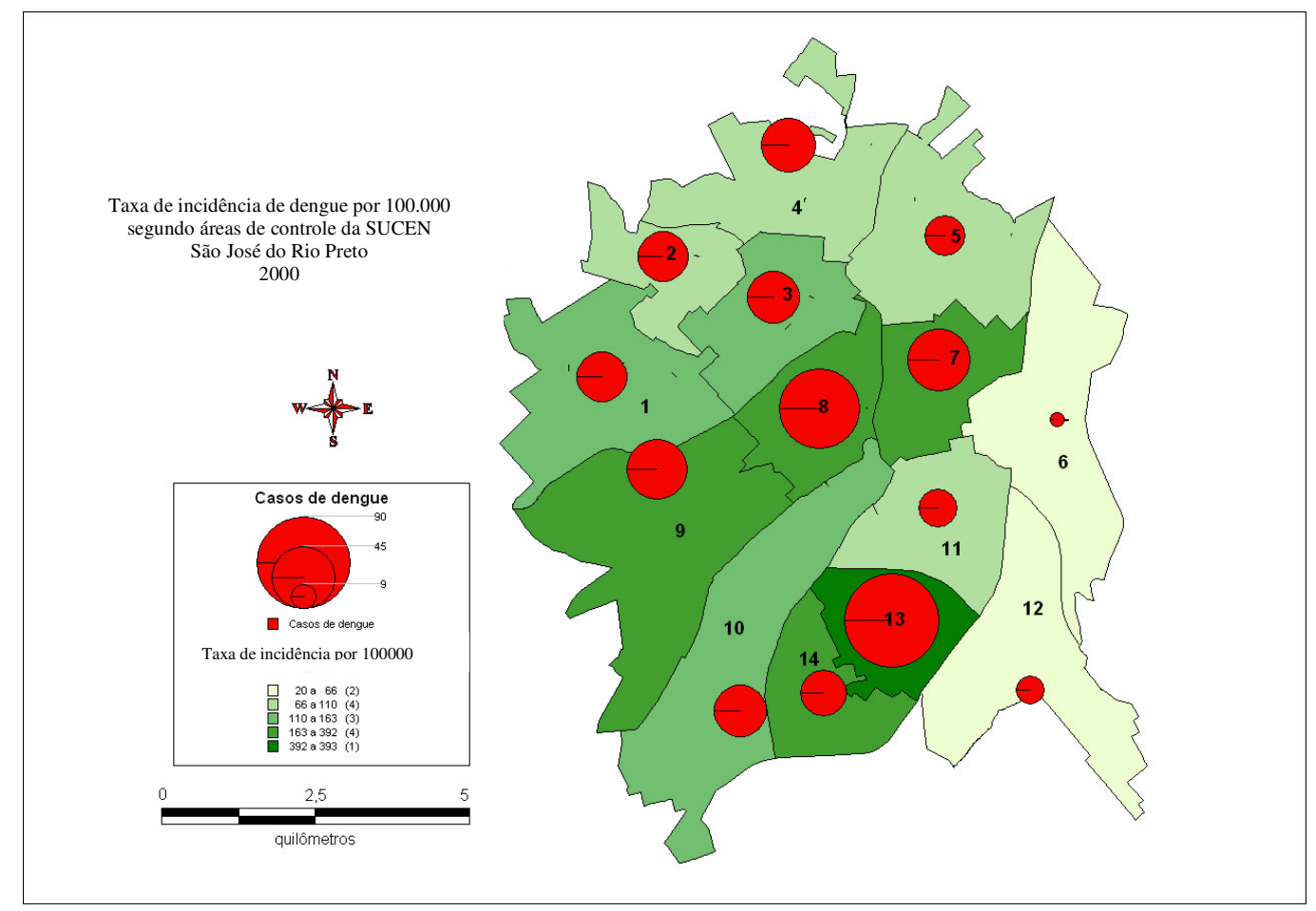

Figura 16 - Distribuição espacial da incidência de dengue por 100.000 habitantes, nas áreas de controle de vetores do município de São José do Rio Preto - Estado de São Paulo, no ano de 2000. 
Em 2000, o I Moran foi 0,0774 com nível de significância estatística p-value de 0,0010, indicando baixa associação espacial global, os aglomerados espaciais classificados como alto-alto se concentraram nas regiões sul (área 13 e 14), centro (área 8) e oeste (área 9) da cidade (Figura 17).
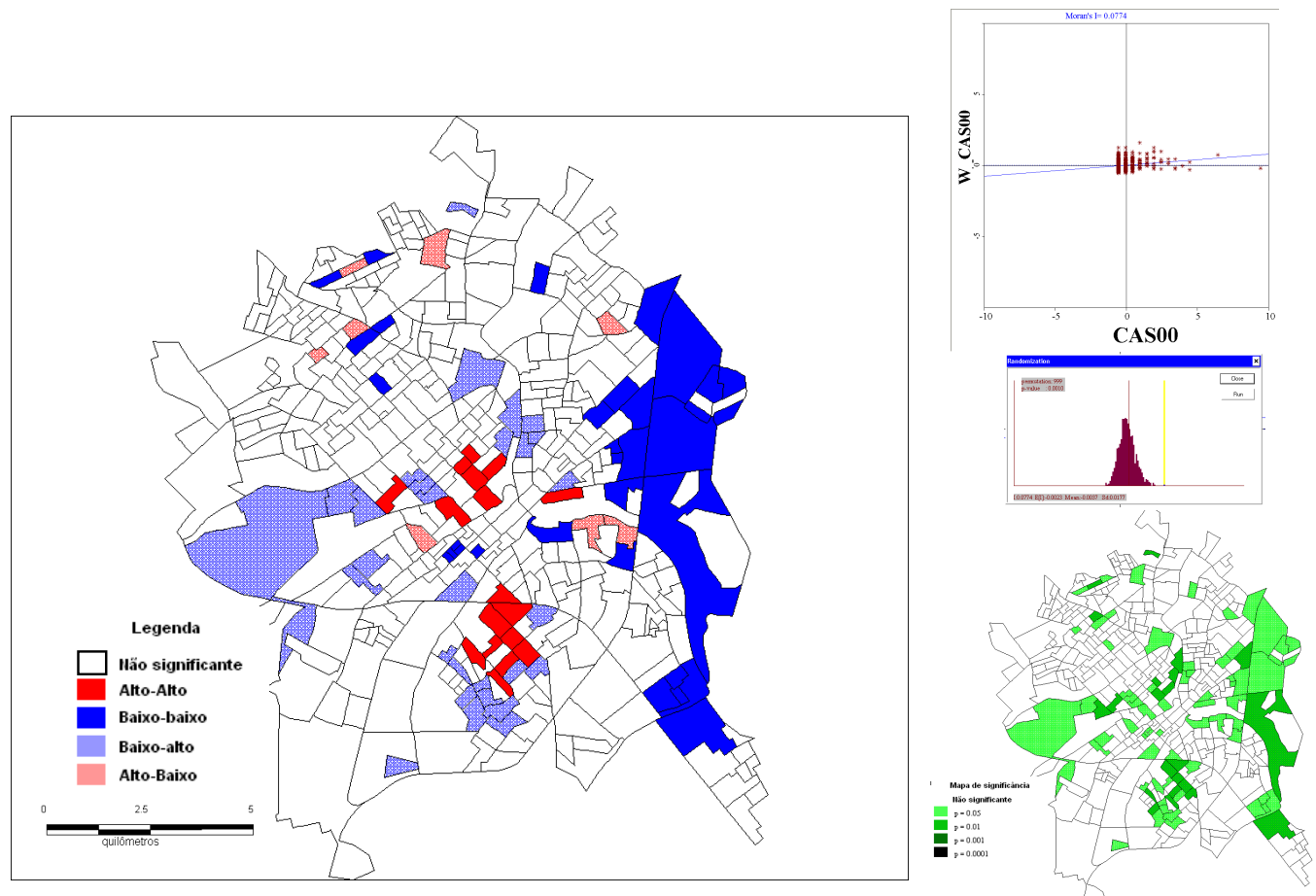

Figura 17 - Distribuição de dengue por setores censitários, evidenciando os aglomerados espaciais; gráfico do diagrama de espalhamento; gráfico de barras e mapa de significância no município de São José do Rio Preto - Estado de São Paulo, no período de 2000. 
No ano de 2001 ocorreu o maior número de casos de dengue na cidade de São José do Rio Preto e a maior incidência foi na área 7, variando entre 2390 e 3610 casos por 100.000 habitantes, as áreas 5, 8, 9 e 11 com incidências entre 2070 e 2390 casos, áreas 3 e 4 entre 1500 e 2070 casos, áreas 6, 12 e 13 com incidência entre 1350 e 1500 casos e finalmente as áreas $1,2,10$ e 14 entre 670 e 1350 casos por 100.000 habitantes. Ocorreram casos de dengue, com altas incidências, em todas as áreas da cidade (Figura 18).

Taxa de incidência de dengue por 100.000 segundo áreas de controle da SUCEN São José do Rio Preto
2001
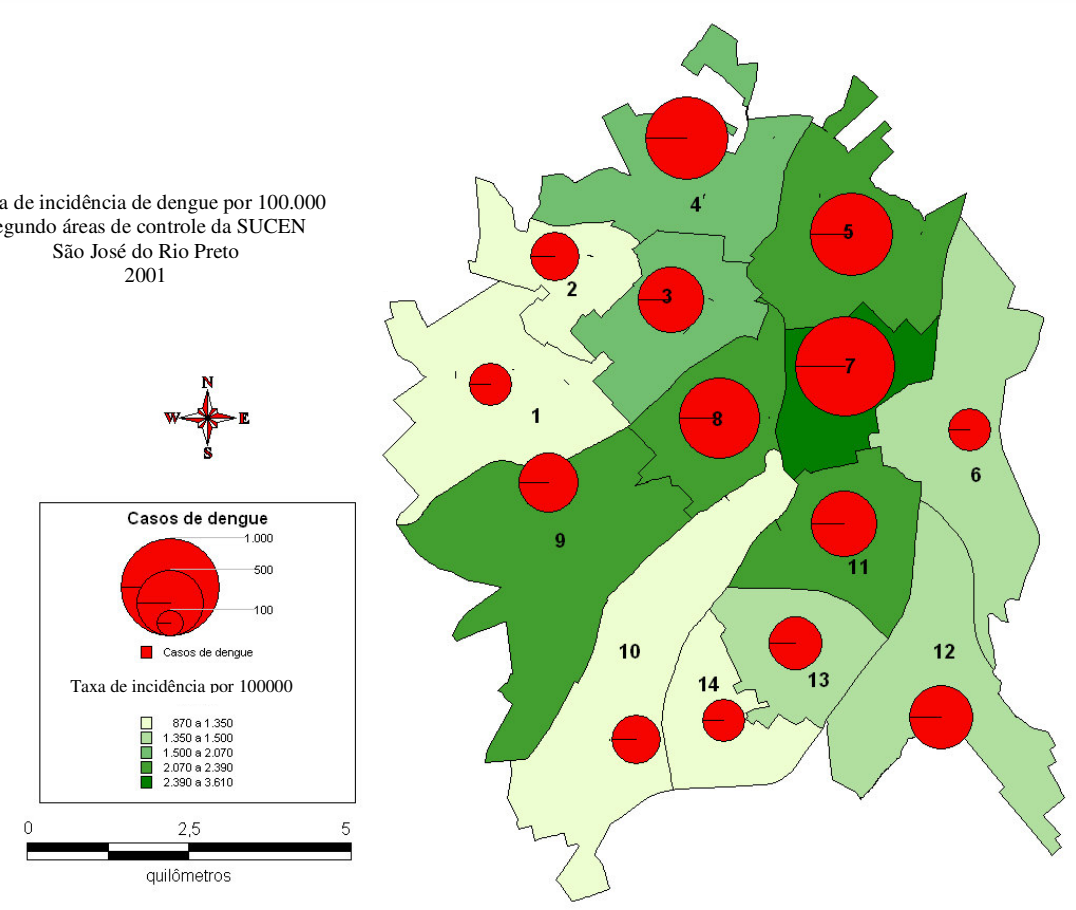

Figura 18 - Distribuição espacial da incidência de dengue por 100.000 habitantes, nas áreas de controle de vetores do município de São José do Rio Preto - Estado de São Paulo, no ano de 2001. 
Na Figura 19 podemos observar que no ano de 2001 o I Moran foi 0,2041 com nível de significância estatística p-value de 0,0010. Os aglomerados espaciais mais significativos, classificados como alto-alto, ocorreram nas regiões leste, norte e centro da cidade. A região oeste (área 9), apesar de apresentar a segunda maior incidência (entre 2070 e 2390), não apresentou aglomerado espacial.
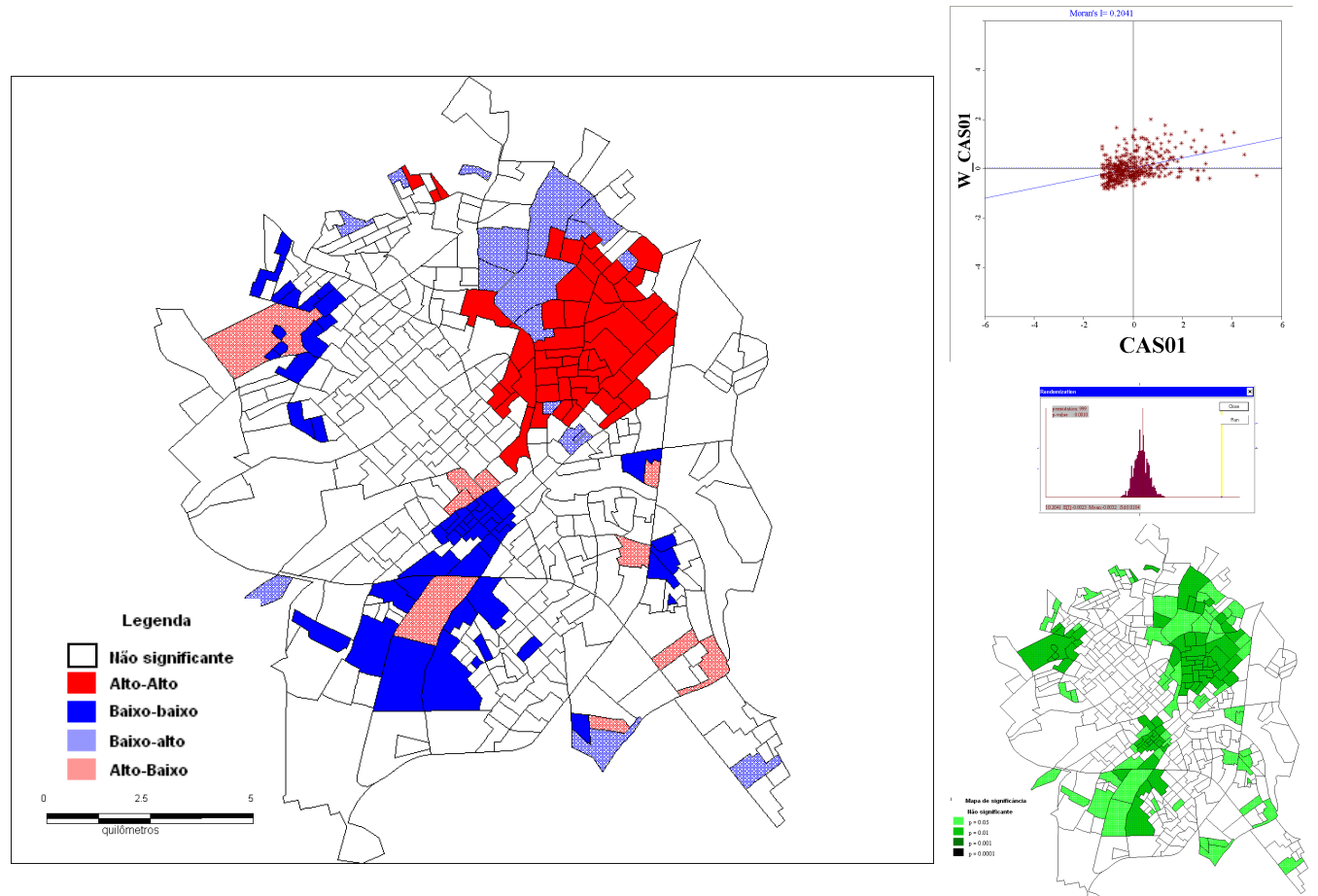

Figura 19 - Distribuição de dengue por setores censitários, evidenciando os aglomerados espaciais; gráfico do diagrama de espalhamento; gráfico de barras e mapa de significância no município de São José do Rio Preto - Estado de São Paulo, no período de 2001. 
Em 2002, a área 2 voltou a apresentar a maior incidência, variando entre 647 e 648 casos por 100.000 habitantes, as áreas 1 e 8 com incidência entre 360 e 647 casos, áreas 3, 9 e 13 entre 206 e 360 casos, áreas 4, 7 e 11 com incidência entre 181 e 206 casos e finalmente as áreas 5, 6, 10, 12 e 14 entre 64 e 181 casos por 100.000 habitantes. As regiões mais atingidas, nesse ano, foram às regiões norte, centro e oeste (Figura 20).

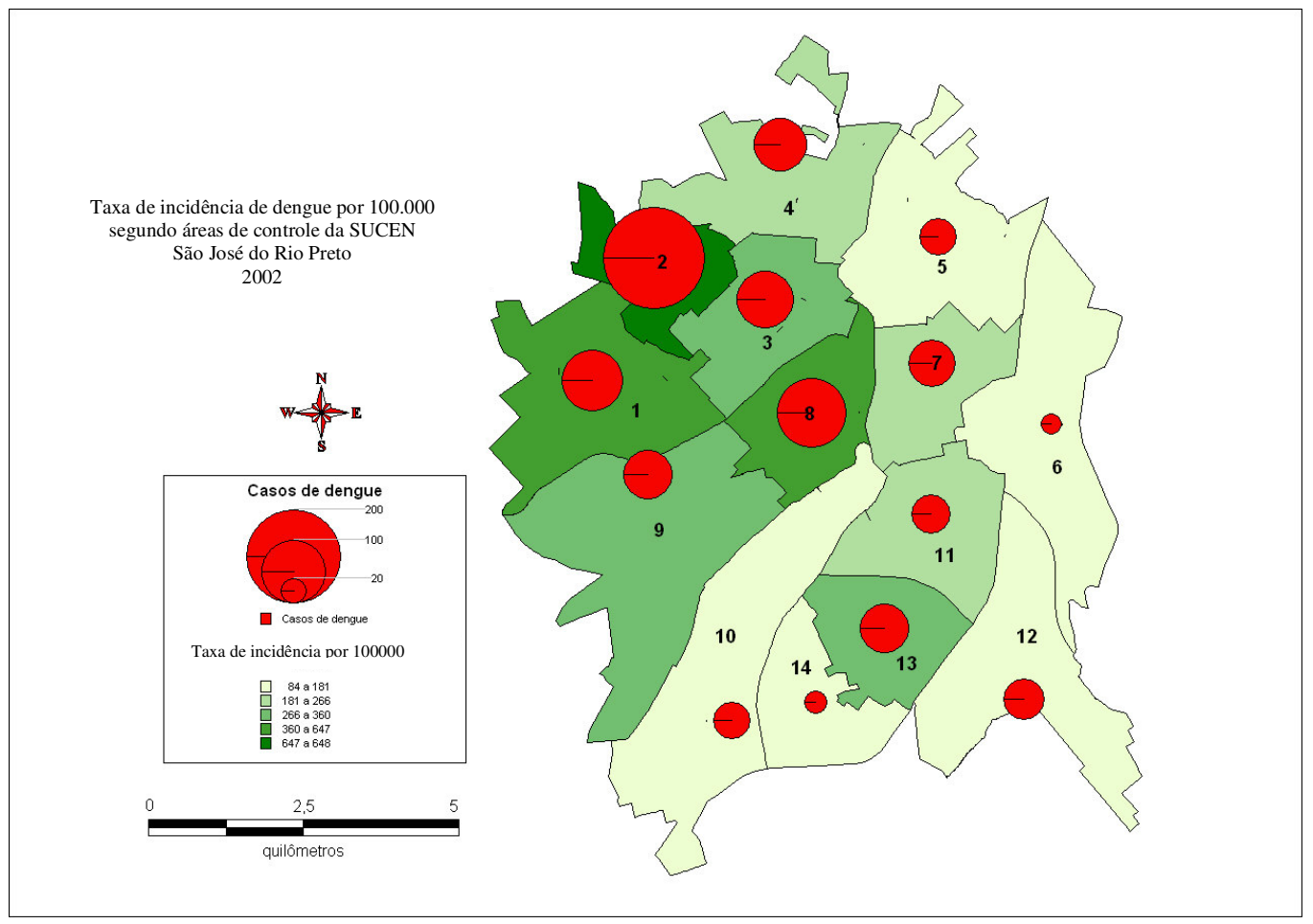

Figura 20 - Distribuição espacial da incidência de dengue por 100.000 habitantes, nas áreas de controle de vetores do município de São José do Rio Preto - Estado de São Paulo, no ano de 2002. 
Em 2002, o I Moran foi 0,1568 com nível de significância estatística p-value de 0,0010 . Os aglomerados espaciais classificados como alto-alto voltaram a se concentrar nas regiões norte (áreas 2 e 3), centro (área 8) e oeste (área 1 e 9) da cidade. Na região sul (área 13), apesar de ter apresentado uma incidência de 266 casos por 100.000 habitantes, não houve aglomerados espaciais significativos (Figura 21).
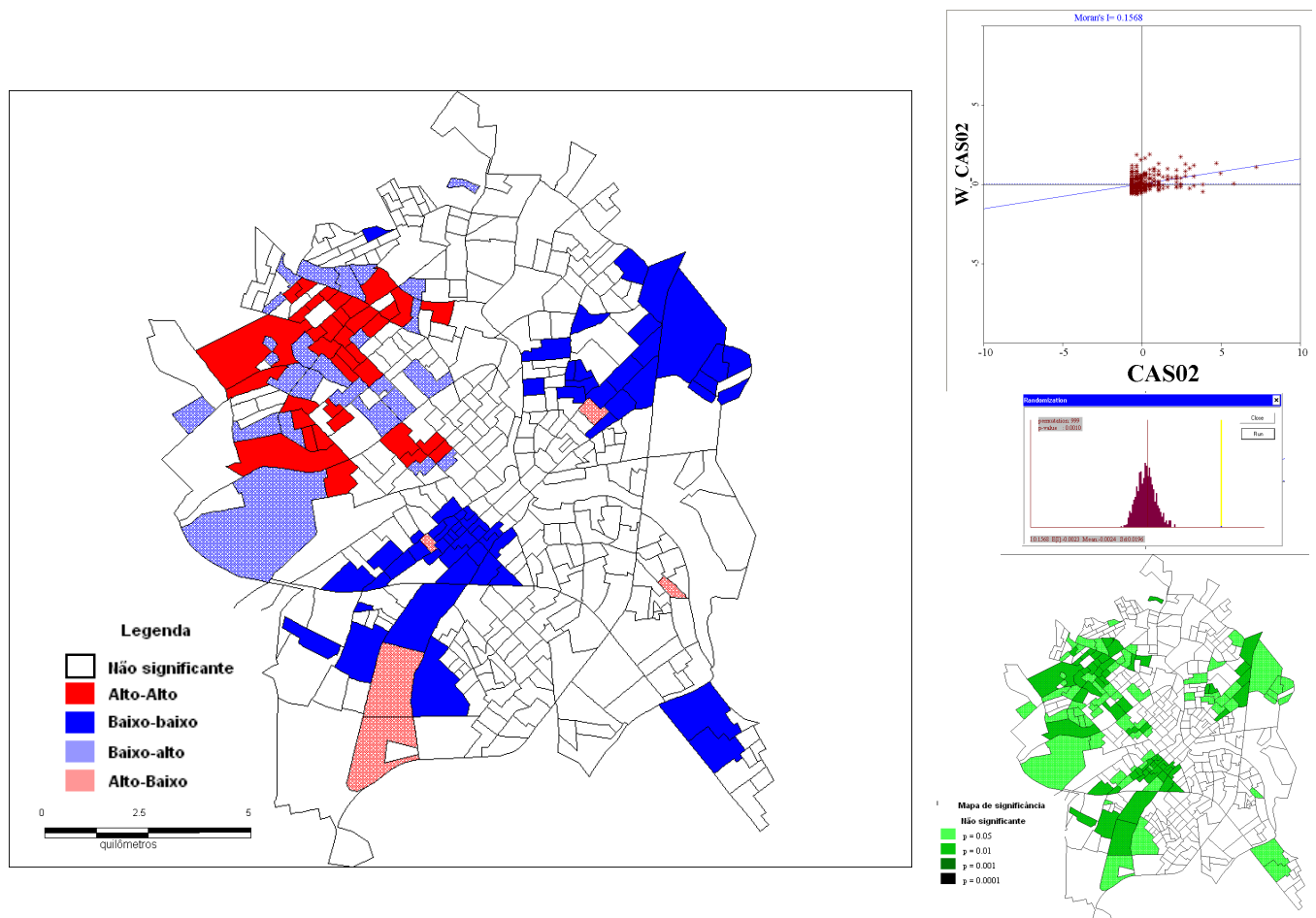

Figura 21 - Distribuição de dengue por setores censitários, evidenciando os aglomerados espaciais; gráfico do diagrama de espalhamento; gráfico de barras e mapa de significância no município de São José do Rio Preto - Estado de São Paulo, no período de 2002. 
No ano de 2003, a área mais atingida foi a 8 com incidência entre 532 e 533 casos por 100.000 habitantes, a área 3 com incidência entre 193 e 532 casos, áreas 7 e 11 entre 117 e 193 casos, áreas 1, 2, 4, 5, 6, 9 e 10 com incidência entre 56 e 117 casos e finalmente pelas áreas 12,13 e 14 com incidência entre 12 e 56 casos por 100.000 habitantes. A região central e norte foram as mais atingidas (Figura 22).

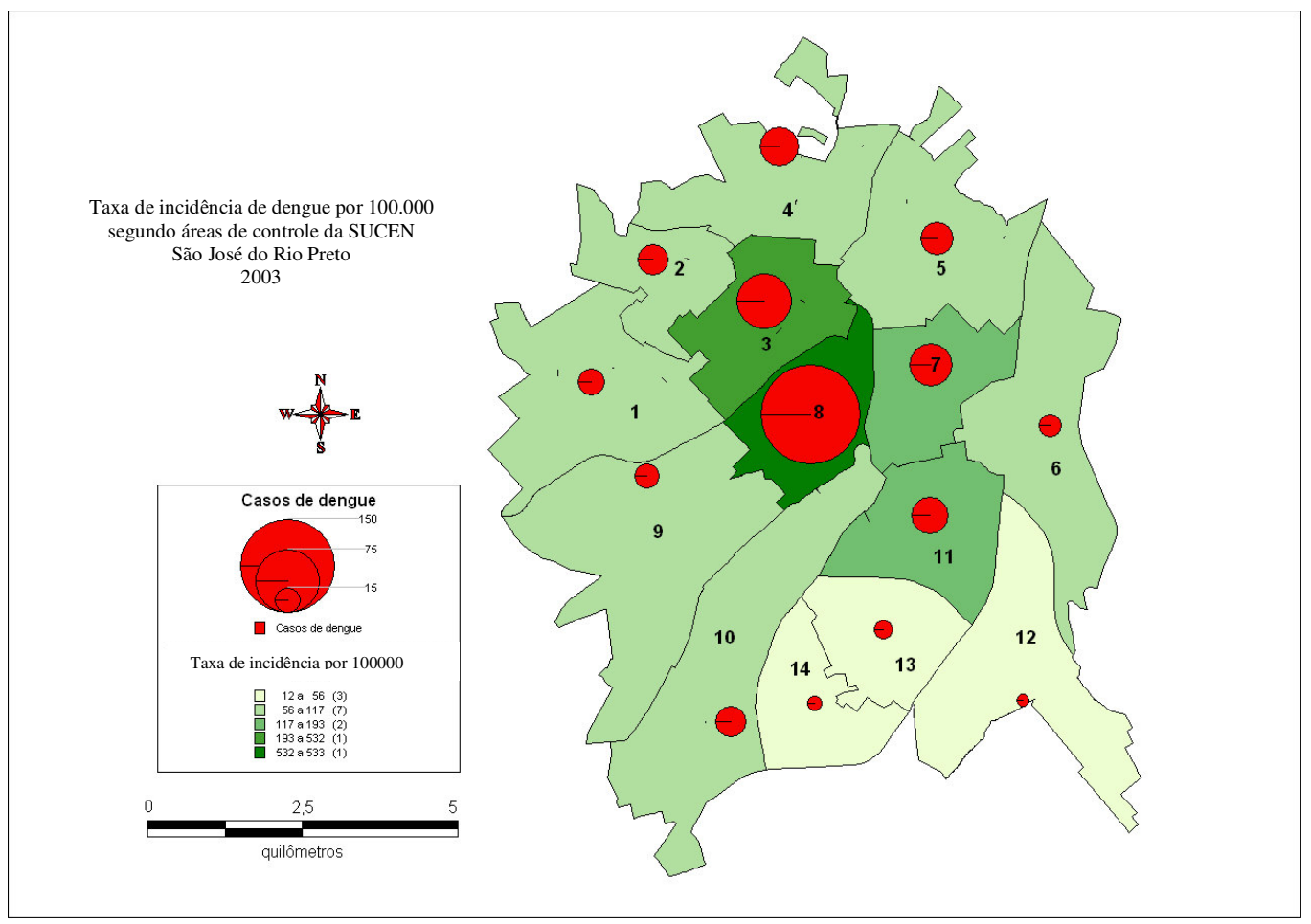

Figura 22 - Distribuição espacial da incidência de dengue por 100.000 habitantes, nas áreas de controle de vetores do município de São José do Rio Preto - Estado de São Paulo, no ano de 2003. 
Na Figura 23 podemos observar o ano de 2003 com I Moran de 0,2182 com nível de significância estatística p-value de 0.0010. Os aglomerados espaciais classificados como alto-alto voltaram a se concentrar nas regiões centro (área 8), norte (área 3) e leste (área 7). A área 11 apesar de ter incidência alta, não apresentou aglomerados espaciais. As regiões central e norte foram as mais atingidas.
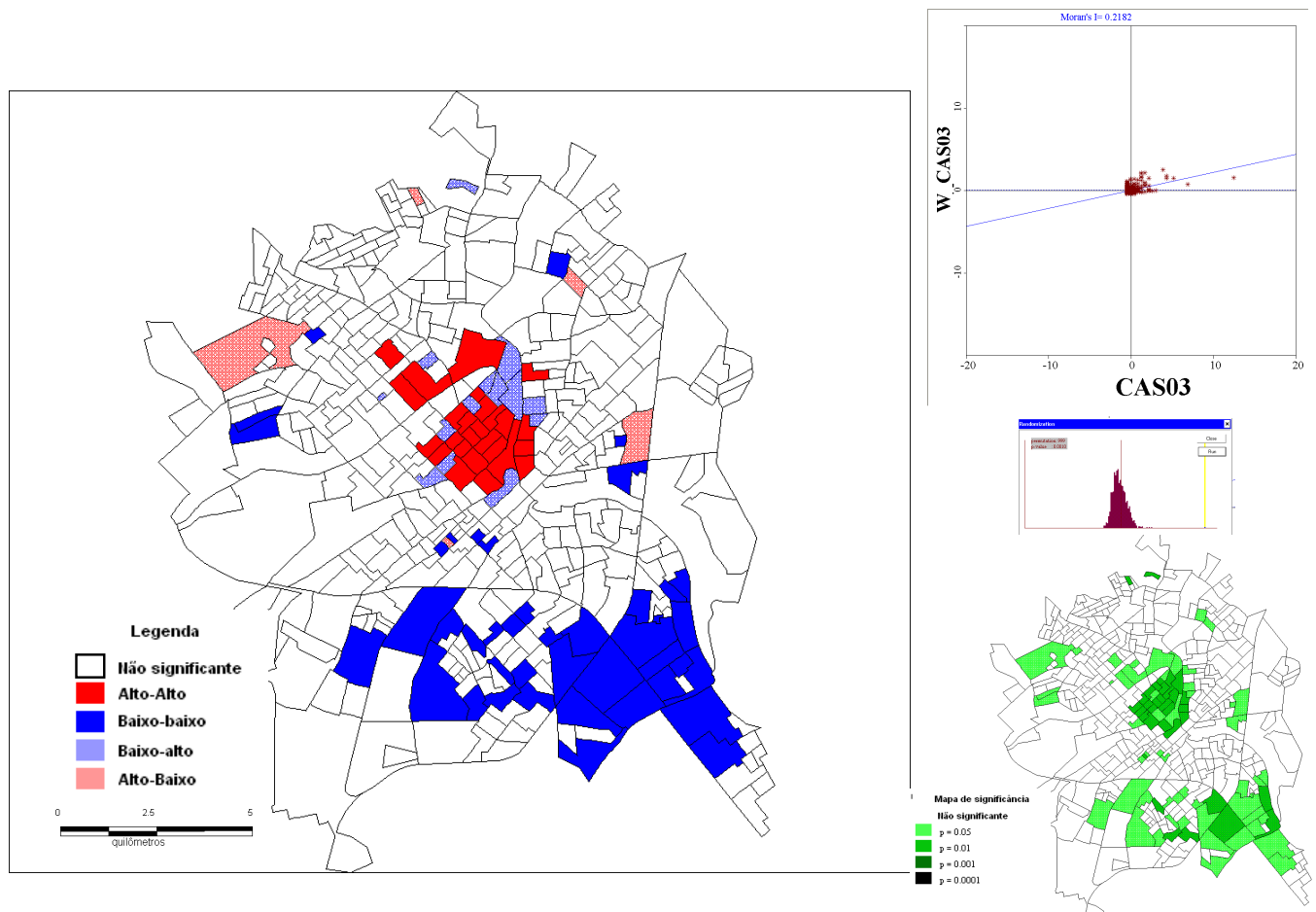

Figura 23 - Distribuição de dengue por setores censitários, evidenciando os aglomerados espaciais; gráfico do diagrama de espalhamento; gráfico de barras e mapa de significância no município de São José do Rio Preto - Estado de São Paulo, no período de 2003. 
Em 2004, as áreas mais atingidas foram a 13 e 14 com incidências que variaram entre 51 e 128 casos por 100.000 habitantes, as áreas 3, 6, 7 e 9 com incidências entre 6 e 51 casos, área 11 entre 4 e 6 casos, áreas 1, 2, 5, 10 e 12 com incidência entre 2 e 4 casos e a área 4 entre 0 e 2 casos por 100.000 habitantes. A região sul foi a mais atingida (Figura 24).

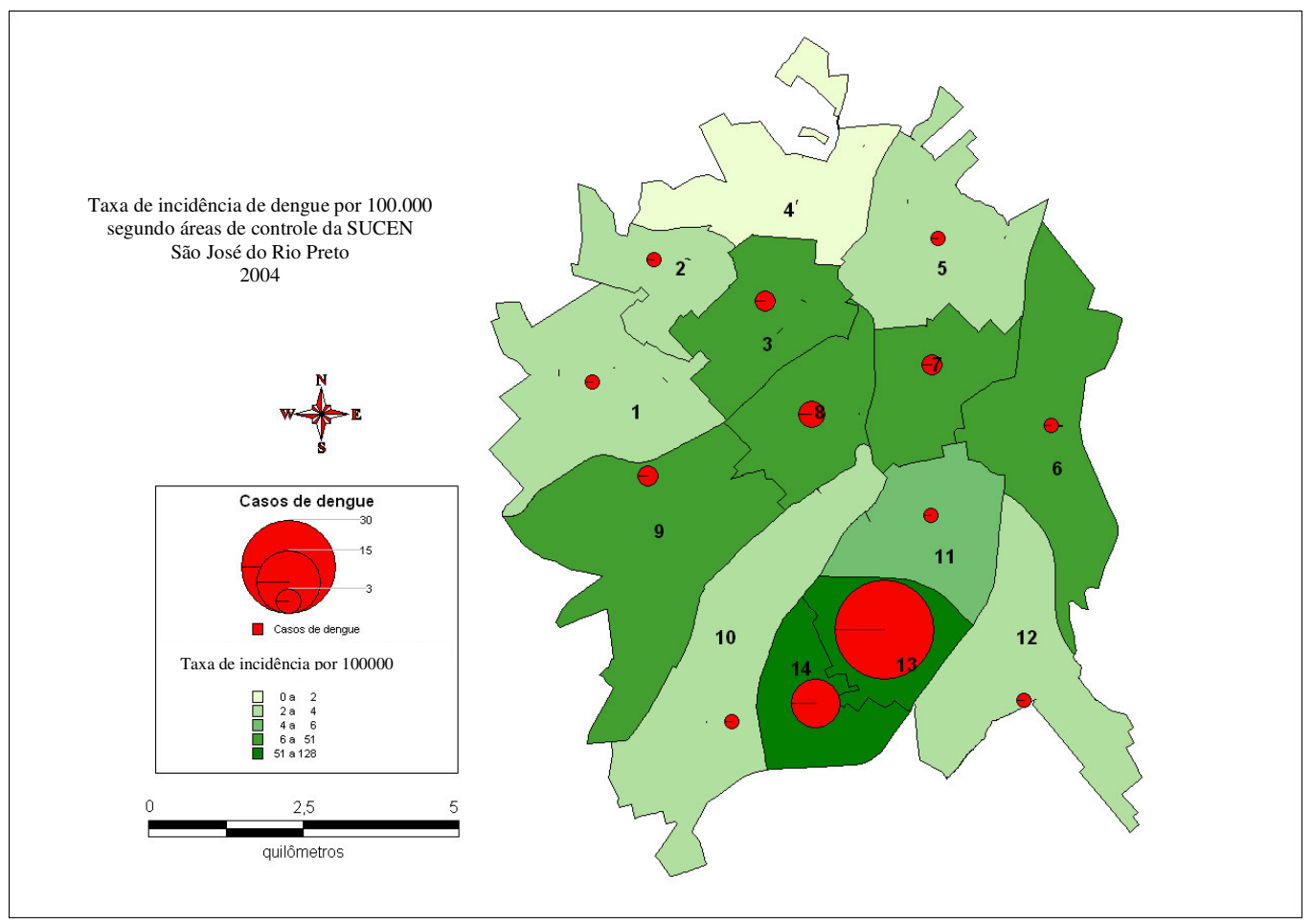

Figura 24 - Distribuição espacial da incidência de dengue por 100.000 habitantes, nas áreas de controle de vetores do município de São José do Rio Preto - Estado de São Paulo, no ano de 2004. 
Nesse ano de 2004, o I Moran foi 0,1184 com nível de significância estatística p-value de 0.0010 . Os aglomerados espaciais classificados como alto-alto se concentraram na região sul (áreas 13 e 14) da cidade, como apresenta a Figura 25.
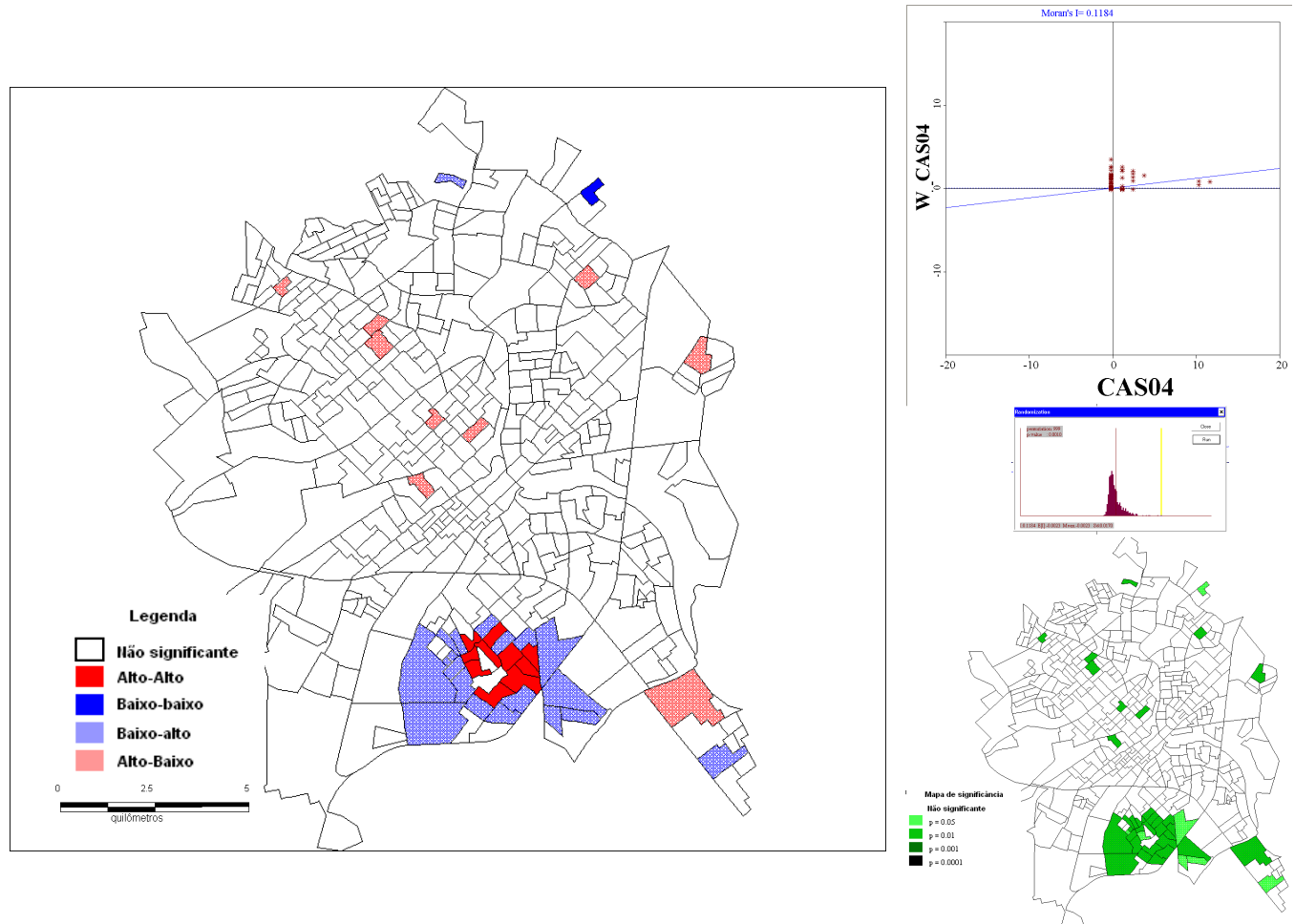

Figura 25 - Distribuição de dengue por setores censitários, evidenciando os aglomerados espaciais; gráfico do diagrama de espalhamento; gráfico de barras e mapa de significância no município de São José do Rio Preto - Estado de São Paulo, no período de 2004. 
No ano de 2005, a área 7 foi a que apresentou maior incidência, que variou entre 265 e 266 casos por 100.000 habitantes, as áreas 3, 5 e 9 com incidência entre 122 e 265 casos, áreas 1, 6, 8 e 10 entre 53 e 122 casos, áreas 2, 4 e 11 com incidência entre 24 e 53 casos e finalmente pelas áreas 12, 13 e 14 com incidência entre 11 e 24 casos por 100.000 habitantes. As regiões leste, norte e oeste foram as mais atingidas (Figura 26).

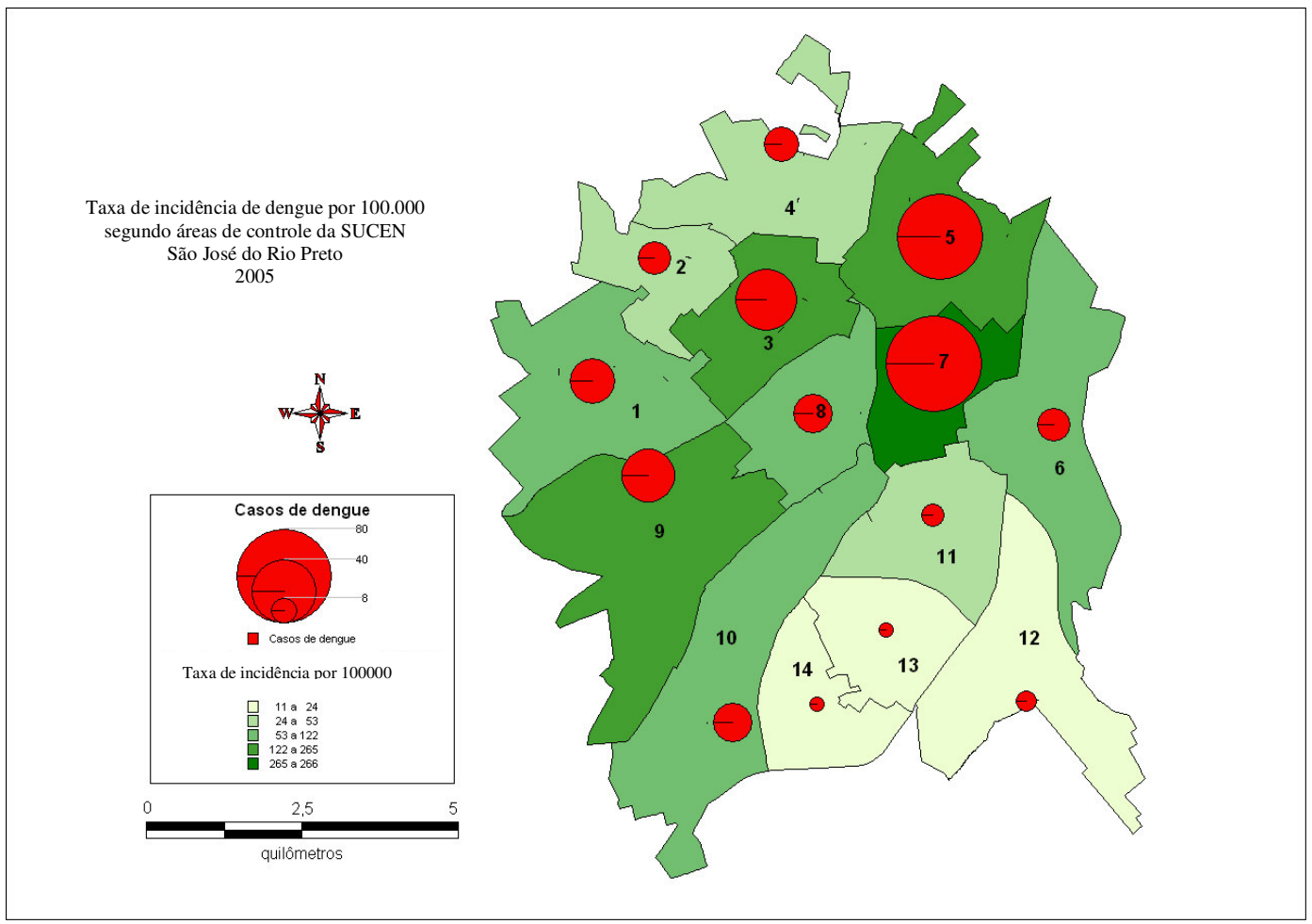

Figura 26 - Distribuição espacial da incidência de dengue por 100.000 habitantes, nas áreas de controle de vetores do município de São José do Rio Preto - Estado de São Paulo, no ano de 2005. 
A Figura 27 apresenta o ano de 2005, com I Moran de 0,1003 com nível de significância estatística p-value de 0,0020, com a maioria dos aglomerados espaciais classificados como alto-alto nas regiões leste (área 7) e norte (áreas 5 e 3). A região oeste (área 9), apesar de ter apresentado o segundo maior intervalo de incidência não apresentou aglomerado espacial.


Figura 27 - Distribuição de dengue por setores censitários, evidenciando os aglomerados espaciais; gráfico do diagrama de espalhamento; gráfico de barras e mapa de significância no município de São José do Rio Preto - Estado de São Paulo, no período de 2005. 
De maneira geral as áreas que apresentaram maiores incidências no período de 1990 a 2005 foram às áreas 7 e 8, variando entre 381 e 432 casos por 100.000 habitantes, as áreas 2 e 3 com incidência variando entre 303 e 381, áreas 4, 5, 9 e 11 entre 263 e 303, áreas 1 e 13 com incidência entre 196 e 263, e pelas áreas 6, 10, 12 e 14 com incidência entre 138 e 196 casos por 100.000 habitantes. Apontando assim que as regiões mais atingidas foram à região leste, centro e norte da cidade, como se pode visualizar na Figura 28.

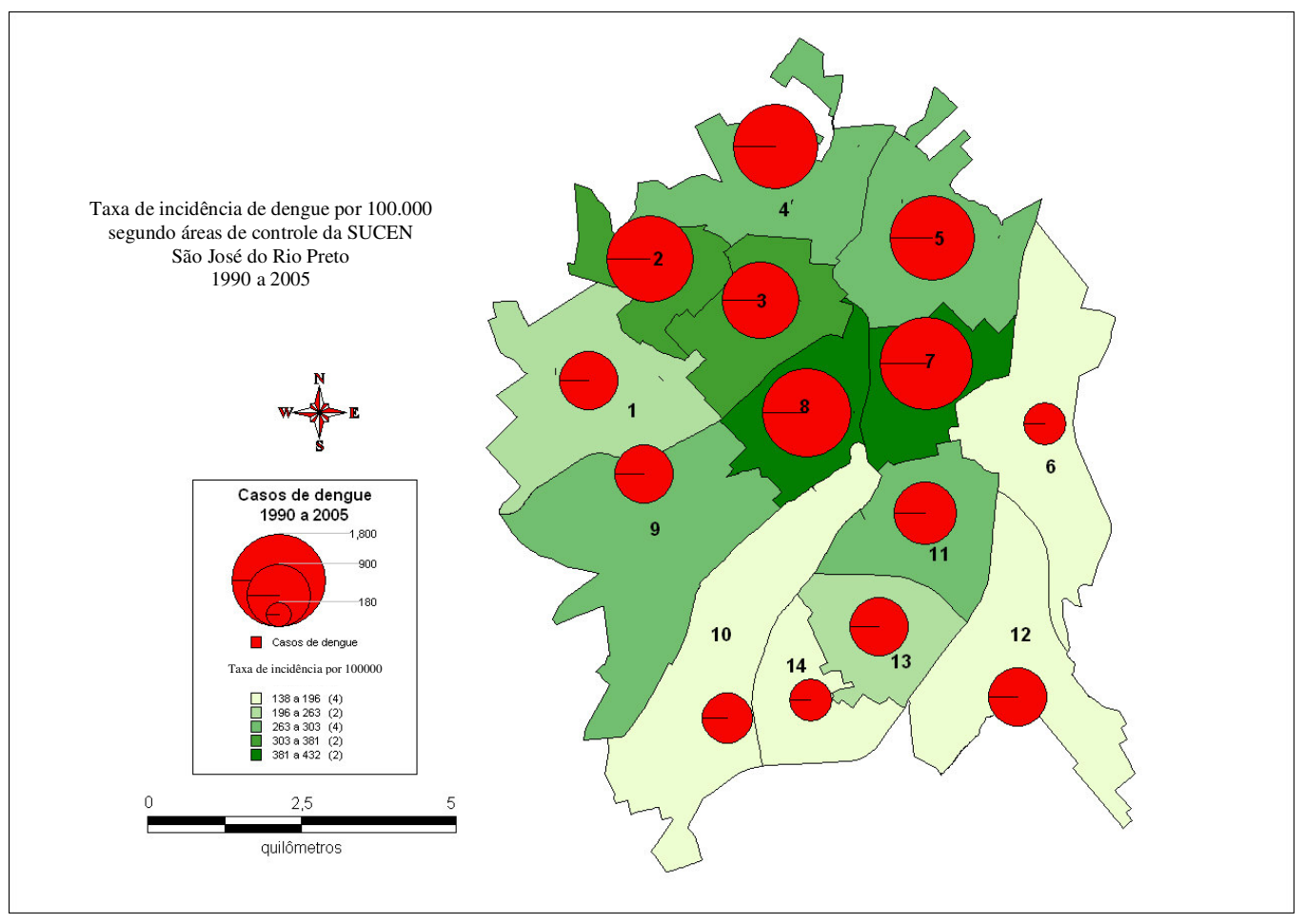

Figura 28 - Distribuição espacial da incidência de dengue por 100.000 habitantes, nas áreas de controle de vetores do município de São José do Rio Preto - Estado de São Paulo, no período de 1990 a 2005. 
Analisando o período de 1990 a 2005 observou-se I Moran de 0,2517 com nível de significância estatística p-value de 0,0010, com a maioria dos aglomerados espaciais classificados como alto-alto na região leste (área 7), seguido da região centro (área 8), norte (áreas 2 e 3) e oeste ( área 1) (Figura 29).
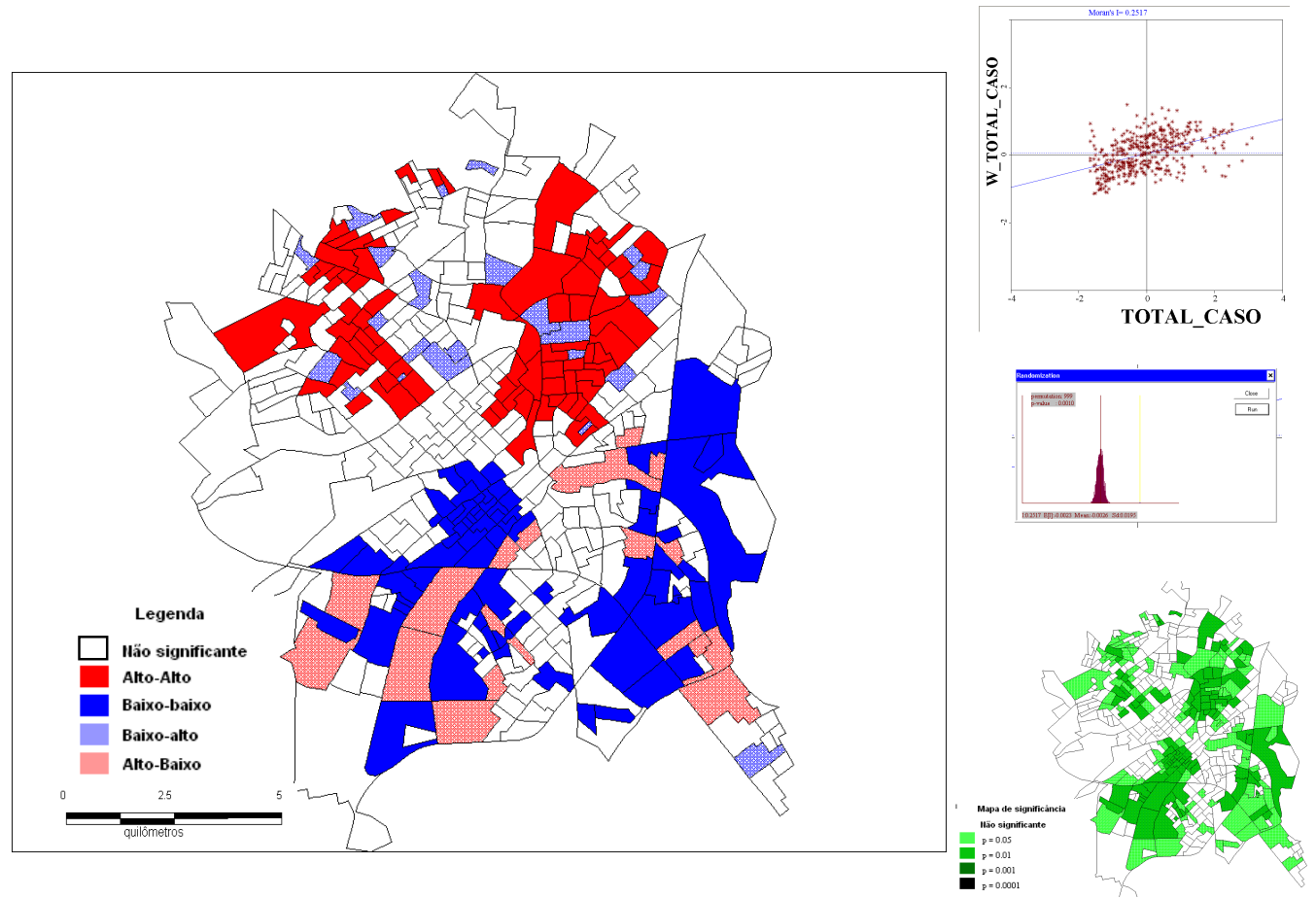

Figura 29 - Distribuição de dengue por setores censitários, evidenciando os aglomerados espaciais; gráfico do diagrama de espalhamento; gráfico de barras e mapa de significância no município de São José do Rio Preto - Estado de São Paulo, no período de 1990 a 2005. 
Observando a Figura 30, nota-se que relacionando a taxa de incidência segundo a variável renda dos responsáveis pelas famílias, é possível dividir a cidade em 3 padrões: baixo (região norte e parte da oeste), médio (região leste e central) e alto (região sul e parte da oeste).

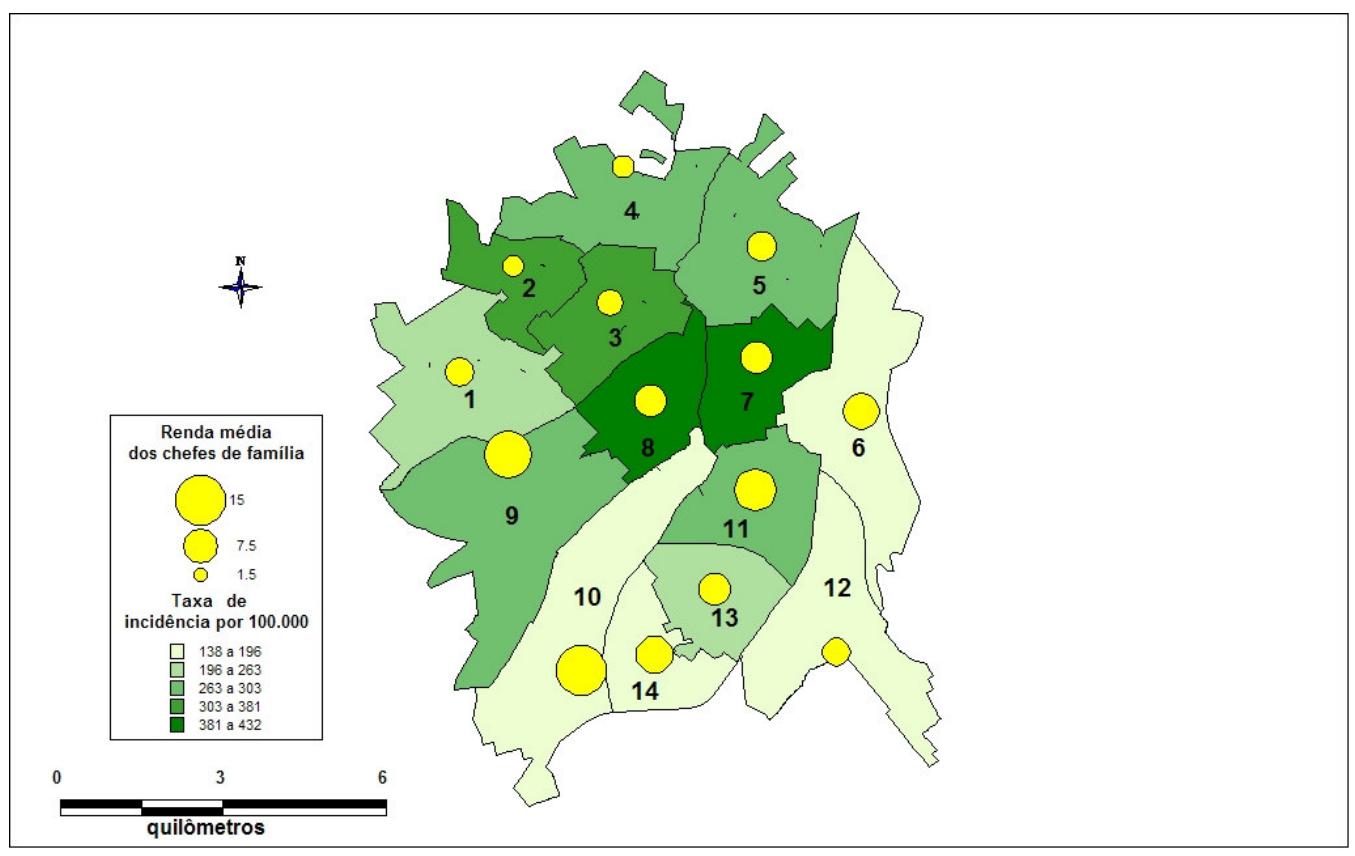

Figura 30 - Distribuição espacial da incidência de dengue por 100.000 habitantes, nas áreas de controle de vetores associado à variável renda média (salário mínimo) dos responsáveis pelas famílias no município de São José do Rio Preto - Estado de São Paulo, no período de 1990 a 2005.

Fonte: IBGE, 2002. 
Relacionando-se a taxa de incidência com a variável grau de escolaridade verificou-se também ser possível dividir a cidade em 3 padrões: baixo (região norte e parte da oeste), médio (região leste e central) e alto (região sul e parte da oeste). Observou-se que a região que concentra a maior incidência no período de 1990 a 2005 foi aquela de padrão de renda e instrução médio (Figura 31).

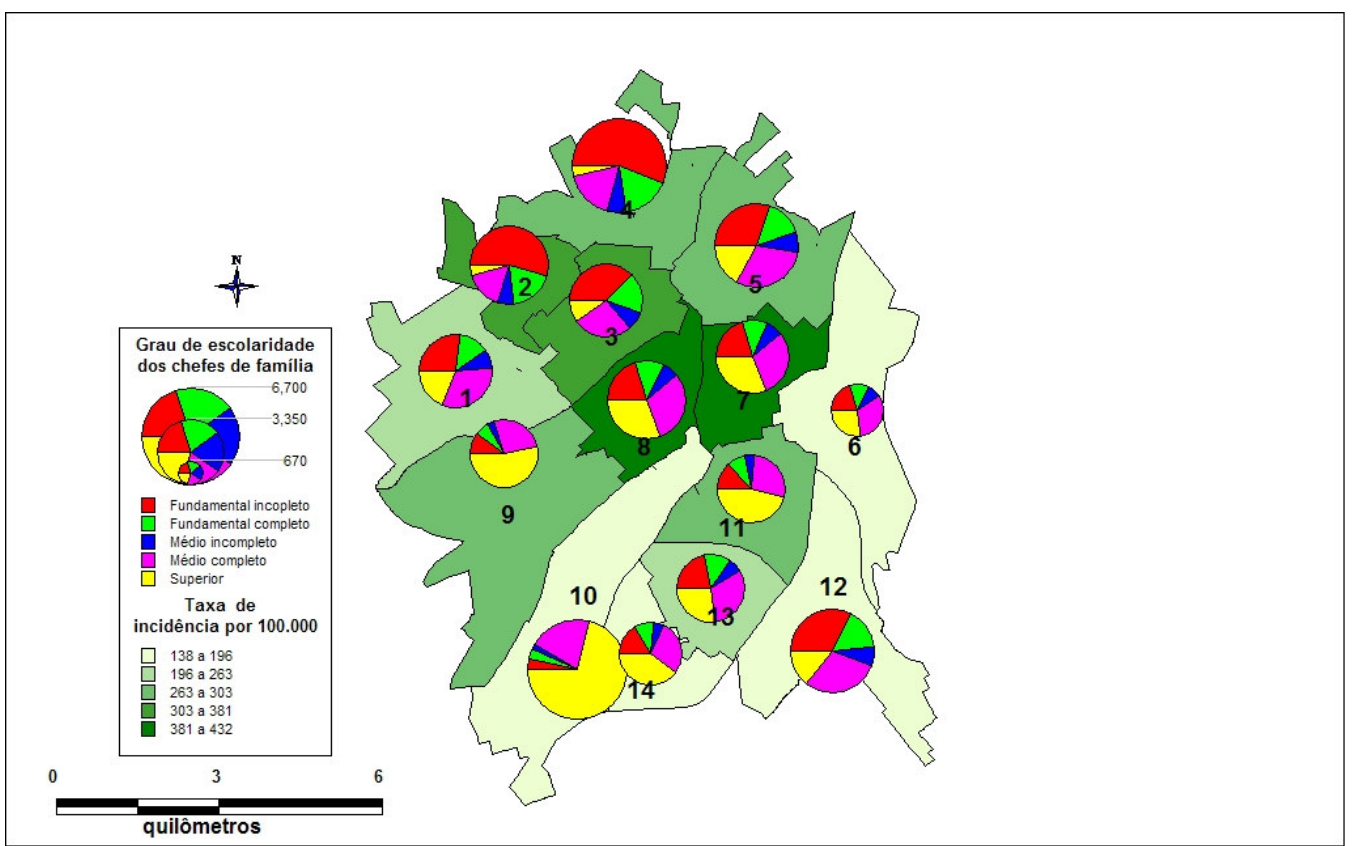

Figura 31 - Distribuição espacial da incidência de dengue por 100.000 habitantes, nas áreas de controle de vetores associado à variável grau de escolaridade no município de São José do Rio Preto - Estado de São Paulo, no período de 1990 a 2005.

Fonte: IBGE, 2002. 
Todas as áreas são atendidas, praticamente 100 \%, pela rede de água, esgoto e coleta de lixo (Figura 32). Com relação à coleta de lixo, esta é realizada nas áreas centrais todos os dias e nas demais áreas em dias alternados.

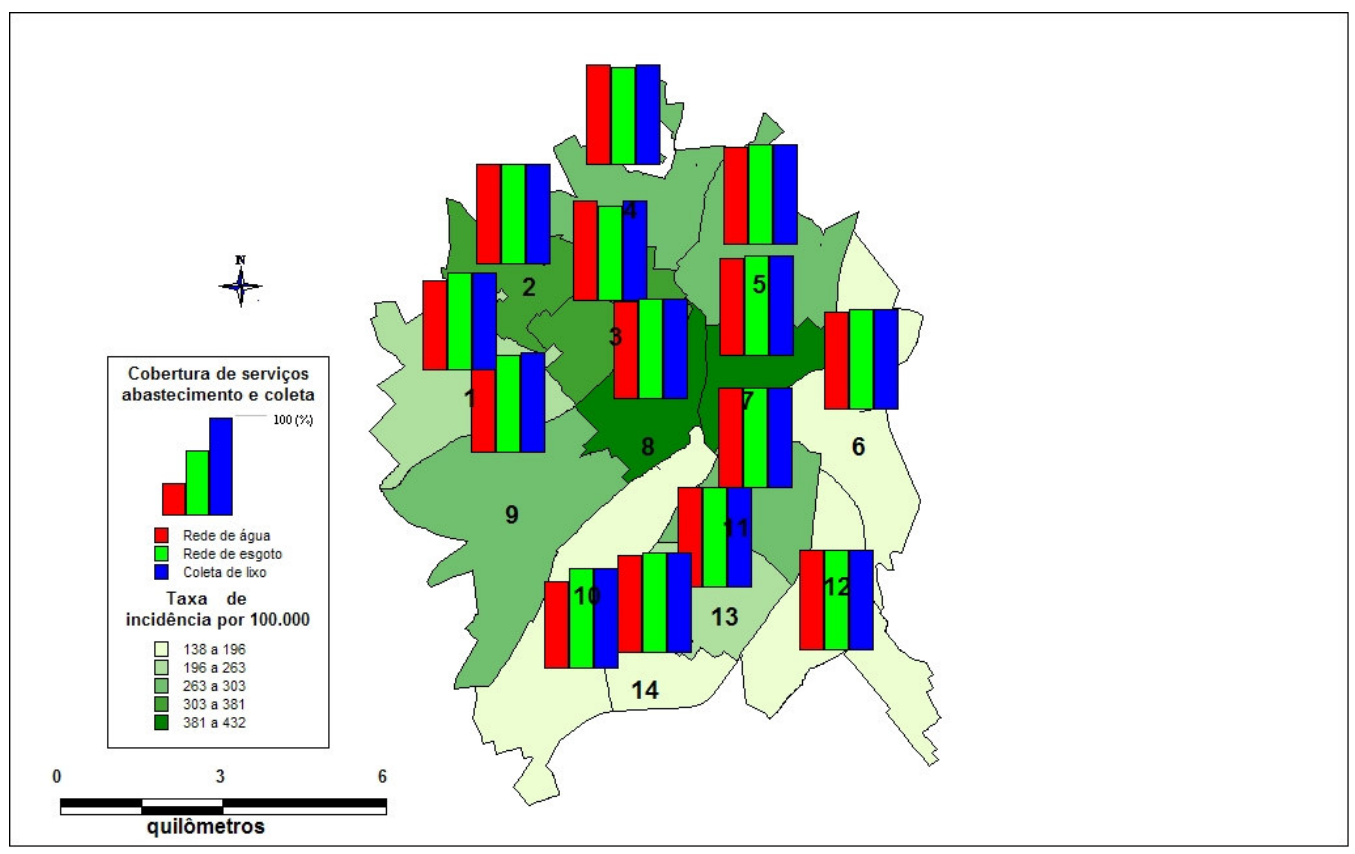

Figura 32 - Distribuição espacial da incidência de dengue por 100.000 habitantes, nas áreas de controle de vetores associado à variável de cobertura de serviços, abastecimento e coleta no município de São José do Rio Preto - Estado de São Paulo, no período de 1990 a 2005.

Fonte: IBGE, 2002. 
Fazendo um corte longitudinal no mapa, pode-se visualizar que a região norte concentra uma densidade demográfica mais elevada do que à região sul (Figura 33).

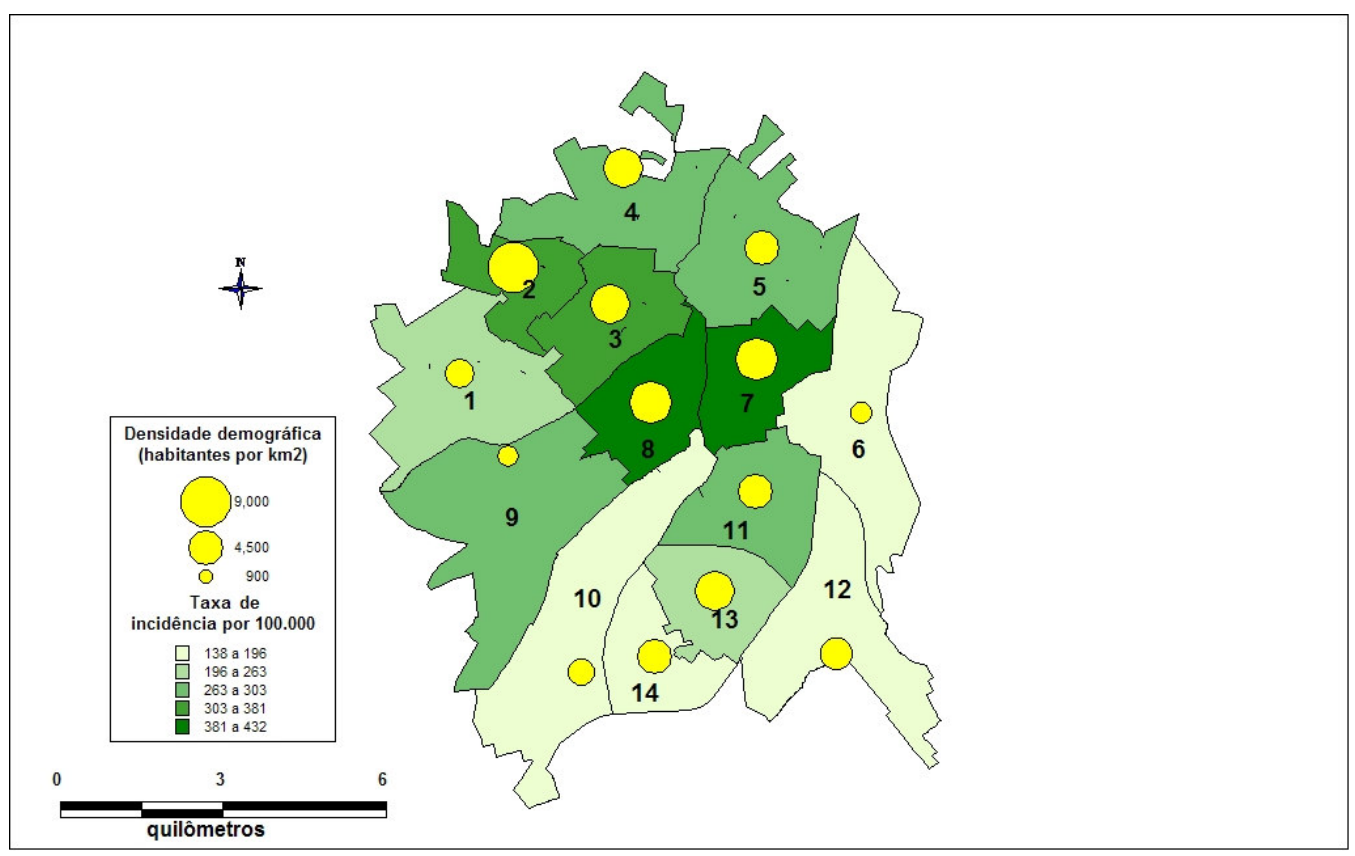

Figura 33 - Distribuição espacial da incidência de dengue por 100.000 habitantes, nas áreas de controle de vetores associado à variável densidade demográfica no município de São José do Rio Preto - Estado de São Paulo, no período de 1990 a 2005.

Fonte: IBGE, 2002. 


\subsection{INCIDÊNCIA EM RELAÇÃO À IDADE}

A Tabela 3 mostra a incidência de dengue por 100.000 habitantes, por idade no período de 1990 a 2005. Observou-se que a incidência foi menor em indivíduos na faixa etária de 0 a 14 anos. Verificou-se maiores incidências nas faixas etárias de 15 a 49 e 50 anos e mais. As incidências nessas duas últimas faixas foram semelhantes.

Tabela 3 - Incidência de dengue por 100.000 habitantes no município de São José do Rio Preto - Estado de São Paulo, segundo a faixa etária, de 1990 a 2005.

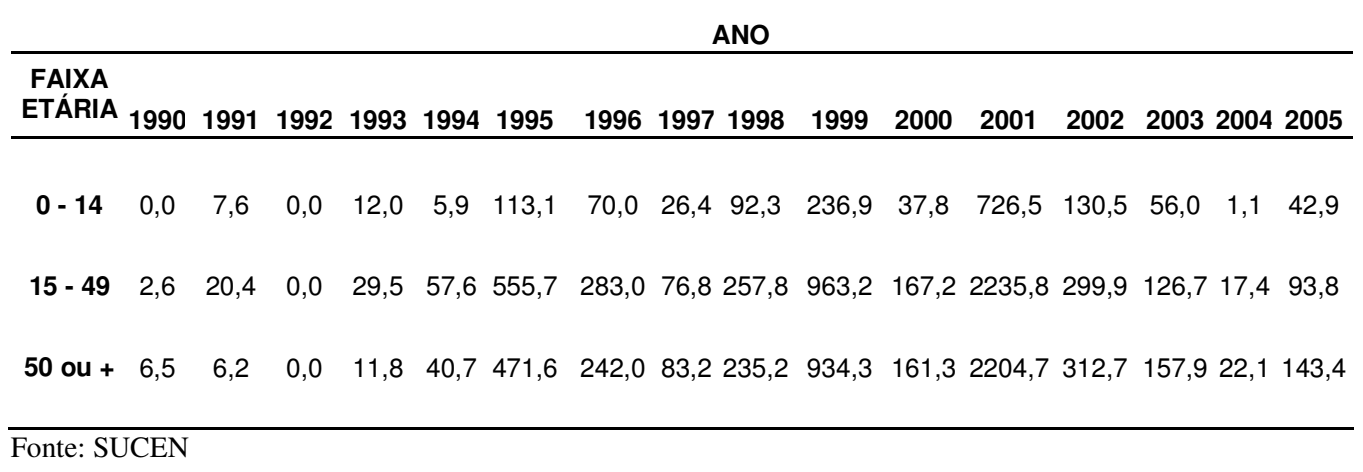




\subsection{INCIDÊNCIA EM RELAÇÃO AO SEXO}

Com relação ao sexo, observou-se que as incidências dos casos de dengue na cidade de São José do Rio Preto, apresentaram variação pequena, sendo ligeiramente maior no sexo feminino, exceto nos anos de 1991 e 2004, quando a maior incidência ocorreu no sexo masculino (Tabela 4).

Tabela 4 - Incidência de casos de dengue por 100.000 habitantes no município de São José do Rio Preto - Estado de São Paulo, segundo sexo, no período de 1990 a 2005.

\begin{tabular}{|c|c|c|c|c|c|c|c|c|c|c|c|c|c|c|c|c|}
\hline & & & & & & & & & ANO & & & & & & & \\
\hline SEXO & 1990 & 1991 & 1992 & 1993 & 1994 & 1995 & 1996 & 1997 & 1998 & 1999 & 2000 & 2001 & 2002 & 2003 & 2004 & 2005 \\
\hline MASC & 2,2 & 18,8 & 0,0 & 14,4 & 25,6 & 365,4 & 196,7 & 57,3 & 168,0 & 643,8 & 110,1 & 1535,2 & 220,6 & 113,5 & 15,4 & 90,4 \\
\hline FEM & 2,8 & 10,3 & 0,0 & 28,6 & 55,0 & 471,1 & 248,7 & 72,8 & 264,3 & 903,7 & 161,0 & 2211,0 & 304,5 & 119,6 & 13,9 & 93,3 \\
\hline
\end{tabular}

Foi realizado o teste de Qui-quadrado com intervalo de confiança de 95\%. Os valores do qui-quadrado foram 0,059434 em 1991, 0,008176 em 1993 e 0,001658 em 1996. Para os outros anos os valores foram superior a 0,05 . 


\subsection{FATORES CLIMÁTICOS}

Na Tabela 5, nota-se que nos anos de 1995, 1999, 2002, 2004 e 2005 a correlação entre o Índice Predial (IP) e a precipitação pluviométrica foi estatisticamente significativa indicando que a quantidade de chuva foi um dos fatores que contribuiu para a elevação da infestação de mosquitos. De maneira geral observa-se que o coeficiente de Correlação de Pearson entre IP e a precipitação pluviométrica foi de 0,223 e é estatisticamente significativa com um p=0,002.

Tabela 5 - Coeficiente de correlação de Pearson (r) e valores de (p) para incidência de dengue (IC) e índice de infestação predial (IP), comparados à precipitação pluviométrica $(\mathrm{mm})$ e temperatura $\left({ }^{\circ} \mathrm{C}\right)$, no município de São José do Rio Preto, São Paulo, no período de 1990 a 2005.

VARIÁVEIS

\begin{tabular}{|c|c|c|c|c|c|c|c|c|}
\hline \multirow{3}{*}{ ANO } & \multicolumn{4}{|c|}{$\begin{array}{l}\text { PRECIPITAÇÃO } \\
\text { PLUVIOMÉTRICA }\end{array}$} & \multicolumn{4}{|c|}{ TEMPERATURA } \\
\hline & \multicolumn{2}{|c|}{$\mathrm{IC}$} & \multicolumn{2}{|c|}{ IP } & \multicolumn{2}{|c|}{ IC } & \multicolumn{2}{|c|}{ IP } \\
\hline & $\mathrm{r}$ & $\mathrm{p}$ & $\mathrm{r}$ & $\mathrm{p}$ & $\mathrm{r}$ & $\mathrm{p}$ & $\mathrm{r}$ & $\mathrm{p}$ \\
\hline 1990 & 0,106 & 0,743 & $-0,04$ & 0,901 & 0,286 & 0,367 & 0,385 & 0,216 \\
\hline 1991 & $0,853 * *$ & 0 & 0,059 & 0,655 & 0,331 & 0,294 & 0,04 & 0,902 \\
\hline 1992 & - & - & 0,011 & 0,974 & - & - & $-0,105$ & 50,744 \\
\hline 1993 & $-0,341$ & 0,277 & $-0,013$ & $0,968-$ & $-0,651 *$ & 0,022 & 0,286 & 0,387 \\
\hline 1994 & 0,002 & 0,995 & 0,576 & 0,05 & 0,181 & 0,573 & 0,104 & 0,755 \\
\hline 1995 & 0,565 & 0,056 & $0,594 *$ & 0,042 & 0,518 & 0,084 & 0,515 & 0,087 \\
\hline 1996 & 0,205 & 0,522 & 0,24 & 0,453 & 0,334 & 0,289 & 0,272 & 0,393 \\
\hline 1997 & 0,082 & 0,739 & $-0,187$ & 0,56 & 0,285 & 0,37 & $-0,324$ & 40,304 \\
\hline 1998 & 0,229 & 0,474 & - & - & 0,268 & 0,399 & - & - \\
\hline 1999 & 0,213 & 0,507 & $0,820 *$ & 0,001 & 0,196 & 0,541 & 0,489 & 0,107 \\
\hline 2000 & $-0,47$ & 0,123 & 0,443 & 0,15 & $-0,18$ & 0,576 & 0,249 & 0,435 \\
\hline 2001 & $-0,227$ & 0,478 & 0,38 & 0,224 & $-0,065$ & 0,842 & 0,257 & 0,421 \\
\hline 2002 & 0,044 & 0,893 & $0,643 *$ & 0,024 & 0,289 & 0,362 & 0,165 & 0,607 \\
\hline 2003 & 0,41 & 0,185 & $-0,019$ & 0,952 & 0,424 & 0,169 & 0,197 & 0,539 \\
\hline 2004 & 0,205 & 0,52 & $0,689 *$ & 0,013 & $-0,181$ & 0,573 & 0,34 & 0,279 \\
\hline 2005 & 0,001 & 0,998 & $0,628^{*}$ & 0,029 & 0,087 & 0,788 & 0,204 & 0,524 \\
\hline TOTAL & 0,009 & 0,901 & 0,223 ** & 0,002 & 0,052 & 0,475 & $0,146^{*}$ & 0,044 \\
\hline
\end{tabular}


A correlação entre IP e temperatura apresentou um valor de coeficiente de 0,146 e é estatisticamente significativo para $\mathrm{p}=0,044$. A precipitação pluviométrica com a temperatura teve coeficiente de Correlação de Pearson de 0,518 e é estatisticamente significativo com p<0,001 (Anexo 2). Já com relação ao IC, este não se correlacionou com nenhuma variável e todos os valores não foram estatisticamente significativos.

As Figuras 34 a 48 evidenciam os resultados das correlações entre a temperatura, precipitação pluviométrica (em valores diários), índice predial e incidência de dengue. As precipitações tiveram seus maiores valores nos meses de janeiro a março, depois diminuíram tornando a elevar-se a partir de novembro e / ou dezembro.

Observou-se que os índices prediais para os anos de 1990, 1991, 1993 e 1994 foram altos nos meses de janeiro a abril, diminuindo entre os meses de maio a outubro, voltando a aumentar em novembro e dezembro. A partir de 1995, as avaliações de infestações foram prejudicadas, devido ao pessoal operacional da SUCEN estar envolvido nas atividades de controle da transmissão de dengue, sendo realizada apenas uma avaliação por ano. No ano de 2004, conseguiu-se fazer mais do que uma avaliação de infestação por que a transmissão de dengue foi menor, ao passo que em 1998 não foi possível realizá-la e em 2000 foi feita em apenas algumas áreas.

Com relação à incidência observa-se nas Figuras 34 a 48 que em 1991 o pico de incidência ocorreu em janeiro. Em 1993 o pico ocorreu em junho. Em 1994 o pico ocorreu em abril. Em 1995, as maiores incidências ocorreram nos meses de janeiro a 
março. Em 1996 e 1997, o pico foi em março. Em 1998, as maiores incidências ocorreram de março a maio. Em 1999, 2000, 2001, 2002 e 2005 o pico ocorreu em abril. Em 2003 o pico ocorreu em março e em 2004 as maiores incidências ocorreram em abril e maio. Portanto, nos primeiros anos não houve coincidências entre os picos, a partir de 1999 a 2005 o pico ocorreu sempre em abril, com exceção de 2003 em que o pico ocorreu em março.

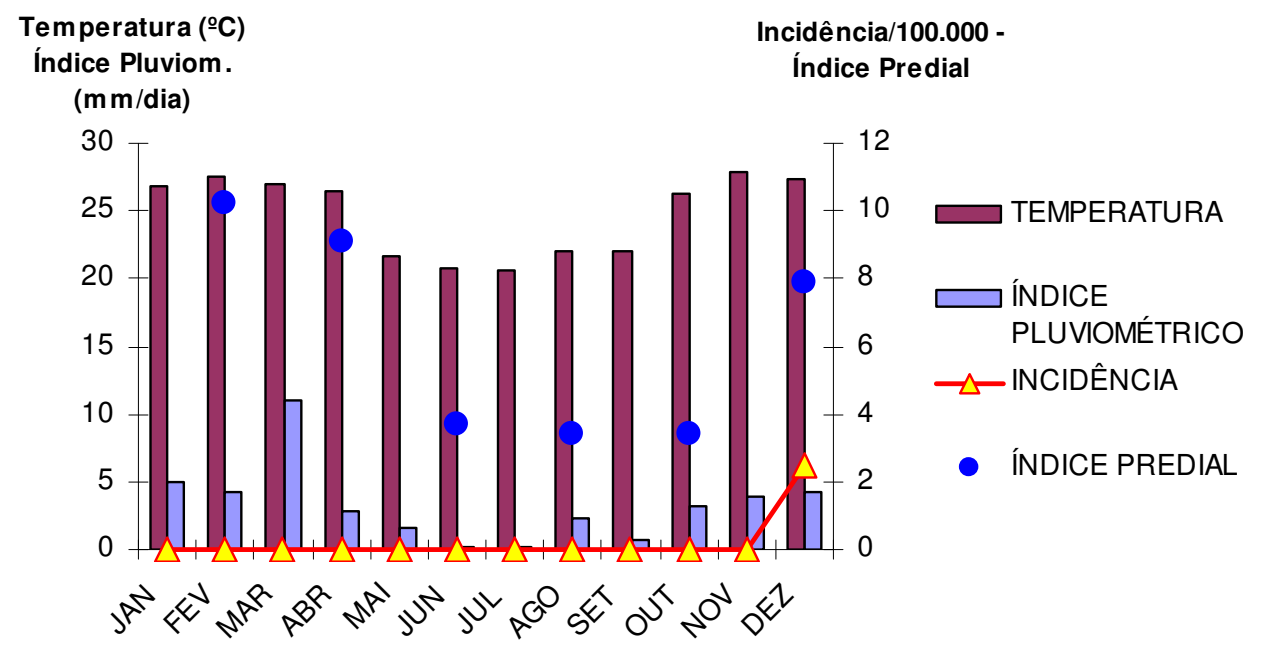

Figura 34 - Índice predial, temperatura, índice pluviométrico e incidência de casos de dengue por mês, no município de São José do Rio Preto - Estado de São Paulo, no ano de 1990. 


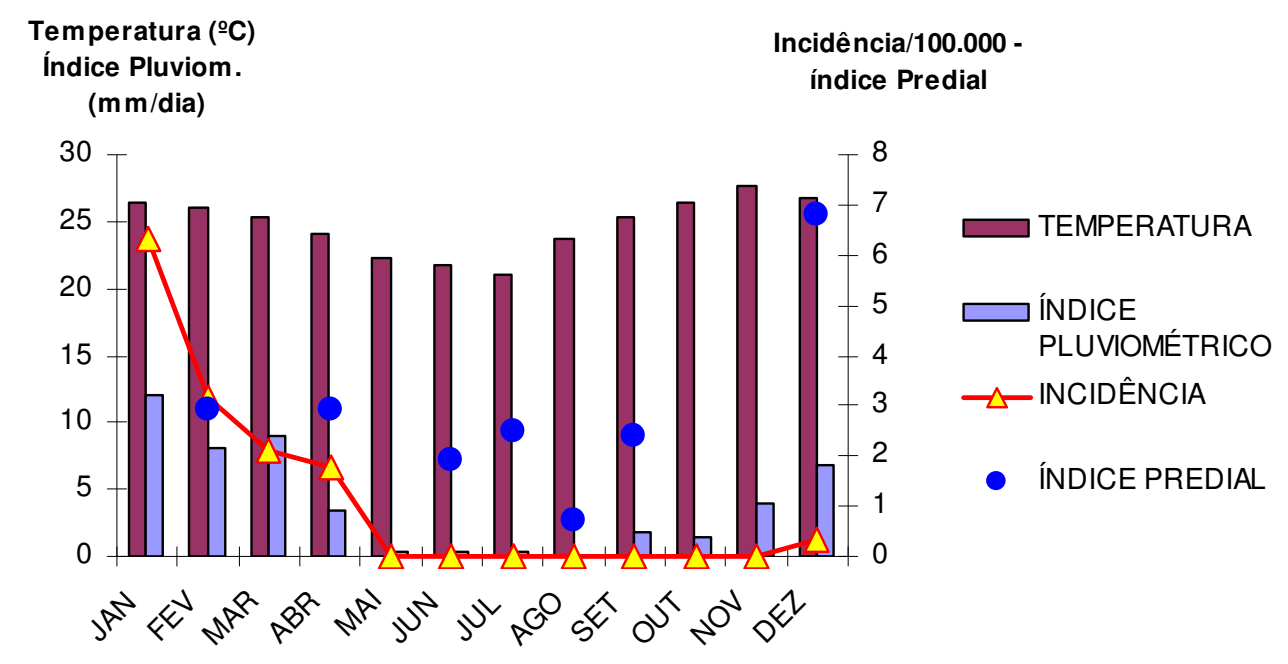

Figura 35 - Índice predial, temperatura, índice pluviométrico e incidência de casos de dengue por mês, no município de São José do Rio Preto - Estado de São Paulo, no ano de 1991.

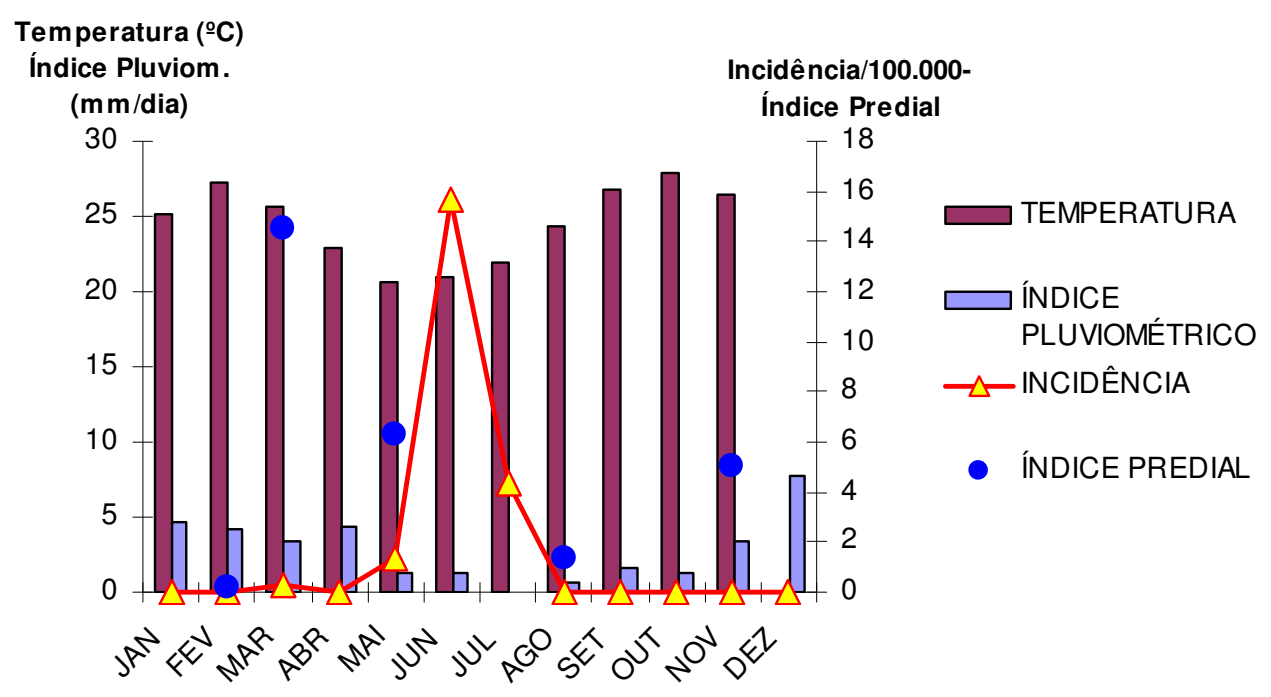

Figura 36 - Índice predial, temperatura, índice pluviométrico e incidência de casos de dengue por mês, no município de São José do Rio Preto - Estado de São Paulo, no ano de 1993. 


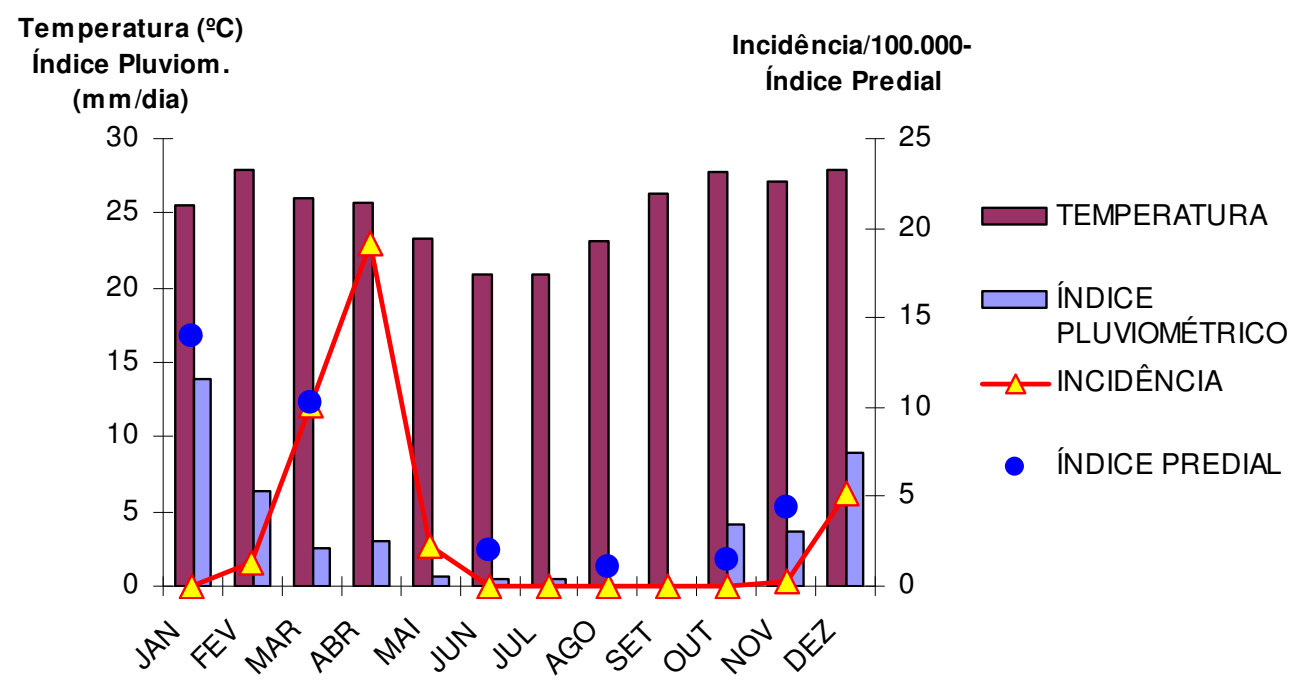

Figura 37 - Índice predial, temperatura, índice pluviométrico e incidência de casos de dengue por mês, no município de São José do Rio Preto - Estado de São Paulo, no ano de 1994.

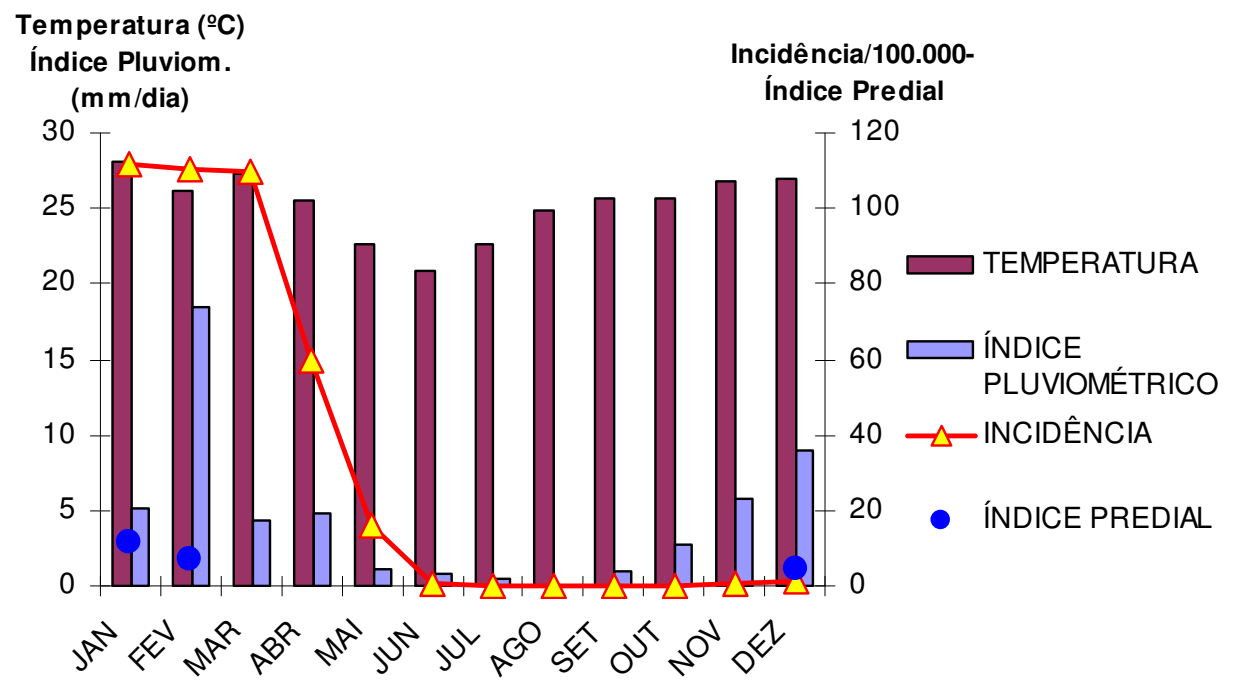

Figura 38 - Índice predial, temperatura, índice pluviométrico e incidência de casos de dengue por mês, no município de São José do Rio Preto - Estado de São Paulo, no ano de 1995. 


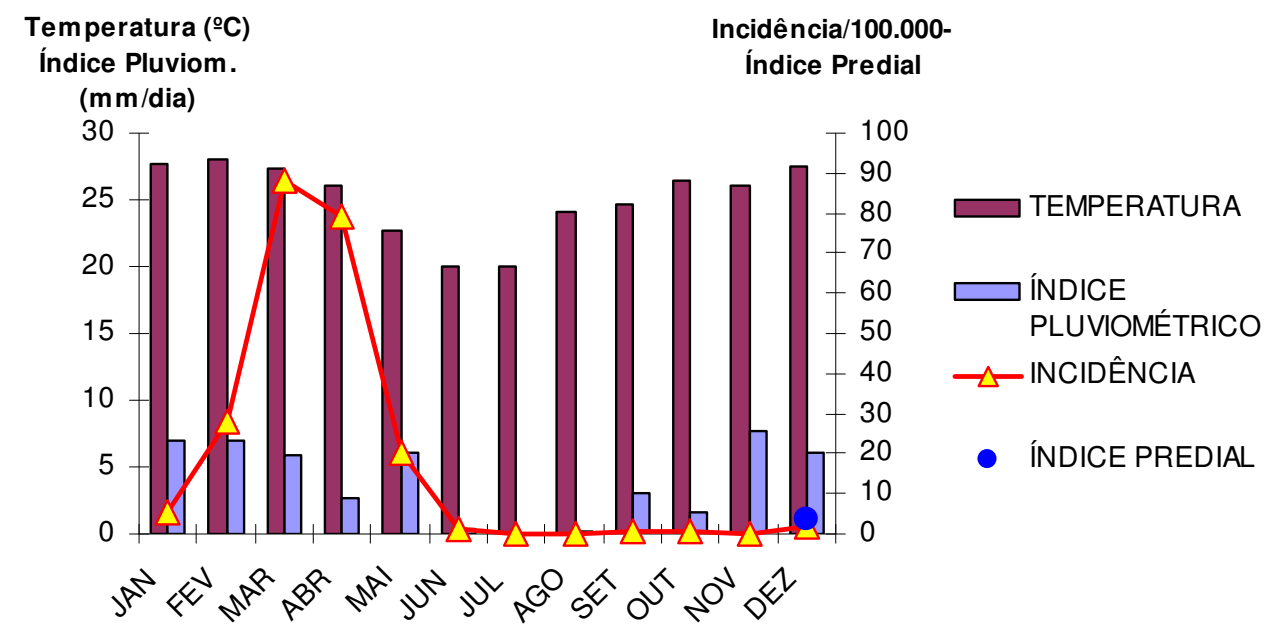

Figura 39 - Índice predial, temperatura, índice pluviométrico e incidência de casos de dengue por mês, no município de São José do Rio Preto - Estado de São Paulo, no ano de 1996.

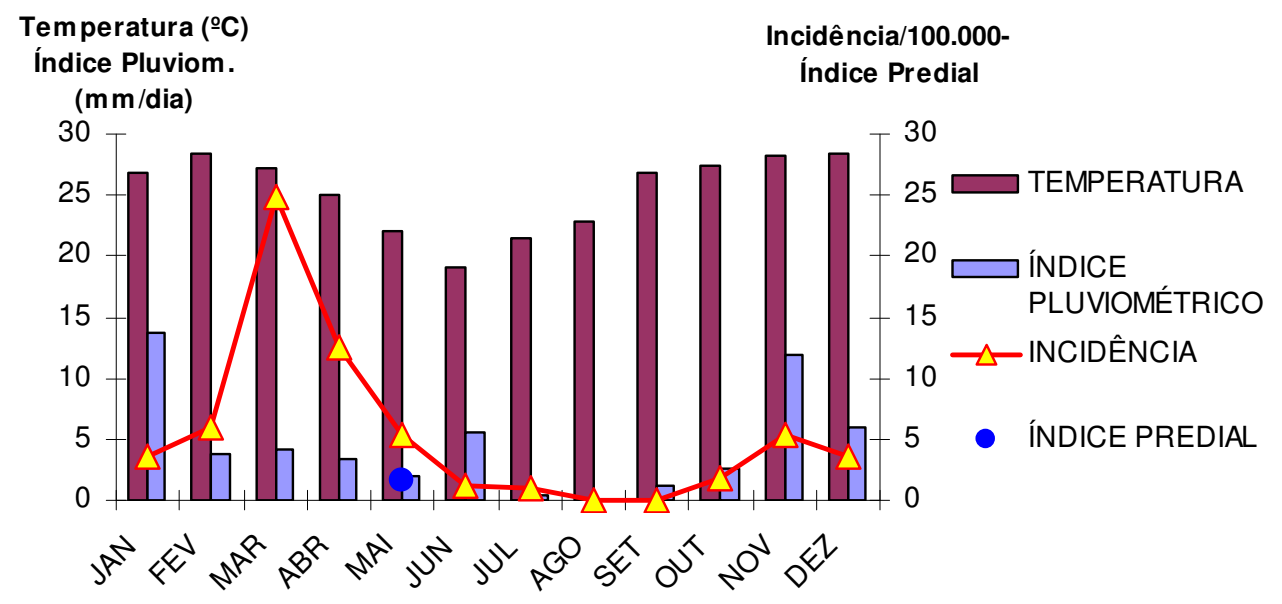

Figura 40 - Índice predial, temperatura, índice pluviométrico e incidência de casos de dengue por mês, no município de São José do Rio Preto - Estado de São Paulo, no ano de 1997. 


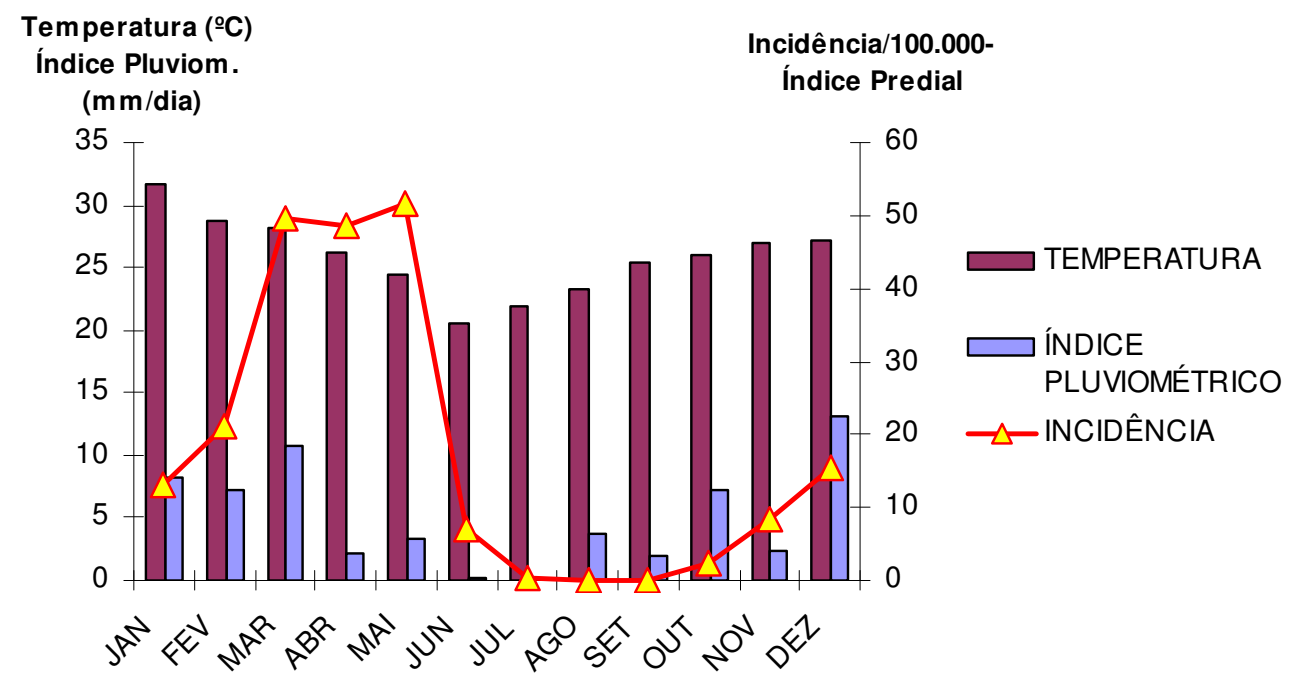

Figura 41 - Índice predial, temperatura, índice pluviométrico e incidência de casos de dengue por mês, no município de São José do Rio Preto - Estado de São Paulo, no ano de 1998.

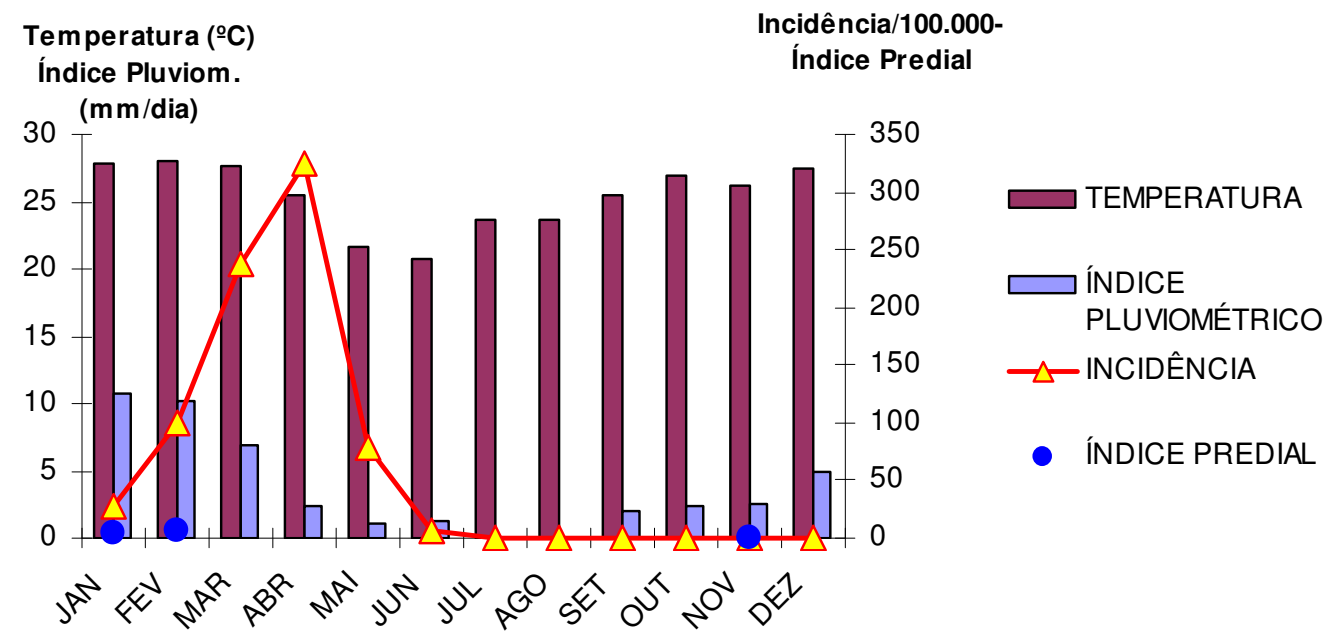

Figura 42 - Índice predial, temperatura, índice pluviométrico e incidência de casos de dengue por mês, no município de São José do Rio Preto - Estado de São Paulo, no ano de 1999. 


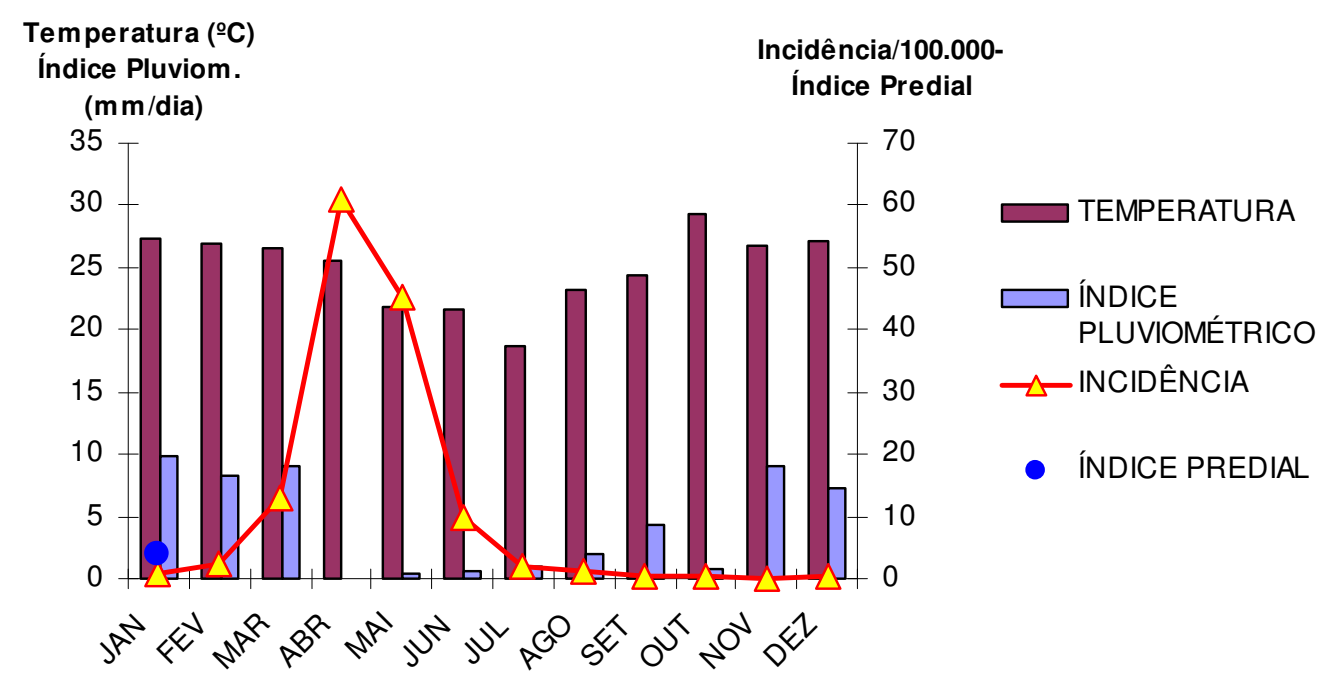

Figura 43 - Índice predial, temperatura, índice pluviométrico e incidência de casos de dengue por mês, no município de São José do Rio Preto - Estado de São Paulo, no ano de 2000.

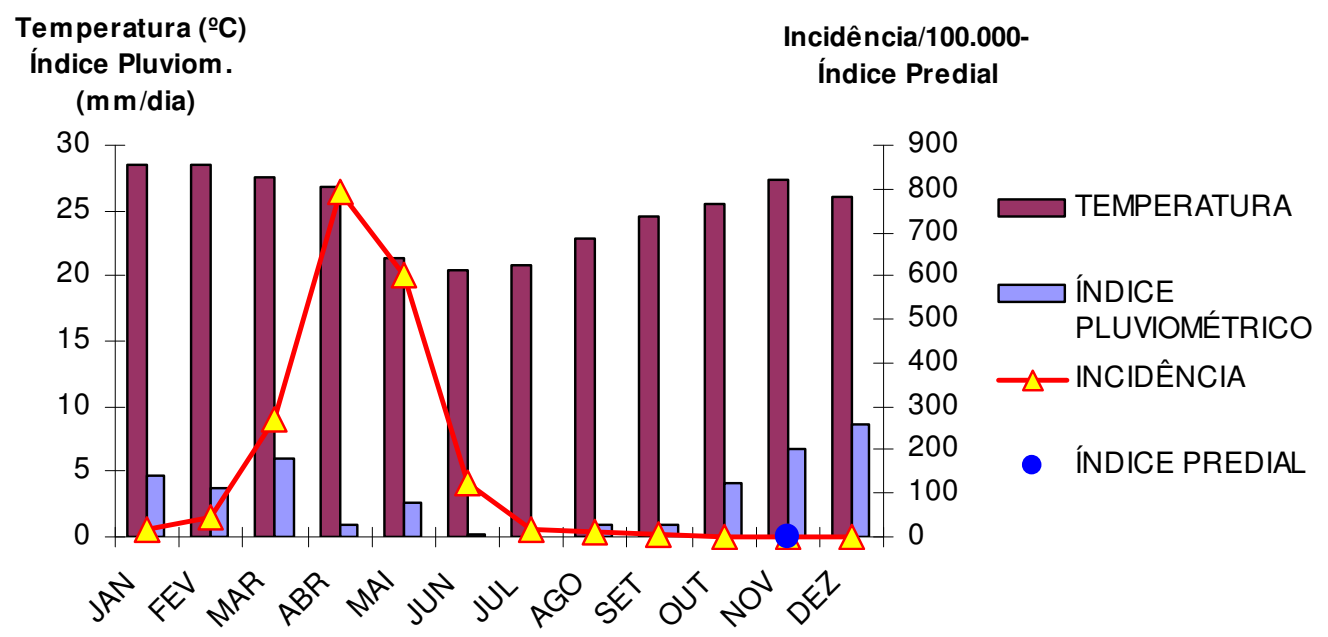

Figura 44 - Índice predial, temperatura, índice pluviométrico e incidência de casos de dengue por mês, no município de São José do Rio Preto - Estado de São Paulo, no ano de 2001. 


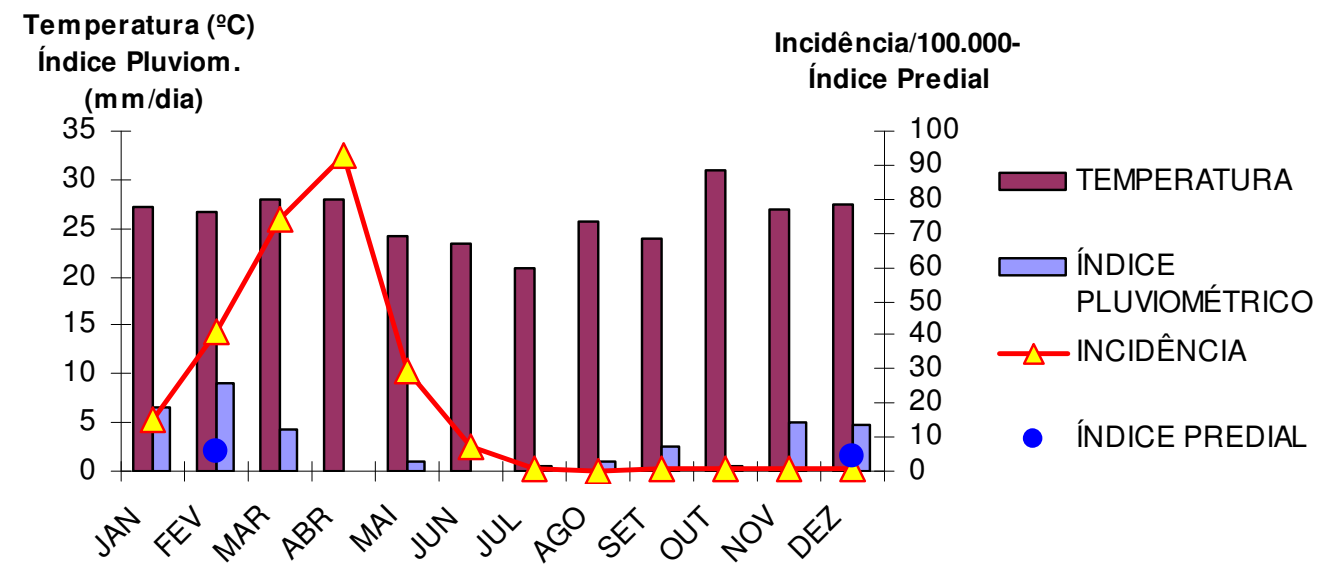

Figura 45 - Índice predial, temperatura, índice pluviométrico e incidência de casos de dengue por mês, no município de São José do Rio Preto - Estado de São Paulo, no ano de 2002.

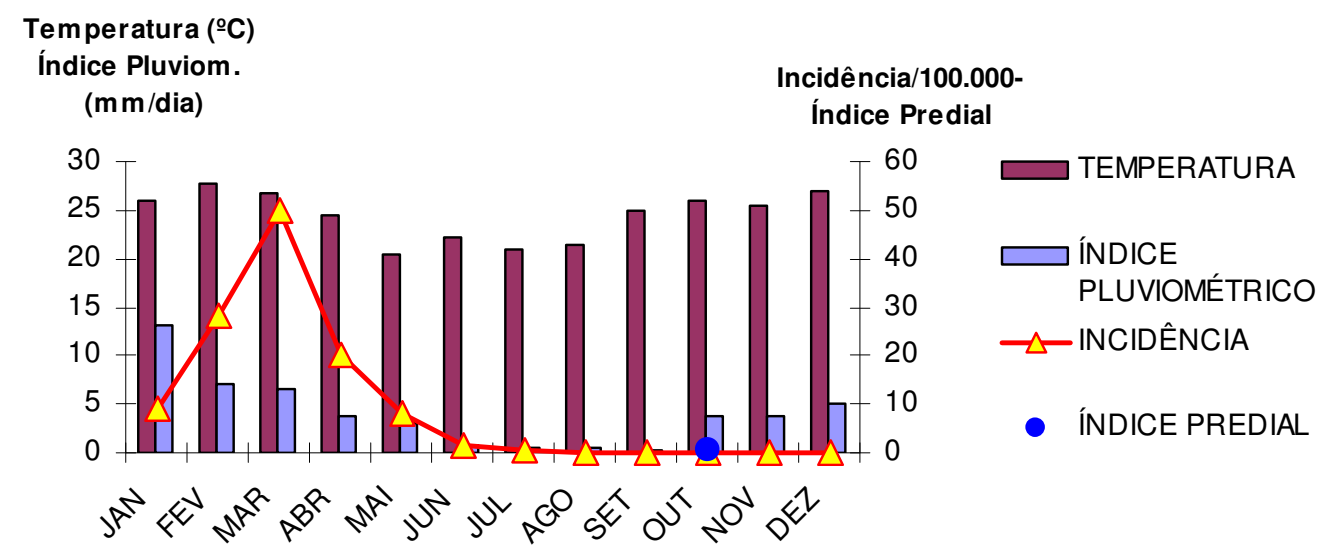

Figura 46 - Índice predial, temperatura, índice pluviométrico e incidência de casos de dengue por mês, no município de São José do Rio Preto - Estado de São Paulo, no ano de 2003. 


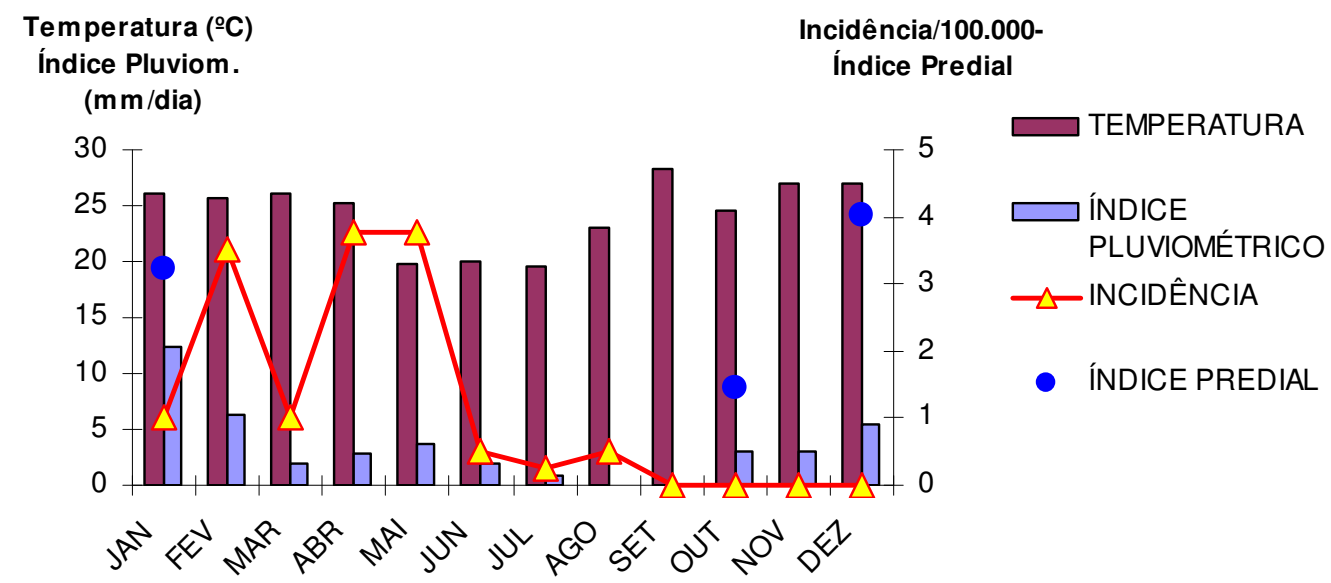

Figura 47 - Índice predial, temperatura, índice pluviométrico e incidência de casos de dengue por mês, no município de São José do Rio Preto - Estado de São Paulo, no ano de 2004.

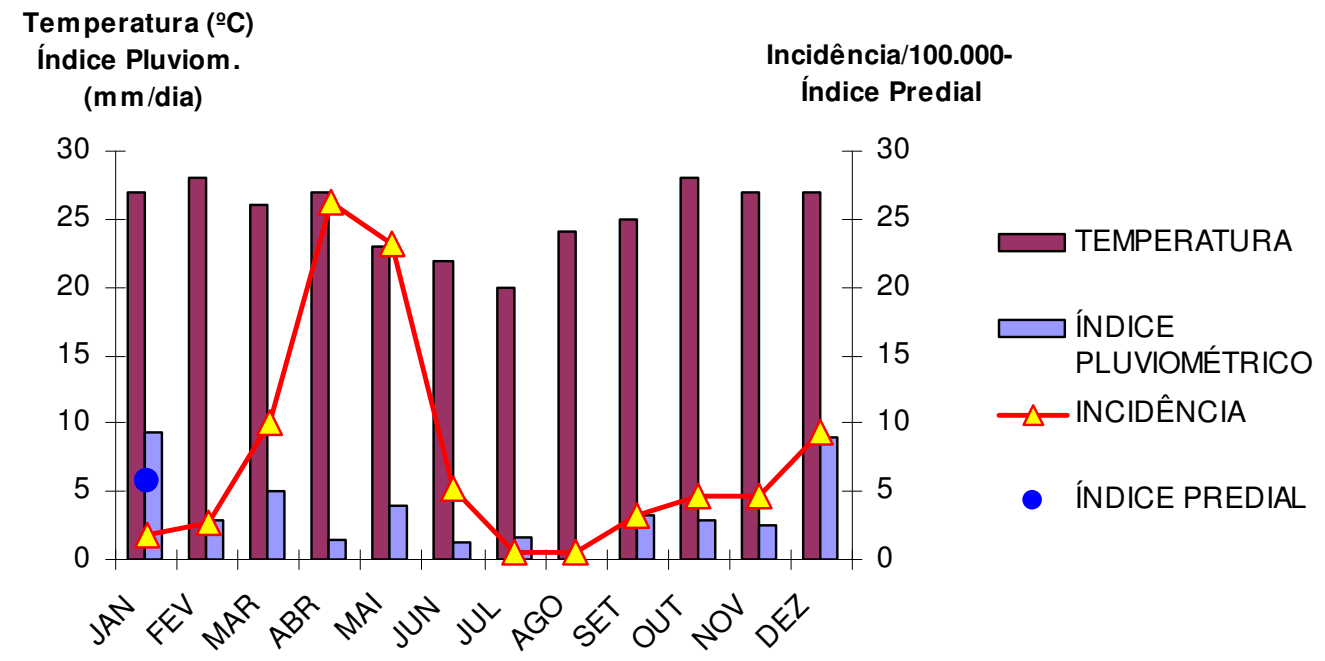

Figura 48 - Índice predial, temperatura, índice pluviométrico e incidência de casos de dengue por mês, no município de São José do Rio Preto - Estado de São Paulo, no ano de 2005. 


\subsection{INFESTAÇÃO DO VETOR - TIPOS DE RECIPIENTES}

Observando a Figura 49 pode-se verificar que durante os anos de 1990 a 1993 há uma predominância do vaso como recipiente positivo, seguido de lata, pote e frasco. Nos anos de 1995 a 1997, os recipientes lata, pote e frasco, passaram a apresentar importância marcante como criadouros positivos, seguido de caixa d'água, e o vaso diminui sua importância.

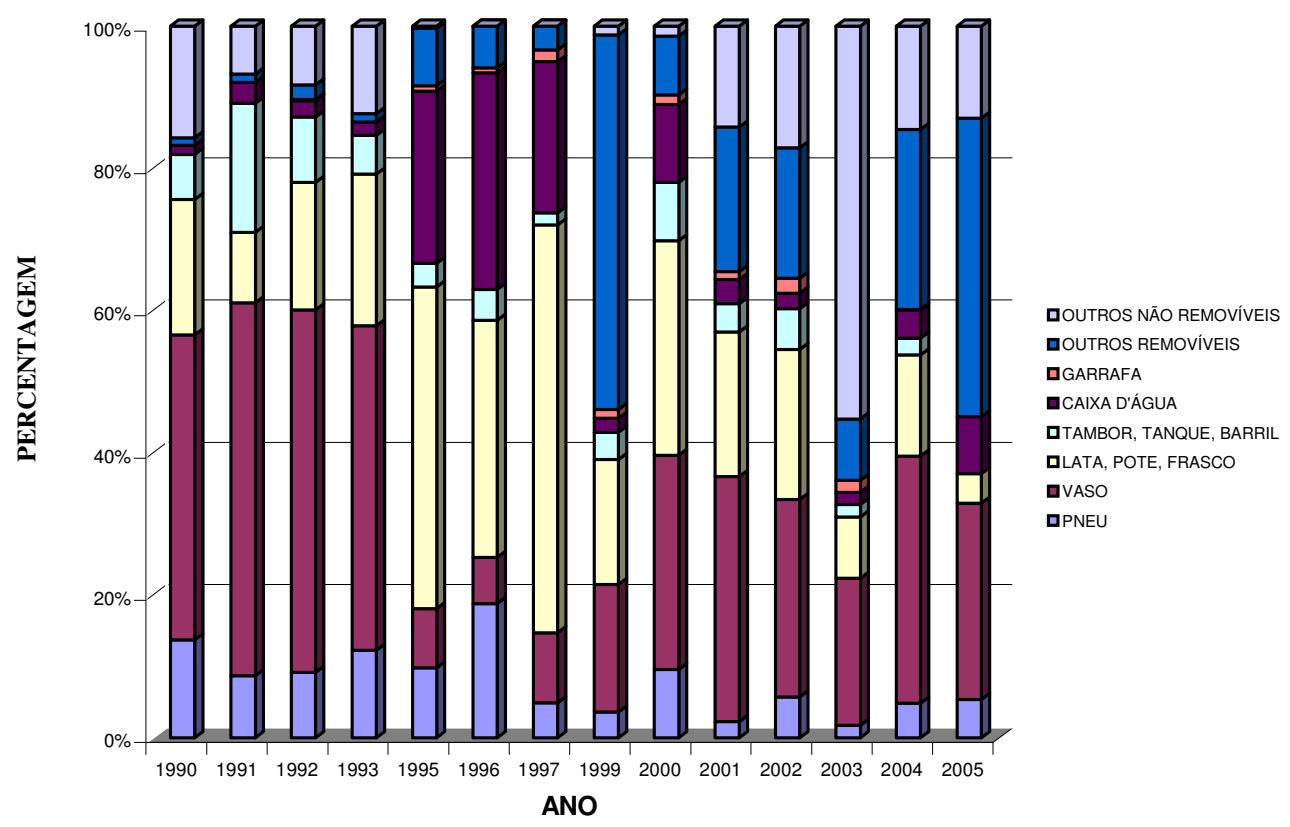

Figura 49 - Tipos de recipientes positivos por ano, no município de São José do Rio Preto - Estado de São Paulo, no período de 1990 a 2005. 
A partir de 1999, o vaso volta a ter importância como recipiente positivo mantendo esse padrão até os dias de hoje, assim como os recipientes classificados como outros removíveis e outros não removíveis.

Levando em conta a distribuição dos tipos de recipientes utilizados como criadouros, compararam-se as diversas áreas do município em relação à distribuição dos mesmos e a sua incidência. Nos anos de 1995 a 1996 havia uma predominância de lata, pote e frasco, seguido de caixa d'água (Figuras 50 e 51).

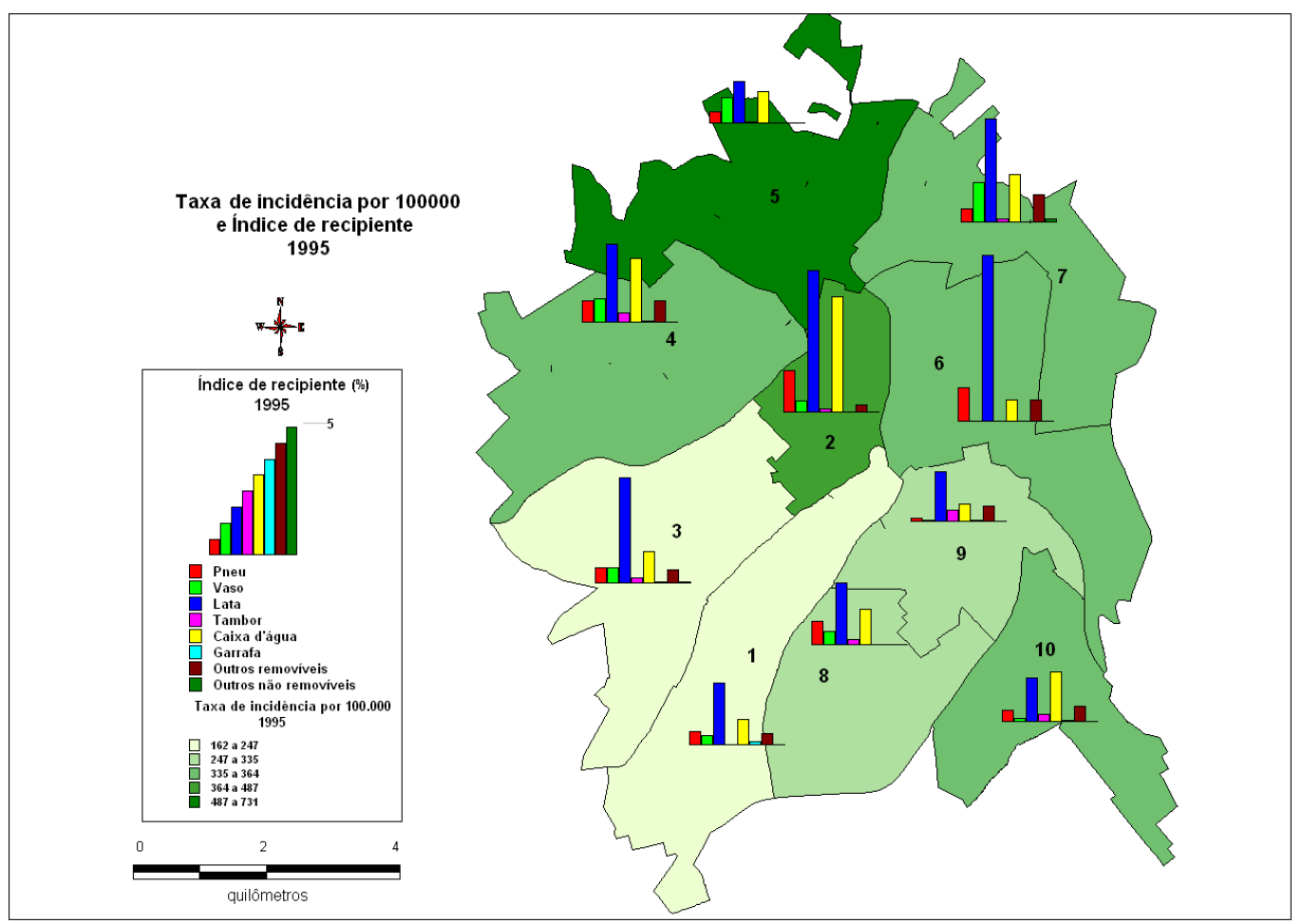

Figura 50 - Mapa de incidência de dengue por 100.000 habitantes e índice de recipientes, por área de controle de vetores, no município de São José do Rio Preto Estado de São Paulo, para o ano de 1995. 
Além dos recipientes lata, pote e frasco e caixa d'água serem os recipientes que tiveram freqüência maior, destacou-se a presença de pneus, tambor, vaso e outros removíveis distribuídos na cidade como um todo no ano de 1996, sendo as regiões norte e centro as mais atingidas (Figura 51).

No final de 1996 foi realizada uma intensa campanha para eliminação de recipientes junto às equipes municipais e o reflexo deu-se no início de 1997 , quando da realização da avaliação de densidade larvária, cujo índice de recipientes foi de maneira geral baixo, contribuído provavelmente para que o município apresentasse um número reduzido de casos de dengue no ano de 1997 (Anexo 1).

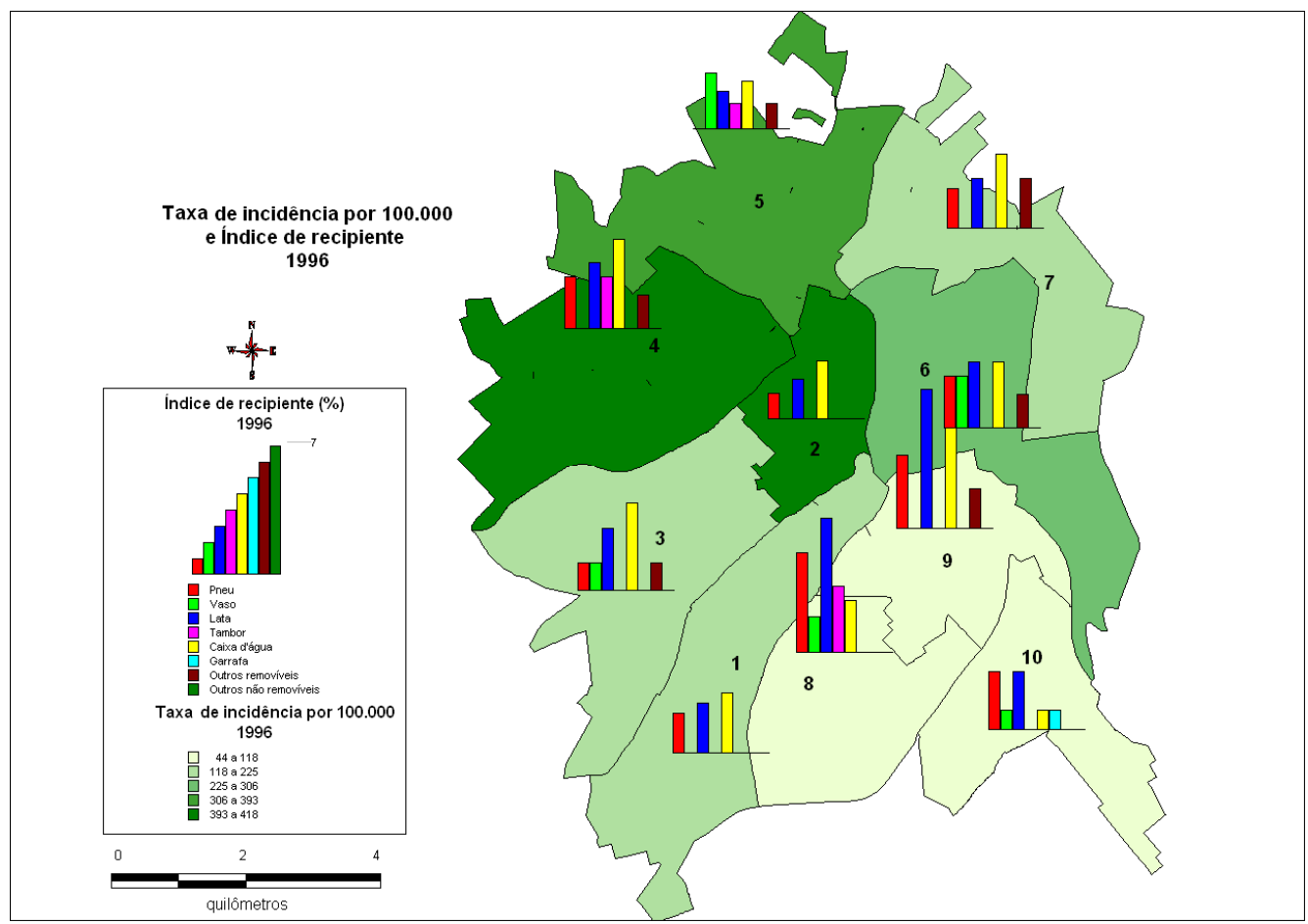

Figura 51 - Mapa de incidência de dengue por 100.000 habitantes e índice de recipientes, por área de controle de vetores, na área urbana do município de São José do Rio Preto - Estado de São Paulo, para o ano de 1996. 
No ano de 1997, os recipientes que se destacaram continuaram sendo lata, pote e frasco e caixa d'água, sendo as regiões oeste, centro e sul as de maior ocorrência (Figura 52).

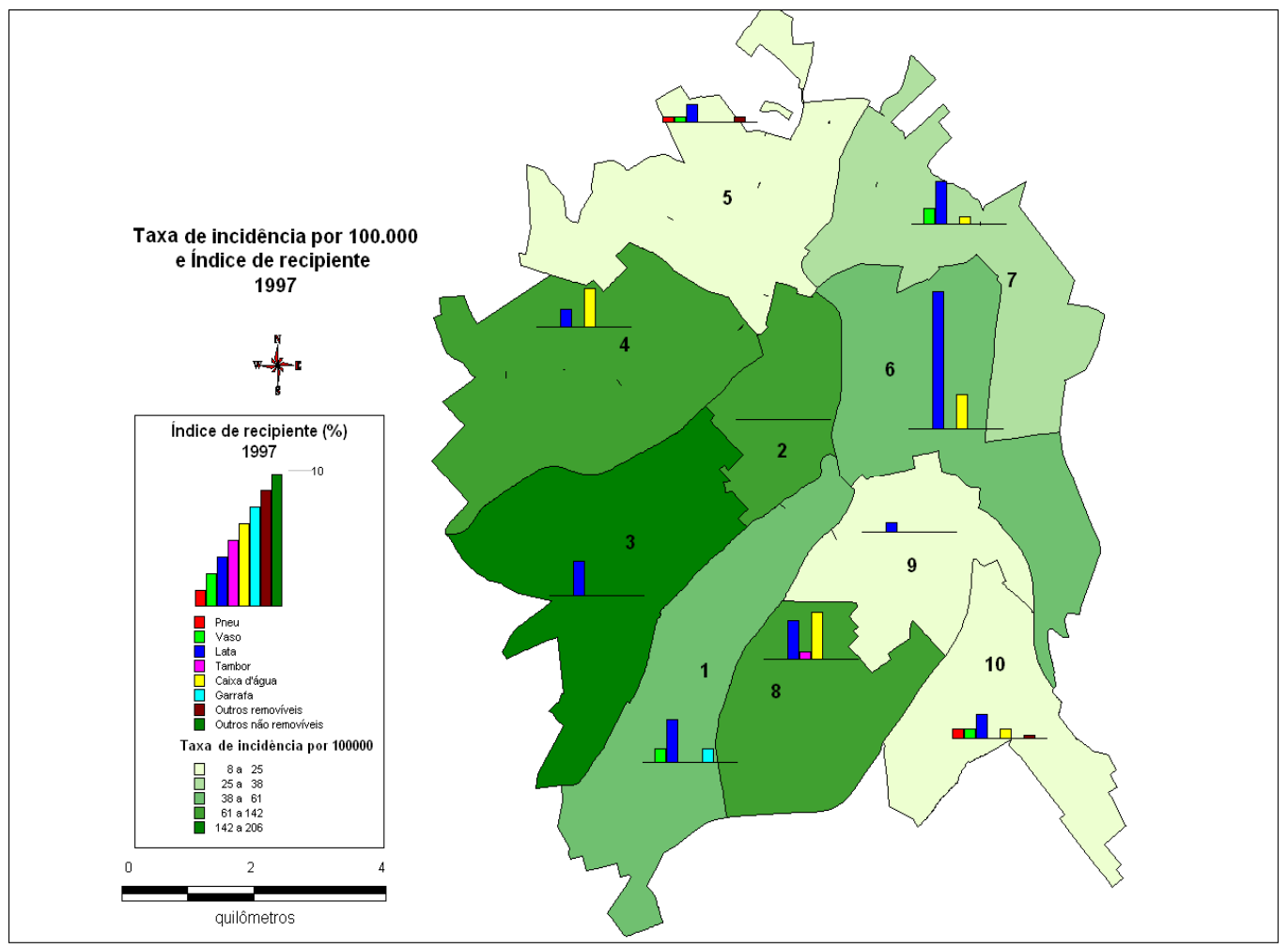

Figura 52 - Mapa de incidência de dengue por 100.000 habitantes e índice de recipientes, por área de controle de vetores, no município de São José do Rio Preto Estado de São Paulo, para o ano de 1997. 
Com relação às outras áreas existe uma heterogeneidade no encontro de tipos de recipientes. Chama a atenção, novamente à presença marcante de vasos durante todos os anos a partir de 1999 (Figura 53). A circulação do vírus DEN-2 foi detectada a partir de 1996, mas somente em 1999 a cidade voltou a ter uma epidemia expressiva, maior do que a que ocorreu em 1995, quando só circulava o sorotipo DEN-1. Nesse ano de 1999 estavam circulando os dois sorotipos, talvez, por isso a região norte e leste voltaram a ser uma das mais atingidas, inclusive como dito anteriormente, também por ser a região de maior densidade populacional.

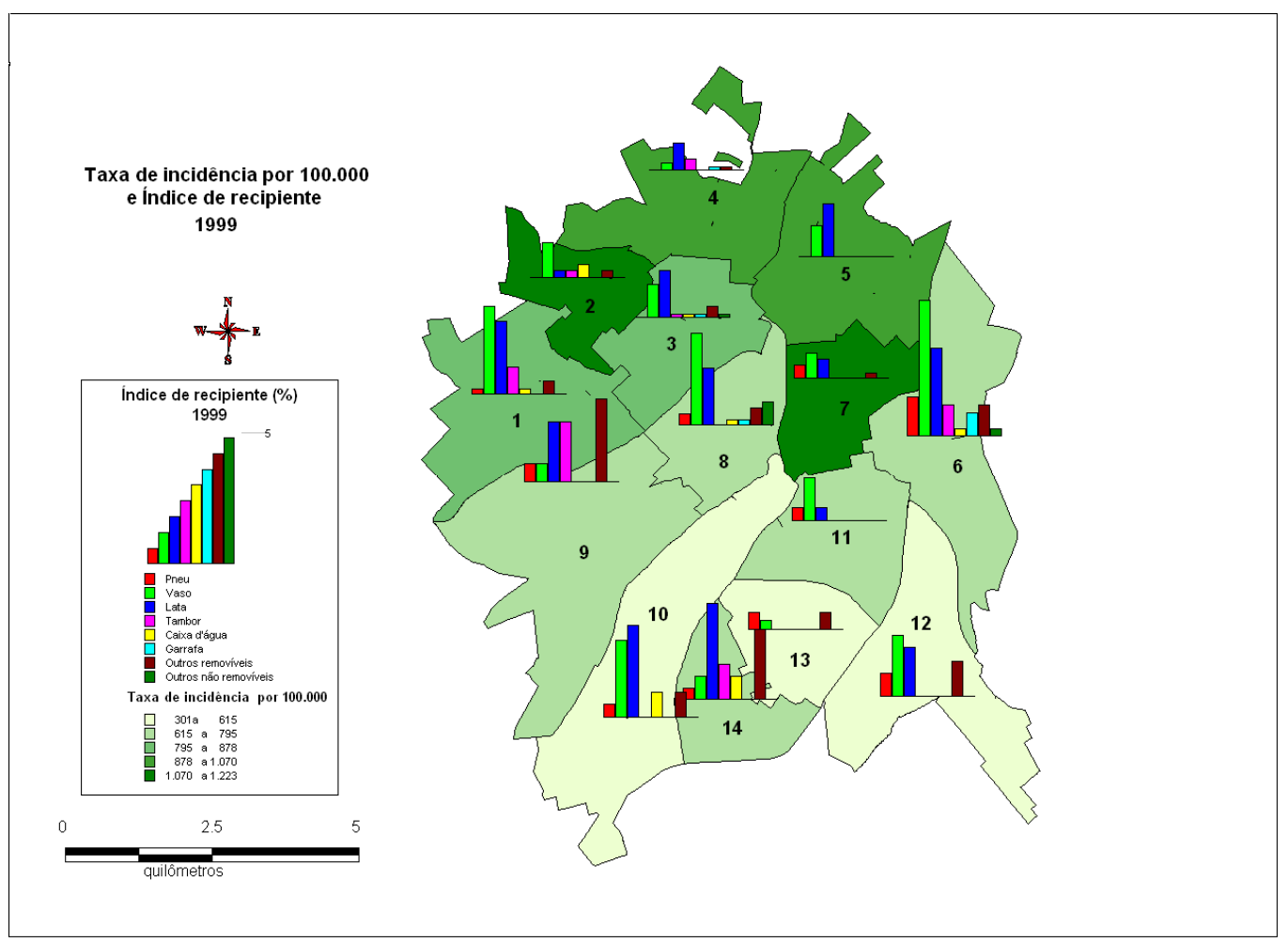

Figura 53 - Mapa de incidência de dengue por 100.000 habitantes e índice de recipientes, por área de controle de vetores, no município de São José do Rio Preto Estado de São Paulo, para o ano de 1999. 
Em 2001, a transmissão se iniciou por área nobre, onde o cultivo de bromélias foi incentivado pelos paisagistas nesse período. Nesse ano, a transmissão do vírus acometeu aproximadamente 7.000 pessoas. Foi a maior epidemia de dengue que o município enfrentou nesse período. Os recipientes que mais se destacaram foram os vasos (incluído as bromélias), lata, pote e frasco, caixa d'água e outros removíveis. As incidências foram altas em todas as áreas, porém as regiões mais atingidas foram à leste, oeste e centro (Figura 54).

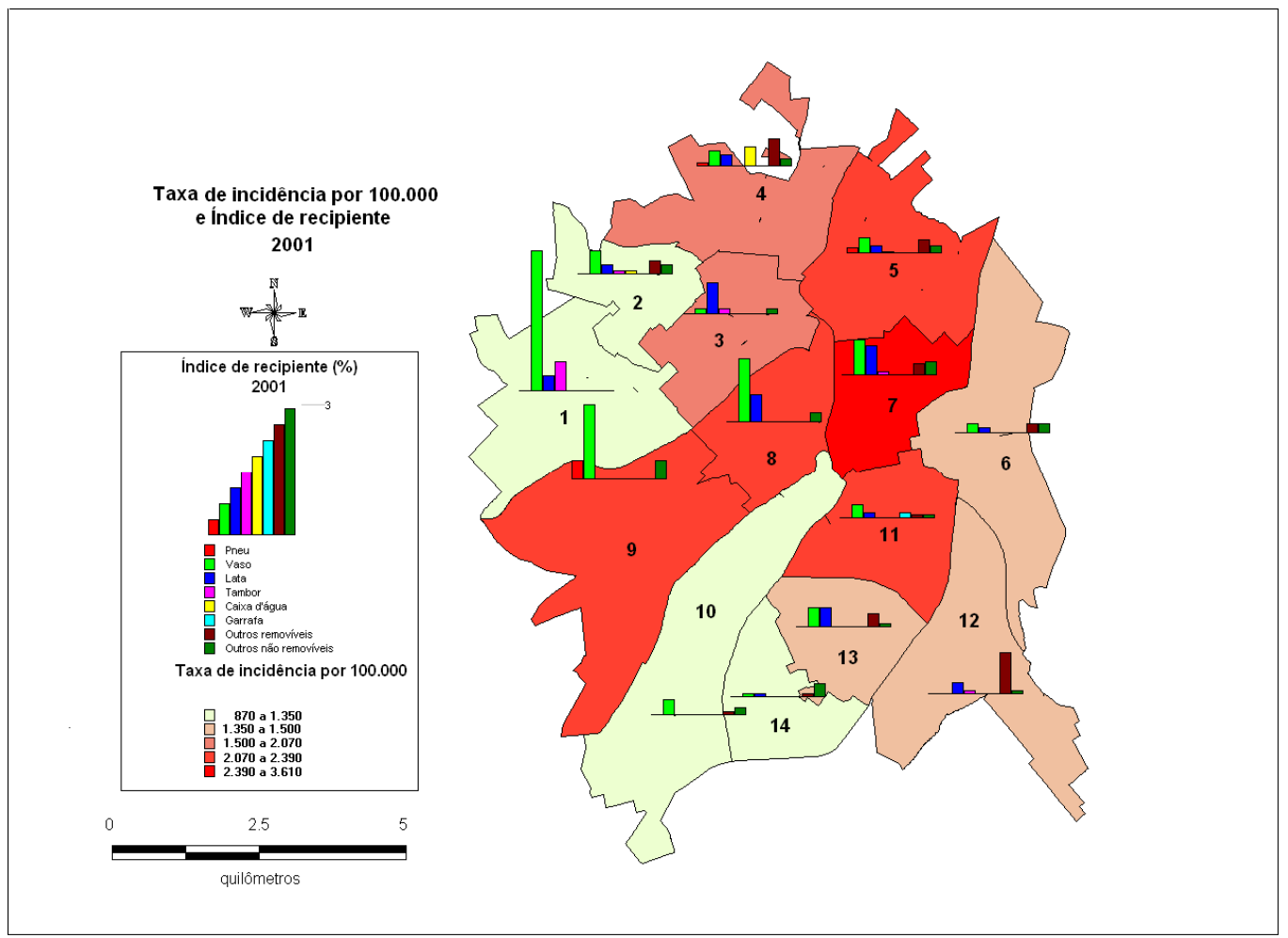

Figura 54 - Mapa de incidência de dengue por 100.000 habitantes e índice de recipientes, por área de controle de vetores, no município de São José do Rio Preto Estado de São Paulo, para o ano de 2001. 
Em 2002, o recipiente vaso continua a se destacar, seguido de lata, pote e frasco, outros removíveis, outros não removíveis e pneus, mostrando que em todas as áreas há uma heterogeneidade com relação aos recipientes, com destaque para o vaso. As maiores incidências continuaram sendo nas regiões norte, centro e oeste (Figura 55).

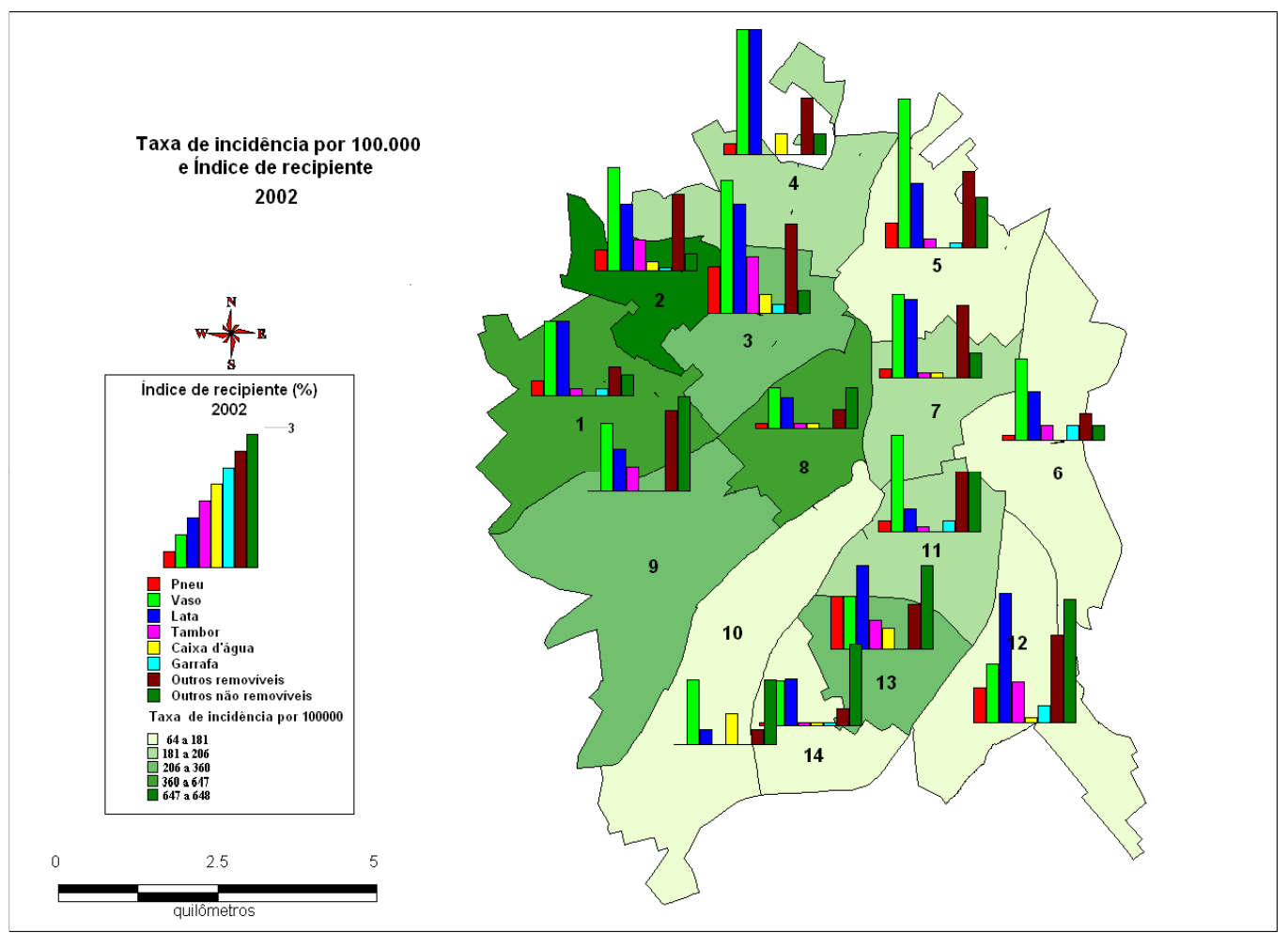

Figura 55 - Mapa de incidência de dengue por 100.000 habitantes e índice de recipientes, por área de controle de vetores, no município de São José do Rio Preto Estado de São Paulo, para o ano de 2002. 
Em 2003, houve redução no encontro de recipientes, sendo os recipientes outros não removíveis os que mais se destacaram, seguido de vasos e lata, pote e frasco. As incidências também foram menores nesse ano destacando-se apenas a região central (área 8), com uma incidência maior de 500 casos por 100.000 habitantes (Figura 56).

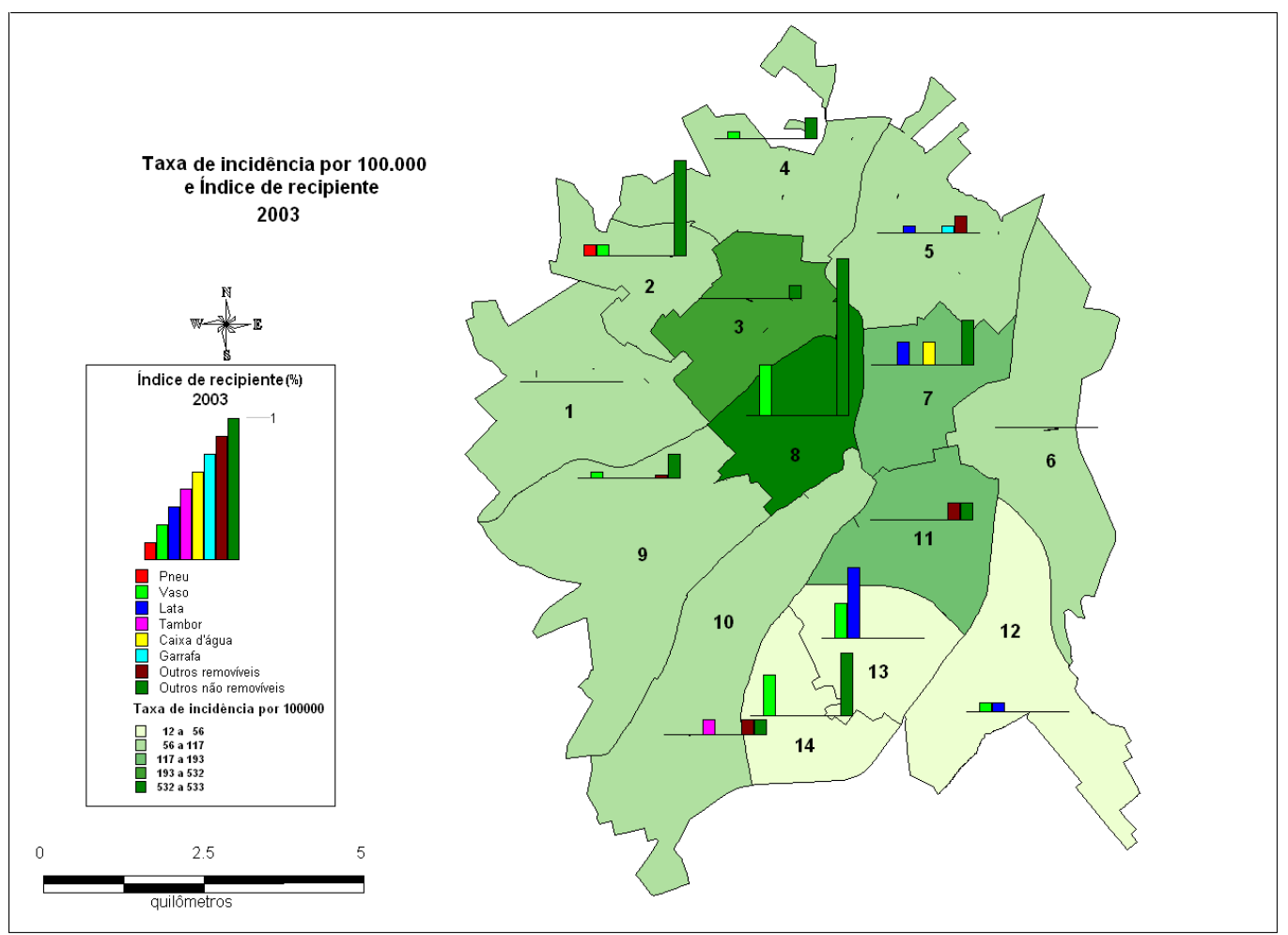

Figura 56 - Mapa de incidência de dengue por 100.000 habitantes e índice de recipientes, por área de controle de vetores, no município de São José do Rio Preto Estado de São Paulo, para o ano de 2003. 
No ano de 2004, o vaso volta a se destacar, seguido de outros removíveis, lata, pote e frasco, outros não removíveis e pneus. Apesar de uma diversidade de recipientes servindo como criadouro estar disponível, nesse ano as incidências de dengue foram baixas, talvez reflexo da menor circulação de vírus no ano anterior. A região que apresentou incidência mais elevada foi a sul (Figura 57).

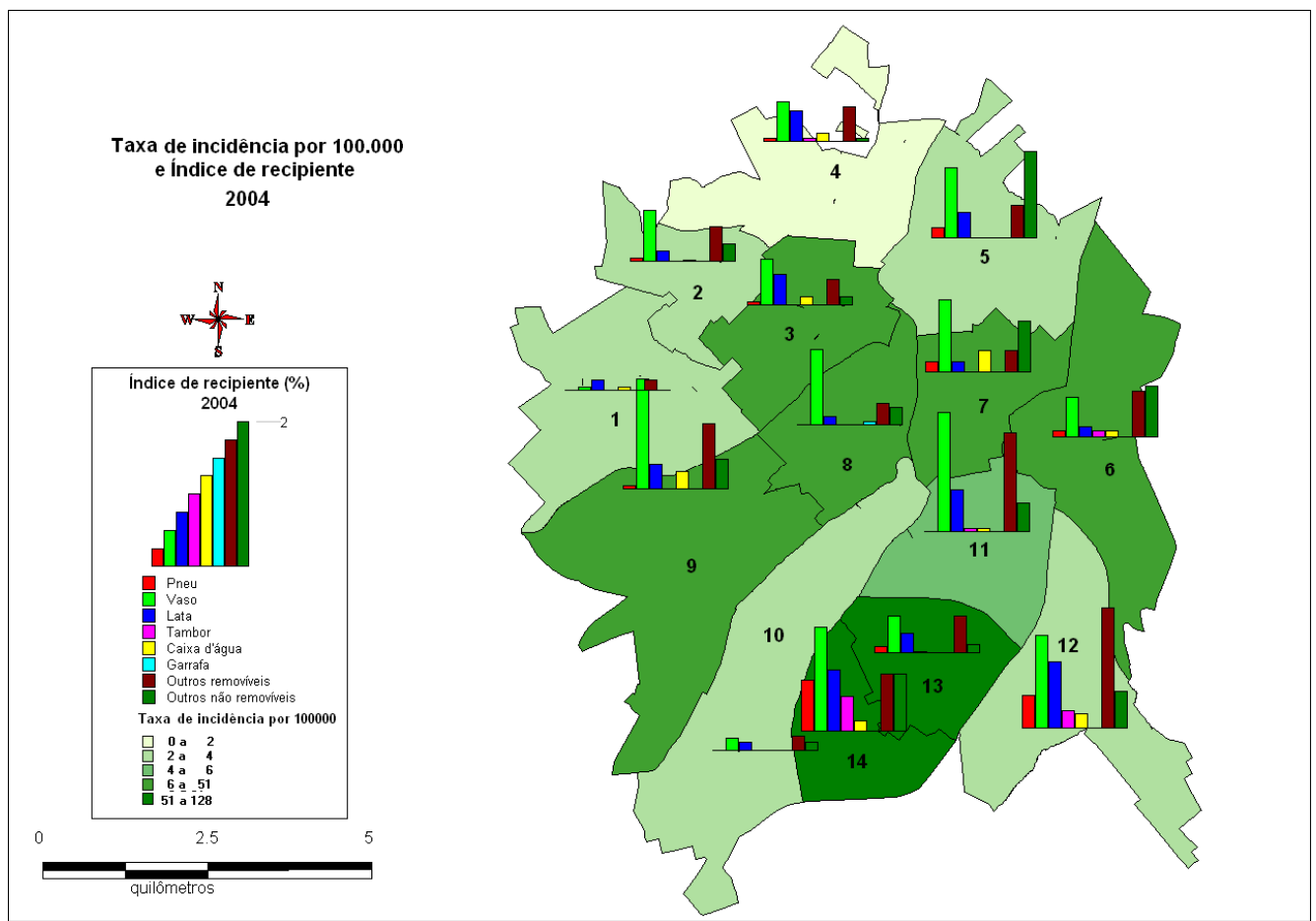

Figura 57 - Mapa de incidência de dengue por 100.000 habitantes e índice de recipientes, por área de controle de vetores, no município de São José do Rio Preto Estado de São Paulo, para o ano de 2004. 
No ano de 2005, o vaso e outros removíveis se destacaram. A incidência foi maior quando comparada à de 2004 , e praticamente toda a cidade apresentou casos de dengue, algumas áreas com maior incidência do que outras (Figura 58).

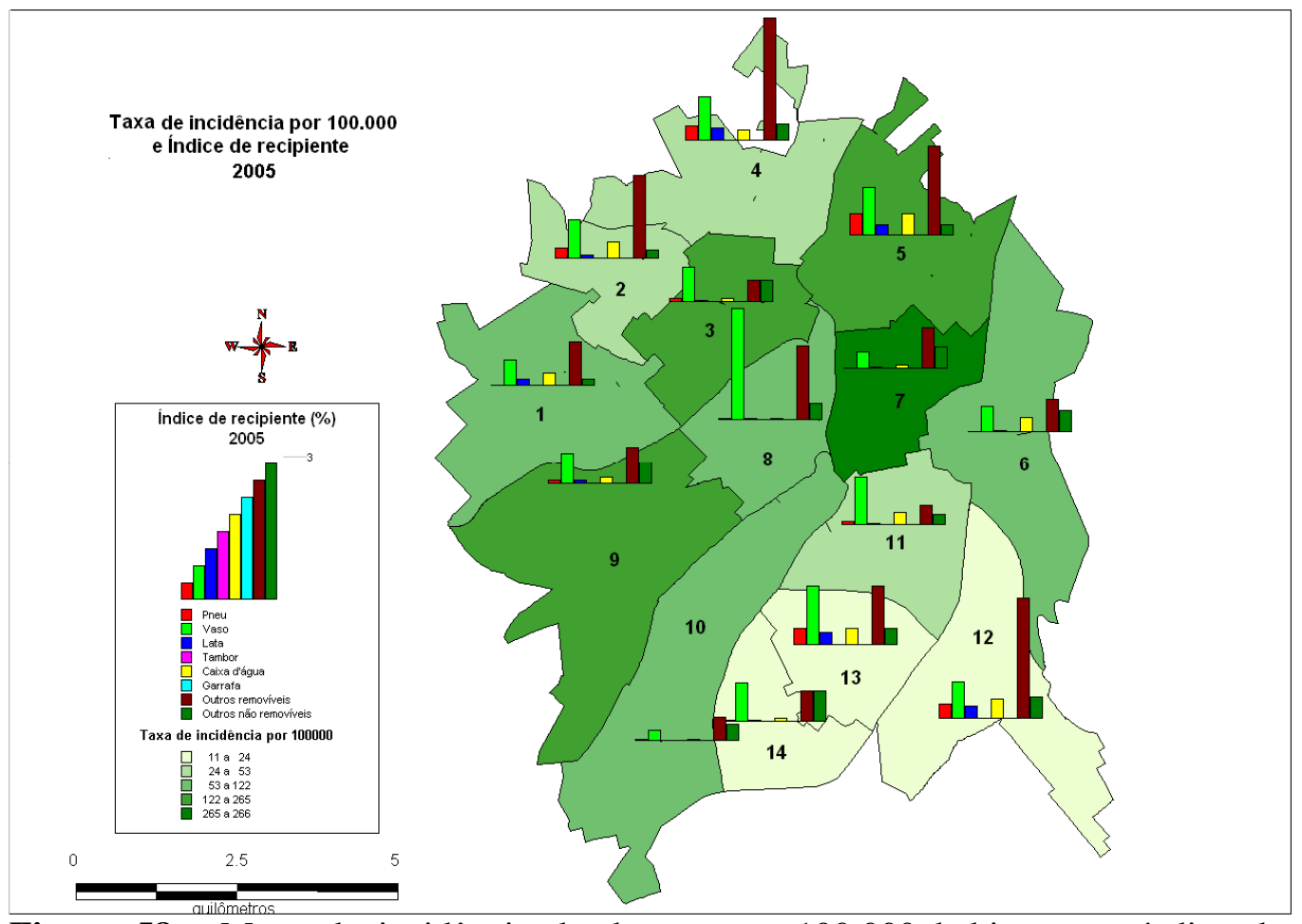

Figura 58 - Mapa de incidência de dengue por 100.000 habitantes e índice de recipientes, por área de controle de vetores, no município de São José do Rio Preto Estado de São Paulo, para o ano de 2005. 


\section{DISCUSSÃO}

O geoprocessamento apresenta vantagens não só para detecção, mas para a apresentação visual de agrupamentos (ROTHMAN, 1990). Neste caso, o geoprocessamento representa ferramenta de divulgação de resultados de investigações que são facilmente compreendidos pela população (BROWN et al, 1984).

O geoprocessamento de informações ambientais e de saúde permite a identificação de variáveis que revelem a estrutura social, econômica e ambiental, onde riscos à saúde estão presentes. Além disso, a ferramenta do geoprocessamento permite o planejamento de ações de controle, medidas de intervenção emergenciais, alocações de recursos e acompanhamento e monitoramento da situação da dengue, sendo instrumento importante de apoio às decisões que devem ser tomadas pelas autoridades de saúde para compreender e interromper o processo de transmissão da dengue em determinada área geográfica (BARCELLOS e BASTOS, 1996; SOUZASANTOS e CARVALHO, 2000; SKABA, et al., 2004).

Nesse estudo demonstrou-se que os casos de dengue não apresentaram distribuição espacial uniforme, pois observou-se alternância dos maiores valores de incidência nas diversas áreas da cidade ao longo dos anos. Alguns autores tentam explicar o comportamento espacial da incidência de dengue, considerando as características dos ambientes e as condições sociais de seus habitantes. Entretanto, notou-se no estudo realizado que ora tem-se maior incidência em bairros com ambiente ocupado por população com padrão econômico e social baixos, ora por 
aquelas com padrão econômico e social elevados (Figuras 30, 31, 32 e 33). Situação semelhante foi observada por BARRERA et al., (2000); VASCONCELOS et al., (2000); SANTOS OO (2003); MONDINI et al., (2005).

O Anexo 1 mostra que em todos os anos a partir de 1998, a dengue ocorreu no município, com maior ou menor intensidade e, ocorrendo praticamente todos os meses do ano, não necessitando de introdutores para continuar a transmissão, ou seja, a transmissão de dengue ocorre independente da introdução de casos oriundos de outras regiões. Observou-se que os maiores números de casos detectados ocorreram nos primeiros meses do ano, quando as condições climáticas eram mais favoráveis tanto ao desenvolvimento do vetor quanto do vírus no organismo do mosquito. Dessa maneira foi possível mostrar que a incidência da dengue em São José do Rio Preto, como em outras regiões do Brasil, é maior nos meses de março a maio (BRASIL, 2002c). No município de São José do Rio Preto, a dengue segue o mesmo padrão nacional de transmissão.

Em 1995, ocorreu número elevado de casos de dengue no município, quando um caso importado, detectado tardiamente, gerou a dispersão da doença. Obviamente, isso ocorreu devido a presença do vetor e da alta suscetibilidade da população para o vírus DEN-1. É provável que se o caso tivesse sido notificado rapidamente e medidas de controle tivessem sido adotadas, a incidência seria menor e a disseminação da infecção interrompida. No entanto, no momento em que foram aplicadas as medidas de controle, elas não interferiram muito, pois grande parcela das populações humana e do vetor estavam infectadas, facilitando a ocorrência da epidemia. Na ocasião, acredita-se que um dos fatores que deve ter contribuído para a dispersão da dengue foi o problema com o abastecimento de água, apesar de toda a 
região norte estar ligada à rede de abastecimento. No entanto, naquele ano, o poço que fazia a distribuição quebrou e a população passou a armazenar água em casa, sem os devidos cuidados para que esses depósitos não se tornassem criadouros de mosquitos. Essa deficiência no abastecimento pode ter gerado condições para o aumento da densidade do vetor na região norte da cidade, o que facilitou a transmissão do vírus. Outro fator é que a área em questão concentra a maior densidade populacional, podendo ser este também, um dos fatores que contribuíram para a incidência elevada de casos.

No final de 1996 foram adotadas ações de controle que visavam à eliminação de todos recipientes que pudessem se tornar criadouros do Aedes aegypti. Esse talvez tenha sido um dos fatores que contribuíram para diminuir a incidência de dengue em 1997. Nesse período, o índice predial foi baixo e ocorreram poucos de casos de dengue.

Com relação à circulação do vírus no Estado de São Paulo, assim como na cidade de São José do Rio Preto, foram identificados casos de dengue pelo sorotipo DEN-1 entre 1990 e 1996. Em 1996, também foram identificados alguns casos de dengue causados pelo sorotipo DEN-2 e, a partir de 2003 casos do sorotipo DEN-3. Atualmente, existem os 3 sorotipos de dengue circulando na cidade (BEPA, 2006).

Nota-se que a partir de 1998 há generalização da transmissão da dengue, praticamente durante o ano todo, com exceção de 2004 (Anexo 1).

Em 1999 ocorreu outra transmissão de dengue com proporções maiores do que a de 1995. Nos anos de 1997 e 1998, as transmissões ocorreram com a presença do sorotipo DEN-1 e 2, mas provavelmente somente em 1999, existiram condições favoráveis de expansão, visto que as maiores incidências ocorreram na região norte, 
onde grande parte da população já tinha imunidade ao sorotipo DEN-1, e praticamente toda a população era suscetível ao DEN-2.

Em 2001, diferentemente do que ocorreu em 1995 e 1999, grande parte da população da área norte da cidade já estava imunizada contra os sorotipos DEN-1 e 2. Nesse ano a transmissão iniciou-se na área de renda e poder aquisitivos maiores. Na região sul, o cultivo de bromélias com fins ornamentais foi bastante incentivado pelos paisagistas. A bromélia constitui micro-habitat no qual podem ocorrer formas imaturas de alguns mosquitos, entre as quais as do Aedes aegypti. A importância de bromélias de uso ornamental como criadouros potenciais de Aedes aegypti foi discutida por MARQUES (2001) e CUNHA et al. (2002). Acredita-se que o uso ornamental de bromélias tenha propiciado o aumento da densidade do vetor que ocupou esses espaços, proliferou e se dispersou para outras áreas da cidade. É interessante assinalar que trabalhadores domésticos que atuavam nas áreas de maior poder aquisitivo eram moradores de bairros localizados na área norte. Assim, casos de infecção pelos sorotipos DEN-1 e DEN-2 que não foram detectados podem ter servido como fonte de dispersão do vírus de localidades da região norte para áreas do sul e do sudeste. Dessa maneira, a dengue se espalhou e atingiu grande número de pessoas, com incidências elevadas em todas as regiões, mostrando que as medidas adotadas não foram suficientes para impedir a generalização da transmissão, devido ao grande número de focos espalhados pela cidade. Isso sugere que a cultura e os hábitos da população desempenham papel importante tanto na infestação como na dispersão desses mosquitos. Dados registrados na literatura indicam que para cada caso de dengue detectado, existem 10 não registrados, ou seja, as fontes de infecção 
estavam sempre presentes e as medidas de controle do vetor não foram suficientes (FIGUEIREDO et al., 1995; SCANDAR, 1998).

Estudos recentes de epidemiologia, empregando caracteres moleculares, indicam que nas Américas circulam os genótipos Americano e Asiático de DEN-2 e o genótipo III de DEN-3, supostamente virulentos (LEITMEYER et al., 1999; COLOGNA e RICO-HESSE, 2003; AQUINO et al., 2006). O genótipo Asiático, considerado mais virulento do que o Americano foi associado com epidemias de FHD/SCD na Índia e África, mas sua introdução em países americanos causou um pequeno número de FHD/SCD (MESSER et al., 2003; OCAZIONEZ et al., 2006). Provavelmente, a circulação do genótipo Americano, menos virulento, funcione como fator de proteção. Em 2000, foi introduzido no Brasil, o sorotipo DEN-3. Dois anos após essa introdução, no Estado do Rio de Janeiro, ocorreu epidemia por esse sorotipo, com manifestações clínicas graves e óbitos (SIMONE et al., 2004; PASSOS et al., 2004; NOGUEIRA et al., 2005). No município de São José do Rio Preto, o sorotipo DEN-2 que foi registrado em 1996, manifestou-se com mais intensidade em 2001, quando ocorreu a maior epidemia do período. O mesmo ocorreu com o sorotipo DEN-3, que foi detectado em 2003, mas somente em 2006 ocorreu transmissão de grandes proporções, inclusive maior do que a de 2001.

A transmissão do vírus dengue, a circulação concomitante de vários sorotipos, o grau de imunidade da população em relação a esses sorotipos e a infestação do vetor aumentam o risco de ocorrência de casos de dengue hemorrágico.

BARRERA et al. (2000) esperavam que bairros da cidade de Maracay Venezuela que tiveram grande número de casos de dengue em um ano, não tivesse no ano seguinte. Isso ocorreria como conseqüência do desenvolvimento de 
imunidade naquela comunidade, mas o estudo mostrou que o padrão de distribuição espacial da dengue se repetiu nos anos estudados nesses mesmos bairros, sugerindo circulação simultânea de vários sorotipos. Situação semelhante ocorreu na cidade de São José do Rio Preto, quando as regiões norte, leste e centro foram as mais atingidas durante o período do estudo. O padrão espacial da dengue pode ser utilizado para prever quais bairros poderão ter incidência maior de dengue no ano seguinte. Dessa maneira, poderão ser adotadas medidas de vigilância e de controle, com estratégia de estratificação das áreas. Assim, será possível identificar as características das áreas que apresentam risco maior de epidemia e, desenhar medidas de controle mais adequadas.

A densidade populacional é fator fundamental para se definir o padrão de transmissão de dengue, pois um número maior de indivíduos em uma área favorece o contato com o vetor e a transmissão pode persistir por mais tempo, ao encontrar grupos maiores de suscetíveis (GÓMEZ-DANTÉS et al., 1995). BARRERA et al., (2000) consideram a densidade populacional importante para estratificar e identificar as áreas mais povoadas e, portanto, com maior risco para a instalação de epidemias de dengue. Essas regiões seriam alvo de vigilância e controle de maneira mais intensa. Para esses autores, a densidade populacional apresenta correlação positiva com o risco de se contrair dengue. Ao mesmo tempo, maior incidência de dengue clássico apresenta correlação positiva com o risco de se adquirir dengue hemorrágico. No presente estudo, observou-se que as regiões norte, leste e central apresentaram várias vezes epidemias de dengue, nas quais a densidade demográfica é mais elevada, e onde existe risco maior de ocorrer transmissão de dengue hemorrágico. 
Estudos realizados em São José do Rio Preto no ano de 1995 por COSTA e NATAL (1998) demonstraram haver associação entre incidência de dengue e os setores censitários, segundo níveis socioeconômicos. Como resultado, demonstrou-se que a incidência de dengue foi mais elevada nos setores onde os moradores tinham menor renda per capita e menor grau de instrução. Na cidade de Maceió, o estudo de SANTOS, OO (2003) apresentou resultado diverso. Resumidamente, não foram encontradas relações entre a incidência de dengue e fatores socioeconômicos, pois áreas com condições economicamente mais favoráveis, também apresentavam riscos elevados de transmissão.

No presente estudo, com relação à renda média dos responsáveis pelas famílias, podemos dividir a cidade em 3 padrões: baixo (região norte e parte da oeste), médio (região leste e central) e alto (região sul e parte da oeste). No estudo realizado em São José do Rio Preto por COSTA e NATAL (1998), a cidade também foi dividida em três unidades ambientais determinadas pelas características socioeconômicas que basicamente coincidem com a divisão observada neste estudo. Esses autores verificaram incidências altas de dengue em áreas com níveis socioeconômicos menores. Entretanto, no presente estudo, observou-se nos anos posteriores, que a região que concentrou o maior número de casos de dengue entre 1990 e 2005 foi a de padrão de renda baixa e média. Vale assinalar que as áreas da região norte da cidade apresentaram sempre incidências médias ou altas no período estudado. Essa característica de incidência maior na região norte pode estar relacionada ao fato de que os casos notificados foram obtidos do sistema de notificação oficial, esse sistema registra os casos dos moradores que buscam assistência médica nos serviços públicos, que são geralmente freqüentados por 
pessoas de menor poder econômico. Dessa maneira, as notificações oficiais possivelmente não incluem todos os casos que ocorreram nas classes de maior poder aquisitivo. Assim, tanto as subnotificações como os casos assintomáticos, podem mascarar o conhecimento real da circulação do vírus da dengue (TEIXEIRA et al., 2003). Apesar dos problemas mencionados, foi possível constatar que no município de São José do Rio Preto ocorreu alternância da transmissão de dengue, ora em regiões com padrão econômico e social elevados, ora em ambientes com padrão mais baixo.

O estudo em questão aponta as regiões com padrões de renda média e baixa como áreas de risco, que podem vir a apresentar formas mais graves da doença, como dengue hemorrágico e síndrome do choque da dengue. Nessas regiões foram observadas as maiores incidências de dengue durante o período estudado. Na região com padrão de renda mais baixa, existe adensamento populacional maior, formado de indivíduos com nível de instrução menor. Diferentemente, na região de padrão de renda média, existe adensamento populacional menor, com indivíduos com nível de instrução maior. Com relação as variáveis, coleta de lixo, rede de água e esgoto, não foram observadas diferenças entre as áreas.

Conhecer a estrutura e dinâmica espacial da dengue é importante para avaliar os riscos ao qual a população está exposta. Estudos de dinâmica espacial da transmissão de dengue podem ser feitos com o emprego de técnicas de georreferenciamento das áreas, com as quais pode-se visualizar o comportamento do vetor e da doença. Assim, procura-se aumentar a rapidez e a eficácia das ações de vigilância e de controle. 
Tendo o homem suscetibilidade universal à infecção e sendo o principal hospedeiro conhecido para o vírus da dengue, é interessante descrever o comportamento da incidência segundo os atributos idade e sexo, para o município de São José do Rio Preto, no período estudado.

Observou-se que no período, a incidência foi menor em indivíduos na faixa etária de 0 a 14 anos. As incidências foram maiores nas faixas etárias de 15 a 49 e 50 anos e mais. As incidências entre essas duas últimas faixas foram semelhantes.

Admite-se que a distribuição da dengue por faixa etária é maior nos grupos de menor idade quando ocorre à introdução de novos sorotipos ou com o esgotamento de suscetíveis no grupo de indivíduos adultos. Com o nascimento de novos indivíduos, existirá a reposição de suscetíveis na população (BARRERA et al., 2000; LOBATO et al., 2002).

TEIXEIRA et al. (2001), em estudo realizado na cidade de Salvador, encontrou valores maiores na faixa dos 20 aos 29 anos, nos três primeiros anos de estudo. Após esse período, os valores maiores foram observados em indivíduos com idade inferior a 10 anos. VASCONCELOS et al. (2000) estudando a epidemia em Prado e Ipupiara (Estado da Bahia), registraram maior incidência na faixa etária dos 45 aos 54 anos. LAPORTA (2004) estudando a epidemia em Santo André, Estado de São Paulo, observou maior incidência na faixa etária superior a 50 anos, em todos os anos, exceto em 2001, quando ela foi maior na faixa de 15 a 49 anos. Por sua vez, CHIARAVALLOTI-NETO (1999) encontrou maior incidência, em São José do Rio Preto, no período de 1990 a 1996, em indivíduos com idade entre 30 e 59 anos, como verificado neste estudo. No inquérito sorológico realizado em Fortaleza (Estado do Ceará), VASCONCELOS et al. (1998) demonstraram que não houve diferença 
estatística significativa entre sexo e idade. Semelhantemente, SCANDAR (1998) não encontrou diferenças entre essas duas variáveis, no inquérito sorológico realizado no município de Paraíso (Estado de São Paulo), concluindo que o risco de se infectar pelo vírus da dengue independe desses atributos. No Acre, LOBATO et al. (2002) observaram que a incidência foi maior na faixa dos 15 aos 49 anos. De modo geral, verifica-se que a doença pode atingir diversas faixas etárias, mas na maioria dos estudos, os resultados mostram que o grupo etário mais afetado é o da idade produtiva.

Tanto os resultados do presente estudo, como os daqueles mencionados, mostraram que a incidência de dengue foi menor na faixa etária de zero a 14 anos. Considerando que indivíduos dessa faixa etária permanecem a maior parte do tempo no domicílio, a baixa incidência em jovens e crianças pode ser devida a fatores que precisam ser melhor investigados. Vários fatores podem ter gerado possível subnotificação de casos na faixa etária em questão. Entre eles, vale assinalar os sintomas de outras doenças febris que podem ser confundidas com dengue, a possibilidade de infecção assintomática (SCANDAR et al., 2003), e a possibilidade do caso não ter sido notificado aos serviços de vigilância. Assim, a subnotificação, nessa faixa etária, pode ser expressiva, em virtude do quadro clínico ser confundido com muitas viroses febris ou ser considerada pela população como doença benigna (TEIXEIRA et al., 1999). NIMMANNITYA (1987) relata que em locais com grande intensidade de casos de dengue hemorrágico, as faixas etárias mais atingidas por essa doença são as crianças e os adolescentes. 
Com relação à incidência por sexo, observa-se que houve variações pequenas, sendo ligeiramente maior no sexo feminino, exceto nos anos de 1991 e 2004, quando a maior incidência ocorreu no sexo masculino.

Vários estudos demonstraram que as incidências de dengue são maiores em indivíduos do sexo feminino (CHIARAVALLOTI-NETO, 1999; VASCONCELOS, 2000; LOBATO, 2002; SANTOS OO, 2003). Uma das explicações seria a maior exposição das mulheres às picadas do mosquito, por permanecerem mais tempo na área interna e externa do domicílio, o que facilitaria a transmissão (VASCONCELOS et al., 1993; GÓMEZ-DANTÉS, 1995). No entanto, VASCONCELOS et al. (1999) e SCANDAR et al. (2003) não observaram diferenças estatisticamente significante na incidência de dengue entre os sexos. Nesse sentido, com base nos resultados dos estudos realizados no Estado do Maranhão (VASCONCELOS et al., 1999) e Paraíso no Estado de São Paulo (SCANDAR et al., 2003), é possível supor que os indivíduos de ambos os sexos estão igualmente expostos ao vetor e ao vírus dengue. A despeito da pequena variabilidade da incidência de dengue entre sexos, os resultados do presente estudo, confirmam a hipótese de que a dengue pode ocorrer independentemente no homem e na mulher, desde que sejam suscetíveis.

As transmissões de dengue, historicamente, têm ocorrido nas estações quentes e chuvosas do ano, quando as condições climáticas favorecem a proliferação do Aedes aegypti e a replicação do vírus (REBÊLO et al., 1999; SILVA e SILVA, 1999). Na cidade de São José do Rio Preto a temperatura é elevada durante todo ano, mantendo-se na média de $25^{\circ} \mathrm{C}$, fator que influencia a transmissão de dengue. A influência da temperatura na transmissão de dengue foi largamente investigada (GÓMEZ-DANTÉS et al., 1995; JETTEN e FOCKS, 1997), pois quando elevada 
influência positivamente nas atividades de repasto sanguíneo das fêmeas dos mosquitos, na sua longevidade, no período de incubação extrínseco do vírus e no tamanho do vetor que indiretamente influência na taxa de picadas. FOCKS et al. (1995) através de modelo de simulação estimou que o período de incubação extrínseco do vírus em $22^{\circ} \mathrm{C}$ é de 16,7 dias e em $32^{\circ} \mathrm{C}$ é de 8,3 dias, ou seja, as fêmeas infectadas em condições de temperaturas elevadas teriam 2,6 vezes mais chance de completar o período de incubação mais rápido do que aquelas expostas a temperaturas mais baixas.

No que tange ao estudo da correlação entre o índice predial (IP) e a precipitação pluviométrica, observou-se que foi significante em alguns anos e em outros não o foi. Esse resultado sugere que, o índice larvário que foi maior no período de chuvas, pode ter sido ocasionado pela existência de recipientes depositados em áreas abertas, o que contribuiu para a elevação do IP. Ao contrário, nos anos em que os valores de correlação não foram estatisticamente significativos, provavelmente os IP menores desses períodos estavam relacionados com a maior participação da população em manter os recipientes sem água. Outros estudos demonstraram que a sazonalidade dos casos coincidiu com o crescimento da pluviosidade (CHIARAVALLOTI NETO, 1992; GLASSER e GOMES, 2002). De maneira geral, pode-se afirmar que maior número de casos, geralmente, ocorreu quando a temperatura e a pluviosidade eram mais elevadas, o que ocasiona aumento da população do mosquito vetor. Padrão semelhante foi observado no estudo realizado, sendo que nos primeiros anos, de 1990 a 1994 não houve coincidência entre os picos de incidência de dengue. No período de 1995 a 2005, o pico ocorreu em abril, com exceção de 2003 quando foi em março. A elevação da incidência da 
dengue nos primeiros meses do ano é o padrão de distribuição temporal da doença no Brasil. Este padrão de distribuição temporal tem sido associado às melhores condições climáticas, dos períodos de verão e outono, para o vetor (TEIXEIRA et al., 1999). A associação positiva entre precipitação, densidade larval e incidência de dengue têm sido destacadas na literatura, embora não se trate de relação observada em todas as regiões do planeta (KUNO, 1995).

Neste estudo, nos anos de 1990 a 1994, os índices (IP e IC) mostraram que a densidade larvária está ligada a sazonalidade e que aumenta à medida que se aproxima o período com índices pluviométricos e temperaturas mais elevados, diminuindo nos meses mais secos e frios. Posteriormente, o índice larvário reflete de modo precário a densidade do mosquito vetor, pois ele foi medido, a partir de 1995, apenas uma vez ao ano. Isso se deve ao fato de que todo o pessoal operacional, disponível na SUCEN de SJRP, estava envolvido na intensificação das atividades de controle do vetor. Este fato dificultou as atividades de rotina de avaliação dos índices larvários. Acredita-se ser este o motivo de não se observar correlações entre o IP e a precipitação pluviométrica em alguns anos e também em relação à incidência de dengue (IC).

EHRENKRANZ (1971) já afirmava que as epidemias de dengue são, de modo geral, explosivas e ocorrem principalmente nas estações chuvosas, como observado neste trabalho. Contudo, fatores não climáticos, como a disponibilidade de criadouros pode ser tão ou mais importante para a transmissão da doença do que a quantidade de chuvas, uma vez que concorrem para a manutenção de altas densidades de Aedes aegypti no meio urbano (PATZ et al., 1998). Fato este, que pode explicar o que se observou neste trabalho, pois as maiores incidências de 
dengue ocorreram no verão e outono, e continuaram ocorrendo com menor intensidade nas outras estações do ano, principalmente após 2001.

$\mathrm{O}$ mosquito Aedes aegypti freqüenta os ambientes intra e peridomiciliar, preferindo criadouros artificiais, tanto aqueles abandonados a céu aberto e preenchidos pelas águas das chuvas quanto àqueles utilizados para armazenar água para uso doméstico (latas, barris, caixa d'água e outros) ou ornamentais como vasos e bromélias. No Estado de São Paulo, estudos realizados referentes ao conjunto de recipientes mostraram que cerca de $90 \%$ dos focos larvários de Aedes aegypti estavam no peridomicílio, onde há grande oferta de criadouros (PEREIRA, 2001). No entanto, os resultados de investigações realizadas em São José do Rio Preto, envolvendo captura de alados, mostraram que $87,3 \%$ das fêmeas adultas foram capturadas no intradomicílio (BARATA et al., 2001). Tanto no Brasil quanto em outros países, larvas de Aedes aegypti têm sido observadas em criadouros naturais como as bromélias ornamentais, ocos de árvores, entre outros (CONSOLI e LOURENÇO de OLIVEIRA, 1998).

Segundo SERVICE (1992), além da classe social, a quantidade de criadouros no domicílio e peridomicílio podem estar também associadas à cultura e hábitos da população. Talvez isso explique a heterogeneidade dos recipientes encontrados na cidade de São José do Rio Preto, no período estudado.

CHIARAVALLOTI-NETO (1992) e COSTA e NATAL (1998) em estudo realizado em São José do Rio Preto destacaram a importância do vaso como criadouro de Aedes aegypti, no período de 1989 a 1995. PEREIRA (2001) estudando os principais criadouros na cidade de Santos, no período de 1999 a 2000, observou que a ordem de preferência era ralo, frasco, vaso e outros materiais. 
Os resultados obtidos neste estudo mostraram que, no período de 1990 a 2005, as atividades humanas propiciaram a dispersão do vetor por toda a área urbana do município. Paralelamente, observou-se que o mosquito Aedes aegypti foi oportunista ao aproveitar a disponibilidade de múltiplos tipos de criadouros, em algumas áreas. O encontro de imaturos nos diversos tipos de criadouros se alternou no decorrer dos anos mostrando que a presença do mosquito no domicílio, dependia da disponibilidade de criadouros e dos hábitos e costumes da população humana. Nos anos de 1990 a 1993 os vasos, seguidos de latas, potes e frascos foram apontados como os principais recipientes positivos para larvas de Aedes aegypti. No período de 1995 a 1997 as latas, potes e frascos se destacaram, seguidos de caixa d'água. Talvez esse resultado se deva ao fato de na região norte, onde a incidência de dengue foi maior, ter ocorrido à distribuição intermitente de água no período, pela quebra da bomba do poço artesiano que abastecia a região, levando a comunidade a manter reservatórios improvisados. Já, em 1999, o vaso voltou a ter importância mantendo esse padrão até os dias de hoje, seguido dos recipientes classificados como outros removíveis e outros não removíveis.

A distribuição heterogênea de recipientes nas diversas áreas deve-se aos trabalhos educativos que inicialmente (1990 a 1994) foram voltados para vasos e posteriormente (1995 a 1997) para latas, potes e frascos. A partir de 1998 passou-se a dar igual importância a todos os recipientes, pois todos apresentavam risco potencial para criar larvas do mosquito Aedes aegypti. Deve-se, ainda, levar em conta a elevada plasticidade ecológica da espécie, que se adapta rapidamente aos recipientes disponíveis. 
LIMA (1988), afirmou que os pneus são um dos principais criadouros nos Estados Unidos, mas no Rio de Janeiro eles têm importância secundária. De maneira semelhante, isso vem sendo observado na cidade de São José do Rio Preto, que apesar de não ter predominância muito alta de pneus usados no ambiente peridomiciliar, estes aparecem com certa freqüência. Entretanto, apesar do encontro de pneus positivos ser pequeno, estes oferecem condições favoráveis à colonização de mosquitos, de acordo com o volume de água e a exposição ao sol. Provavelmente, o número baixo de pneus encontrados, deve-se as intensas campanhas realizadas, que culminou no recolhimento desses materiais pela Associação Nacional de Indústrias de Pneus (ANIP).

Segundo LIMA (1988), o conhecimento dos criadouros é de importância fundamental para o controle do Aedes aegypti. Determinando a importância de cada recipiente, é possível traçar estratégias de controle do mosquito Aedes aegypti, e conseqüentemente, da dengue.

Obviamente, com a inexistência de vacina eficaz, o controle da dengue depende do controle do vetor e isso significa reduzir os criadouros dos mosquitos. Estudos mostraram que campanhas de controle envolvendo a participação da comunidade têm reduzido os índices de infestação do vetor (GUBLER e CLARK, 1994; FERNANDEZ et al., 1993). Em pesquisa realizada no município de São José do Rio Preto, CHIARAVALLOTI-NETO (1997) mostrou que a população tem conhecimento tanto sobre o vetor da dengue, como das maneiras de impedir a sua proliferação, mas isso não foi suficiente para evitar as sucessivas epidemias de dengue que ocorreram no município. Assim, é necessário investir na participação da população no processo de prevenção da doença. Para isso serão necessárias 
mudanças no comportamento e nos hábitos das pessoas. Dessa maneira, será possível reduzir e eliminar os criadouros potenciais do mosquito transmissor do vírus da dengue.

Com a utilização de técnicas de geoprocessamento para mapear as áreas de focos do mosquito vetor e dos casos de dengue, pode-se identificar os locais de maior risco de transmissão. Dessa maneira, as informações entomológicas e epidemiológicas notificadas pelos serviços de saúde podem ser processadas no sistema, de maneira rápida, possibilitando melhor visualização e direcionamento das atividades de controle do mosquito. 


\section{CONCLUSÕES}

1. A incidência de dengue foi maior na faixa etária dos 15 aos 49 anos e 50 anos e mais.

2. Com relação à incidência por sexo, observa-se que houve variações pequenas, sendo ligeiramente maior no sexo feminino, sugerindo que o resultado varia conforme o tipo de exposição dos indivíduos ao vírus, e que ambos os sexos tem igual chance de contrair a dengue.

3. A correlação de Pearson positiva entre IP e pluviosidade observada em alguns períodos sugere que a presença do vetor é mais elevada no período chuvoso. Ao contrário, nos anos, para os quais não foi observada correlação, provavelmente ocorreu maior participação da população em manter recipientes secos. Vale considerar que o fato do IP ter sido medido uma vez por ano pode ter influenciado nos resultados.

4. Observou-se distribuição heterogênea de criadouros artificiais, nas diversas áreas durante os anos de estudo. No período de 1990 a 1993, os principais recipientes positivos para larvas de Aedes aegypti foram vasos, latas, potes e frascos. No período de 1995 a 1997 os recipientes latas, potes, frascos e caixa d'água mereceram destaque. A partir de 1999, os vasos voltaram a ter 
importância mantendo esse padrão, seguido de recipientes classificados como outros removíveis e outros não removíveis.

5. O pneu apareceu com pequena freqüência em todos os anos no ambiente peridomiciliar, mas constitui criadouro importante, pois oferece condições favoráveis para a proliferação do Aedes aegypti.

6. A análise espacial permitiu visualizar que a ocorrência da dengue não apresenta padrão de distribuição uniforme. Observando-se as taxas de incidência entre os anos estudados, notou-se a alternância dos valores obtidos nas diversas áreas da cidade.

7. As taxas de incidência de dengue em períodos epidêmicos e interepidêmicos sugerem que a transmissão de dengue é endêmica no município de São José do Rio Preto.

8. Com relação às áreas, destacam-se a dois e três (localizadas na região norte), sete (leste) e oito (centro) que durante todo o período apresentaram incidência elevada de dengue. Isso sugere que essas áreas apresentam risco maior de ocorrência de dengue hemorrágico.

9. As técnicas de análise espacial apresentam potencial para a vigilância e controle da doença da dengue, pois permitem visualizar os casos, o índice de 
infestação, os tipos de recipientes, a densidade populacional e outros fatores importantes para o direcionamento das atividades de controle.

10. As variáveis socioeconômicas parecem não ter influência na transmissão da dengue. Observou-se que a enfermidade ocorre tanto em regiões com padrão socioeconômico elevado, como naquelas de padrão baixo, no município de São José do Rio Preto no período estudado. 


\section{RECOMENDAÇÕES}

O município deve acompanhar a evolução de cada tipo de recipiente, em conjunto com a adaptação do mosquito ao ambiente urbano. Paralelamente, desenvolver estudos para avaliar o envolvimento da população na mudança de hábitos e costumes relativos à manutenção de possíveis criadouros de mosquitos.

Como foi abordado no estudo, quando ocorreu à interferência da área educativa sobre a utilização de determinados materiais que se transformavam em criadouros, houve redução dos mesmos, implicando na diminuição de casos de dengue. Portanto, investir nas atividades educativas no sentido de mudar os hábitos e costumes da comunidade, para evitar a criação e ou manutenção de possíveis criadouros é de importância vital para o controle da proliferação do Aedes aegypti.

Com a utilização da técnica do georreferenciamento de casos de dengue e índices de infestação do mosquito, a Secretaria Municipal de Saúde poderá agir com maior rapidez, identificando os locais de maior risco de transmissão da doença e direcionando as ações de controle do mosquito, em determinado espaço geográfico e tempo real, racionalizando os recursos utilizados nos trabalhos de controle da infestação, além de acompanhar e monitorar a situação da dengue.

O município de São José do Rio Preto deve direcionar trabalhos diferenciados de controle do mosquito, para as áreas norte, leste e centro, onde as ocorrências de casos de dengue sempre foram mais destacadas e, portanto com maior risco de 
ocorrer casos de dengue hemorrágico. Estas atividades devem preceder os períodos de maior intensidade pluviométrica e de temperaturas elevadas (setembro, outubro, novembro), visando retirar o maior número de criadouros e orientar a população quanto aos cuidados que devem ser tomados. Não devendo ser esquecida a técnica e qualidade do trabalho desenvolvido pelo agente de controle de vetores. 


\section{REFERÊNCIAS BIBLIOGRÁFICAS}

ALVES, M. C. G. P.; ALMEIDA, M. C. R. Plano amostral para cálculo de densidade larvária de Aedes aegypti e Aedes albopictus no estado de São Paulo Brasil. Revista de Saúde Pública, São Paulo, v. 25, n. 4, p. 251-256, 1991.

AQUINO, A. V. et al. Molecular epidemiology of dengue type 3 virus in Brazil and Paraguay, 2002-2004. The American Journal of Tropical Medicine and Hygiene, Cleveland, Ohio, v. 75, n. 4, p. 710-715, 2006.

ARONOFF, S. Geographic information systems. Ottawa: WDL Publications, 1989.

BARATA, E. A. M. F. et al. População de Aedes aegypti em área endêmica de dengue, Sudeste do Brasil. Revista de Saúde Pública, São Paulo, v. 35, n. 3, p. 237 242, 2001.

BARCELLOS, C.; BASTOS, F. I. Geoprocessamento, ambiente e saúde: uma união possível? Cadernos de Saúde Pública, Rio de Janeiro, v. 12, n. 3, p. 389-397, 1996.

BARCELLOS, C. et al. Identificação de locais com potencial de transmissão de dengue em Porto Alegre através de técnicas de geoprocessamento. Revista da Sociedade Brasileira de Medicina Tropical, São Paulo, v. 38, n. 3, p. 246-250, 2005 .

BARRERA, R. et al. Deficiência en serviços públicos y cria de Aedes aegypti en Venezuela., Boletín de la Oficina Sanitaria Panamericana, Washington, US, v. 118, p. 410-423, 1995.

BARRERA, R. et al. Estratificación de uma ciudad hiperendémica em dengue hemorágico. Revista Panamericana de Salud Publica, Washington, US, v. 8, p. 225-233, 2000.

BARRETO, C. M. Sistema de informação geográficas para distritos de saúde. Revista Baiana de Saúde Pública, Salvador, v. 21, p. 57-70, 1995.

BEPA - Secretaria de Estado da Saúde de São Paulo. Boletim Epidemiológico Paulista, São Paulo, v. 3, p. 36-39, 2006. Suplemento 1.

BRASIL. Ministério da Saúde. Fundação Nacional de Saúde. Plano diretor de erradicação do Aedes aegypti no Brasil. Brasília, DF, 1996.

BRASIL. Ministério da Saúde. Fundação Nacional de Saúde. Programa nacional de controle da dengue. Brasília, DF, 2002a. 
BRASIL. Ministério da Saúde. Fundação Nacional de Saúde. Programa nacional de controle da dengue. Amparo legal à execução das ações de campo: imóveis fechados, abandonados ou com acesso não permitido pelo morador. Brasília, DF, $2002 b$.

BRASIL. Ministério da Saúde. Fundação Nacional de Saúde. Guia de vigilância epidemiológica. Brasília, DF, 2002c.

BRASIL. Ministério da Saúde. Secretaria de Vigilância em Saúde. Dengue. Disponívelem:<http://portal.saude.gov.br/portal/arquivos/pdf/graficos_dnc_casoseobitos_dengue_ pdf>. Acesso em: 03 out. 2006.

BROWN, I. F.; SILVA JUNIOR, A. G.; GOMES, H. M. Geologia ambiental em um programa de saúde comunitária: exemplo do bairro de Anaia, São Gonçalo, RJ. In: Congresso Brasileiro de Geologia, 33., 1984, Rio de Janeiro. Anais... Rio de Janeiro: Sociedade Brasileira de Geologia, 1984. p. 295-301.

CALADO, D. C.; SILVA, M. A. N. Avaliação da influência da temperatura sobre o desenvolvimento de Aedes albopictus. Revista de Saúde Pública, São Paulo, v. 36, n. 2, p. 173-179, 2002.

CATI - Secretaria de Agricultura e Abastecimento do Estado de São Paulo. Monitoramento e informação sobre condições climáticas Disponível em: $<$ http://www.cati.sp.gov.br>. Acesso em: jan. 2006.

CAUSEY, O. R.; THEILER, M. Virus antibody survey on sera of residents of the Amazon valley in Brazil. The American Journal of Tropical Medicine and Hygiene, Cleveland, Ohio, v. 7, n. 1, p. 36-41, 1958.

CHIARAVAlloti Neto, F. Aedes aegypti na região de São José do Rio Preto, Estado de São Paulo. 1992. Dissertação (Mestrado em Saúde Pública) - Faculdade de Saúde Pública, Universidade de São Paulo, São Paulo, 1992.

CHIARAVALLOTI NETO, F. Conhecimentos da população sobre dengue, seus vetores e medidas de controle em São José do Rio Preto, São Paulo. Cadernos de Saúde Pública, Rio de Janeiro, v. 13, n. 3, p. 447-453, 1997.

CHIARAVALLOTI NETO, F. Epidemiologia da dengue nas regiões de São José do Rio Preto e Araçatuba, São Paulo, 1990 a 1996. 1999. Tese (Doutorado em Saúde Pública) - Faculdade de Saúde Pública, Universidade de São Paulo, São Paulo, 1999.

CHIESA, A. M.; WESTPHAL, M. F.; KASHIWAGI, N. M. Geoprocessamento e a promoção da saúde: desigualdades sociais e ambientais em São Paulo. Revista de Saúde Pública, São Paulo, v. 36, n. 5, p. 559-567, 2002. 
COLOGNA, R.; RICO-HESSE, R. American genotype structures decrease dengue virus output from human monocytes and dendritic cells. Journal of Virology, v. 77, n. 7, p. 3929-3938, 2003.

CONSOLI, R. A. G. B.; LOURENÇO-DE-OLIVEIRA, R. Principais mosquitos de importância sanitária no Brasil. Rio de Janeiro: Fiocruz, 1998.

COSTA, A. I. P.; NATAL, D. Distribuição espacial da dengue e determinantes socioeconômicos em localidade urbana no sudoeste do Brasil. Revista de Saúde Pública, São Paulo, v. 32, n. 3, p. 232-236, 1998.

CVE - SÃO PAULO (Estado). Secretaria de Estado da Saúde. Centro de Vigilância Epidemiológica. Casos autóctones de dengue. Disponível em: <www.cve.saude.sp.gov.br/htm/cve_dengue.html>. Acesso em: set. 2006.

CUNHA, S. P. et al. Presença de Aedes aegypti em Bromeliaceae e depósitos com plantas no município do Rio de Janeiro, RJ. Revista de Saúde Pública, São Paulo, v. 36, n. 2, p. 244-245, 2002.

DAL FABBRO, A. L. Estudo epidemiológico do dengue em Ribeirão Preto no período 1990-1997. 1997. Tese (Doutorado em Saúde Pública) - Faculdade de Medicina de Ribeirão Preto, Universidade de São Paulo, São Paulo, 1997.

DATASUS. Informações demográficas: município de São José do Rio Preto. Brasília, DF, 2006. Disponível em: <http://tabnet.datasus.gov.br/cgi/tabcgi $>$. Acesso em: 20 fev. 2006.

DONALISIO, M. R.; GLASSER, C. M. Vigilância entomológica e controle de vetores do dengue. Revista Brasileira de Epidemiologia, São Paulo, v. 5, n. 3, p. 259-272, 2002.

DOMINGOS, M. F. Aspectos da ecologia de Aedes aegypti (Linnaeus) em Santos, São Paulo, Brasil. 2005. Tese (Doutorado em Saúde Pública) - Faculdade de Saúde Pública, Universidade de São Paulo, São Paulo, 2005.

DONALISIO, M. R. O dengue no espaço habitado. São Paulo: Hucitec, 1999.

EHRENKRANZ, J. N. Pandemic dengue in Caribeban countries and the Southern United States Past: present and potencial problems. New England Journal of Medicine, Boston, v. 285, n. 26, p. 1460-1469, 1971.

FERNANDEZ, E.; LAGOS, I.; SHERMAM, C. Advances in the Aedes aegypti community-based control project in el progreso. Journal of the American Mosquito Control Association, Fresno, CA, v. 9, p. 449, 1993. 
FIGUEIREDO, L. T. M. et al. Encusta Serológica sobre el dengue em Ribeirão Preto, São Paulo, Brasil. Boletín de la Oficina Sanitaria Panamericana, Washington, US, v. 118, p. 499-509, 1995. Suplemento 6.

FIGUEIREDO, L. T. M. et al. Estudo sobre diagnóstico laboratorial e sintomas do dengue, durante epidemia ocorrida na região de Ribeirão Preto, SP, Brasil. Revista do Instituto de Medicina Tropical de São Paulo, São Paulo, v. 34, n. 2, p. 121-130, 1992.

FIGUEIREDO, L. T. M. Dengue in Brasil: past, present and future perspective. Dengue Bulletin, New Delhi, Índia, v. 27, p. 25-33, 2003.

FOCKS, D. A. et al. A simulation model of the epidemiology of urban dengue fever: literature analysis, model development, preliminary validation and samples of simulation results. The American Journal of Tropical Medicine and Hygiene Cleveland, Ohio, v. 53, p. 489-506, 1995.

FORATTINI, O. P. Entomologia médica. São Paulo: EDUSP, 1962. v. 1.

GEODA. An introduction to spatial data analysis. Disponível em: <http://www.geoda.uiuc.edu/geoda/geoda $>$. Acesso em: 16 nov. 2006.

GLASSER, C. M.; GOMES, A. C. Clima e sobreposição de Aedes aegypti e Aedes albopictus na infestação do Estado de São Paulo. Revista de Saúde Pública, São Paulo, v. 36, n. 2, p. 166-172, 2002.

GÓMEZ-DANTÉS, H.; RAMOS-BONIFAZ, B.; TAPIA-CONYER, M. C. El riesgo de transmisión del dengue: un espacio para la estratificación. Salud Pública de México, México, DF, v. 37, p. 88-97, 1995.

GUBLER, D. J. Dengue. In: MONATH, T. P. The arboviruses: epidemiology and ecology. Boca Raton, FL: CRC Press, 1988. v. 2, p. 223-260.

GUBLER, D. J.; CLARK G.G. Community-based integrate control of Aedes aegypti: a brief overview of current programs. The American Journal of Tropical Medicine and Hygiene, Cleveland, Ohio, v. 50, p. 50-60, 1994. Suplemento 6.

GUBLER, D. J. Human arbovirus infections worldwide. Annals of the New York Academy of Sciences, New York, US, v. 951, p. 13-24, 2001.

GUBLER, D. J. The global emergence/resurgence of arboviral diseases as public health problems. Archives of medical research, México, DF, v. 33, n. 4, p. 330-342, 2002.

HALSTEAD, S. B. Dengue haemorragic fever: a public health problem and a field for research. Bulletin World Health Organization, Genebra, v. 58, n. 1, p. 1-21, 1980. 
HALSTEAD, S. B. The pathogenesis of dengue: molecular epidemiology in infections disease. American Journal of Epidemiology, Baltimore, US, v. 114, n. 5, p. 632-648, 1981.

HARRINGTON, L. C.; EDMAN, J. D.; SCOTT, T. W. Why do female Aedes aegypti (Diptera: Culicidae) feed preferentially and frequently on human blood? Journal of Medical Entomology, Washington, DC, v. 38, n. 3, p. 411-422, 2001.

IBGE - Instituto Brasileiro de Geografia e Estatística. Censo demográfico 2000. Rio de Janeiro, 2002.

IBGE - Instituto Brasileiro de Geografia e Estatística. Cidades@. Disponível em: $<$ http://www.ibge.gov.br/cidadesat/extras/perfil.php>. Acesso em: 20 fev. 2006.

INPE - Instituto Nacional de Pesquisas Espaciais. Cursos. Disponível em: $<$ http://www.dpi.inpe.br/cursos/ser301/ementa.html>. Acesso em: 2006.

JETTEN, T. H.; FOCKS, D. A. Potencial changes in the distribuition of dengue transmission under climate warning. The American Journal of Tropical Medicine and Hygiene, Cleveland, Ohio, v. 57, p. 285-297, 1997.

KOURI, G. P.; GUZMAN, M. G.; BRAVO, J. Why dengue haemorragic fever in Cuba?: an integral analysis. Transactions of the Royal Society of Tropical Medicine and Hygiene, London, GB, v. 81, n. 5, p. 821-823, 1987.

KOURI, G. P. et al. Remergence of dengue in Cuba: a 1997 epidemic in Santiago de Cuba. Emerging Infectious Diseases, Atlanta, US, v. 4, n. 1, p. 89-92, 1998.

KUNO, G. Review of the factors modulating dengue transmission. Epidemiologic Reviews, Baltimore, US, v. 17, p. 321-335, 1995.

LAPORTA, J. L. Dengue e infestação do Aedes aegypti no município de Santo André, São Paulo. 2004. Tese (Doutorado em Saúde Pública) - Faculdade de Saúde Pública, Universidade de São Paulo, São Paulo, 2004.

LEITMEYER, K. C. et al. Dengue virus structural differences that correlate with pathogenesis. Journal of Virology, Washington, DC, v. 73, n. 6, p. 47384747, 1999.

LIMA, M. M. Criadouros de Aedes aegypti encontrados em alguns bairros da cidade do Rio de Janeiro. Cadernos de Saúde Pública, Rio de Janeiro, v. 4, n. 3, p. 293300, 1988.

LOBATO, C. et al. Aspectos epidemiológicos e entomológicos da dengue no Estado do Acre, 2000 e 2001. In: Congresso da Sociedade Brasileira de Medicina Tropical, 28., 2002, Foz do Iguaçu. Anais... São Paulo: Sociedade Brasileira de Medicina Tropical, 2002. p. 87. 
MARQUES, G. R. A. M. Aedes albopictus e outros mosquitos (Diptera Culicidae) em brómelias terrestres em Ilhabela, litoral do Estado de São Paulo, Brasil. 2001. Tese (Doutorado em Saúde Pública) - Faculdade de Saúde Pública, Universidade de São Paulo, São Paulo, 2001.

MARZOCHI, K. B. F. Dengue in Brazil: situation, transmission and control - a proposal for ecological control. Memórias do Instituto Oswaldo Cruz, Rio de Janeiro, v. 89, n. 2, p. 235-245, 1994.

MAYER, J D. The role of special analysis and geographic data in the detection of desease causation. Social Science and Medicine, New York, US, v. 17, p. 12131221, 1983.

MAZINE, C. A. B. et al. Disposable containers as larval habitats for Aedes aegypti in a city with regular refuse collection: a study in Marilia, São Paulo State, Brazil. Acta Tropica, Basel, CH, v. 62, p. 1-13, 1996.

MCCONNEL, K. J.; GUBLER, D. J. Guidelines on the cost-effectiveness of larval control programs to reduce dengue transmission in Puerto Rico. Revista Panamericana de Salud Pública, Washington, DC, v. 14, n. 1, p. 9-16, 2003.

MEDRONHO, R. A. A geografia do dengue no município do Rio de Janeiro: uma análise por geoprocessamento. 1993. Dissertação (Mestrado em Saúde Pública) Escola Nacional de Saúde Pública, Fundação Oswaldo Cruz, Rio de Janeiro, 1993.

MEDRONHO, R. A. Geoprocessamento e saúde: uma abordagem do espaço saúdedoença. Rio de Janeiro: FIOCRUZ/CICT/NECT, 1995.

MEDRONHO, R. A.; PEREZ M. A. Distribuição das doenças no espaço e no tempo. In: CARVALHO, D. M. et al. Epidemiologia. São Paulo: Atheneu, 2002.

MENGUETTE, A. A. C.; DECANINI, M.; IMAI, N. N. Ensino de SIG na faculdade de ciências e tecnologia da UNESP. In: SIMPÓSIO BRASILEIRO DE GEOPROCESSAMENTO, 1997, São Paulo. Anais... Escola Politécnica, Universidade de São Paulo, 1997. p. 433-440.

MESSER, W. B. et al. Emergence and global spread of a dengue serotype 3, subtype III virus. Emerging Infectious Diseases, Atlanta, US, v. 9, p. 800-809, 2003.

MONDINI, A. et al. Análise espacial da transmissão de dengue em cidade de porte médio do interior paulista. Revista de Saúde Pública, São Paulo, v. 39, n. 3, p. 444451, 2005.

MOORE, C. G. The future vector born disease control: needs and directions. Bulletin Society Vector Ecology, v. 15, p. 1-4, 1990. 
MORRISON, A. C. et al. Increased fecundity of Aedes aegypti fed human blood before release in a mark-recapture study in Puerto Rico. Journal of the American Mosquito Control Association, Fresno, CA, v.15, n. 2, p. 98-104, 1999.

NIMER, E. Climatologia da Região Sudeste do Brasil. Introdução à climatologia dinâmica. Revista Brasileira de Geográfica, v. 34, p. 3-48, 1972. Suplemento 1.

NIMMANNITYA, S. Dengue haemorrhagic fever in Thailand. The Southeast Asian journal of tropical medicine and public health, Bangkok, TH, v. 18, p.291-4, 1987.

NOGUEIRA, R.M. et al. Tipo 3 do vírus do Dengue, Brasil, 2002. Emerging infectious diseases, Atlanta, US, v. 11, p. 1376 -81, 2005.

OCAZIONEZ, R. et al. Temporal distribution of dengue virus serotypes in Colombian endemic area and dengue incidence: re-introduction of dengue-3 associated to mild febrile illness and primary infection. Memórias do Instituto Oswaldo Cruz, Rio de Janeiro, v. 101, p. 725-731, 2006.

OMS - ORGANIZAÇÃO MUNDIAL DA SAÚDE. Dengue hemorrágica: diagnóstico, tratamento, prevenção e controle. 2. ed. São Paulo: Santos, 2001.

OPAS - ORGANIZAÇÃO PAN-AMERICANA DA SAÚDE. Sistemas de informação geográfica em saúde: Conceitos Básicos, Brasília, DF, p. 124, 2002.

PANG, T. Dengue haemorrahagic fever: vírus or host response? Bioessays, Cambridge, US, v. 6, n. 3, p. 141-144, 1987.

PASSOS, M. et al. Clinical differences observed in patients with dengue caused by different serotypes in the epidemic of 2001/2002, occurred in Rio de Janeiro. Revista da Sociedade Brasileira de Medicina Tropical, São Paulo, v. 37, p. 293-295, 2004.

PATZ, J. A.; MARTENS, W. J. M.; FOCKS, D. A.; JEFTTEN, T. H. Dengue fever epidemic potencial as projected by general circulation models of global climate change. Environmental Health Perspectives, Boston, US, v. 16, n. 3, p. 147-153, 1998.

PEREIRA, M. Produtividade e habitats larvários de Aedes aegypti em Santos, Estado de São Paulo. 2001. Tese (Doutorado em Saúde Pública) - Faculdade de Saúde Pública, Universidade de São Paulo, São Paulo, 2001.

PINHEIRO, F. P. Los programas de erradicacion y de control del Aedes aegypti em lãs Américas. OPS/HCP/HCT, 1996.

REBÊLO, J. M. M. et al. Distribuição de Aedes aegypti e do dengue no Estado do Maranhão, Brasil. Cadernos de Saúde Pública, Rio de Janeiro, v. 15, n. 3, p. 477486, 1999. 
RODRIGUES, M. SIGs e suas conseqüências no Brasil. In: SIMPÓSIO BRASILEIRO DE GEOPROCESSAMENTO, 1995, São Paulo. Anais... São Paulo: Escola Politécnica, Universidade de São Paulo, 1995.

ROSEN, L. La pathogenèse de la dengue hemorragique: discusión critique des hypothèses actuelles. Bulletin Society of Pathology, v. 79, p. 342-349, 1986.

ROSEN, L. The emperor's new clothes revisited, or reflections on the pathogenesis of dengue hemorrhagic. The American Journal of Tropical Medicine and Hygiene, Cleveland, Ohio, v. 26, n. 3, p. 337-343, 1977.

ROTHMAN, K. J. A sobering start for the cluster busters'conference. American Journal of Epidemiology, Baltimore, US, v. 132, p. 6-13, 1990.

SANTOS, R. S. Fatores associados à ocorrência de formas imaturas de Aedes aegypti na Ilha do Governador, Rio de Janeiro, Brasil. Revista da Sociedade Brasileira de Medicina Tropical, São Paulo, v. 32, n. 4, p. 373-382, 1999.

SANTOS, A.; MARÇAL JÚNIOR, O.; VICTORIANO, M. R. Incidência do dengue na zona urbana do município de Uberlândia, MG, em 1999. Bioscience Journal, Uberlândia, v.18, p. 33-40, 2002.

SANTOS, O. O. Estudo epidemiológico da dengue em Maceió, Alagoas, no período de 1997 a 2002. 2003. Tese (Doutorado em Saúde Pública) - Faculdade de Saúde Pública, Universidade de São Paulo, São Paulo, 2003.

SANTOS, L. S. Avaliação das ações de controle da dengue: aspectos críticos e percepção da população. 2003. Dissertação (Mestrado em Saúde Pública) - Centro de Pesquisa Aggeu Magalhães, Fundação Oswaldo Cruz NESC/CPqAM/FIOCRUZ, Rio de Janeiro, 2003.

SCANDAR, S. A. S. Dengue no município de Paraíso. São Paulo/Brasil, 1993. 1998. Dissertação (Mestrado em Epidemiologia) - Universidade Federal de São Paulo, Escola Paulista de Medicina - UNIFESP, São Paulo, 1998.

SCANDAR, S. A. S. et al. Inquérito sorológico, após epidemia de Dengue, Paraíso São Paulo. Revista do Instituto Adolfo Lutz, São Paulo, v. 62, n. 2, p. 83-89, 2003.

SERVICE, M. W. Importance of ecology in Aedes aegypti control. The Southeast Asian journal of tropical medicine and public health, Bangkok, TH, v. 23, p. 681690, 1992.

SILVA, H. H.G.; SILVA, I. G. Influência do período de quiescência dos ovos sobre o ciclo de vida do Aedes aegypti (Linnaeus, 1762) (Díptera: Culicidae) em condições de laboratório. Revista da Sociedade Brasileira de Medicina Tropical, São Paulo, v. 32, n. 4, p. 349-355, 1999. 
SILVEIRA, A. C. Dengue: aspectos epidemiológicos e de controle. Revista da Sociedade Brasileira de Medicina Tropical, São Paulo, v. 31, p. 5-14, 1998. Suplemento 2.

SJRP - SÃO JOSÉ DO RIO PRETO - Prefeitura Municipal. Conjuntura econômica. Disponívelem:<http://www.riopreto.sp.gov.br/externos/sm_planejamento/conjuntura_economica20 06.pdf>. Acesso em: 15 set 2006.

SKABA, D. A. et al. Geoprocessamento dos dados da saúde: o tratamento dos endereços. Cadernos de Saúde Pública, Rio de Janeiro, v. 20, n. 6, p. 1753-1756, 2004.

SIMONE, T. S. et al. Dengue virus surveillance: the cocirculation of DENV-1, DENV-2 and DENV-3 in the state of Rio de Janeiro, Brazil. Transactions of the Royal Society of Tropical Medicine and Hygiene, London, GB, v. 98, p. 553-562, 2004.

SOUZA-SANTOS, R.; CARVALHO, M. S. Análise da distribuição espacial de larvas de Aedes aegypti na Ilha do Governador, Rio de Janeiro, Brasil. Cadernos de Saúde Pública, Rio de Janeiro, v. 16, n. 1, p. 31-42, 2000.

STAR, J.; ESTES, J. GIS: na introduction. Englewood Cliffs Prentice-Hall, 1990.

TAUIL, P. L. Urbanização e ecologia do dengue. Cadernos de Saúde Pública, Rio de Janeiro, v. 17, p. 99-102, 2001. Suplemento.

TEIXEIRA, M. G.; BARRETO, M. L.; GUERRA, Z. Epidemiologia e medidas de prevenção do dengue. Informe Epidemiológico do SUS, Brasilia, DF, v. 8, p. 5-33, 1999.

TEIXEIRA, M. G. et al. Epidemiologia do dengue em Salvador - Bahia. Revista da Sociedade Brasileira de Medicina Tropical, São Paulo, v. 34, n. 3, p. 269-274, 2001.

TEIXEIRA, M. G. et al. Dinâmica de circulação do vírus da dengue em uma área metropolitana do Brasil. Epidemiologia e Serviços de Saúde, Salvador, v. 12, n. 2, p. 87-97, 2003.

THEME FILHA, M. M.; BARAN, M. Dengue hemorrágico em crianças durante a epidemia de dengue no município de Rio de Janeiro, 1990 - 1991. In: CONGRESSO BRASILEIRO DE EPIDEMIOLOGIA, 2., 1992, Belo Horizonte. Resumos. Belo Horizonte: ABRASCO, 1992. p. 62.

THU, H. M.; AYE, K. M.; THEIN, S. The effect of temperature and humidity on dengue virus propagation in Aedes aegypti mosquitos. The Southeast Asian journal of tropical medicine and public health, Bangkok, TH, v. 29, p. 280-284, 1998. 
VASCONCELOS, P. F. C. et al. Epidemia de febre clássica de dengue causada pelo sorotipo 2 em Araguaiana, Tocantins, Brasil. Revista do Instituto de Medicina Tropical, São Paulo, v. 35, p. 141-148, 1993. Suplemento 2.

VASCONCELOS, P. F. C. et al. Epidemia de dengue em Fortaleza, Ceará, 1994: inquérito soro epidemiológico aleatório. Revista de Saúde Pública, São Paulo, v. 32, n. 5, p. 447-454, 1998.

VASCONCELOS, P. F. C. et al. Inquérito soro-epidemiológico na Ilha de São Luis durante epidemia de dengue no Maranhão. Revista da Sociedade Brasileira de Medicina Tropical, São Paulo, v. 32, n. 2, p. 171-179, 1999.

VASCONCELOS, P. F. C. et al. Epidemia de dengue em Ipupiara e Prado, Bahia. Inquérito soroepidemiológico. Revista da Sociedade Brasileira de Medicina Tropical, São Paulo, v. 33, n. 1, p. 61-67, 2000.

WINCH, P. J. et al. Community-based dengue prevention programs in Puerto Rico: impact on knowledge, behavior, and residential mosquito infestation. The American Journal of Tropical Medicine and Hygiene, Cleveland, Ohio, v. 67, n. 4, p. 363370, 2002. 


\section{ANEXOS}

\section{ANEXO 1}

Casos de dengue por mês e ano no município de São José do Rio Preto - Estado de São Paulo, no período de 1990 a 2005.

\begin{tabular}{|c|c|c|c|c|c|c|c|c|c|c|c|c|c|}
\hline \multicolumn{14}{|c|}{ CASOS DE DENGUE } \\
\hline \multirow{2}{*}{ ANO } & \multicolumn{12}{|c|}{ MESES } & \multirow[b]{2}{*}{ TOTAL } \\
\hline & JAN & FEV & MAR & ABR & MAI & JUN & JUL & AGO & SET & OUT & NOV & DEZ & \\
\hline 1990 & 0 & 0 & 0 & 0 & 0 & 0 & 0 & 0 & 0 & 0 & 0 & 7 & 7 \\
\hline 1991 & 18 & 9 & 6 & 5 & 0 & 0 & 0 & 0 & 0 & 0 & 0 & 1 & 39 \\
\hline 1992 & 0 & 0 & 0 & 0 & 0 & 0 & 0 & 0 & 0 & 0 & 0 & 0 & 0 \\
\hline 1993 & 0 & 0 & 1 & 0 & 4 & 47 & 13 & 0 & 0 & 0 & 0 & 0 & 65 \\
\hline 1994 & 0 & 4 & 31 & 59 & 7 & 0 & 0 & 0 & 0 & 0 & 1 & 16 & 118 \\
\hline 1995 & 352 & 348 & 346 & 187 & 50 & 3 & 1 & 1 & 0 & 0 & 2 & 5 & 1295 \\
\hline 1996 & 18 & 91 & 285 & 256 & 66 & 4 & 0 & 0 & 2 & 1 & 0 & 6 & 729 \\
\hline 1997 & 12 & 20 & 83 & 42 & 18 & 4 & 3 & 0 & 0 & 6 & 18 & 12 & 218 \\
\hline 1998 & 45 & 72 & 170 & 167 & 177 & 24 & 1 & 0 & 0 & 8 & 29 & 53 & 746 \\
\hline 1999 & 96 & 348 & 833 & 1144 & 274 & 23 & 2 & 3 & 0 & 0 & 2 & 1 & 2726 \\
\hline 2000 & 3 & 8 & 47 & 219 & 162 & 35 & 7 & 4 & 2 & 1 & 0 & 1 & 489 \\
\hline 2001 & 56 & 169 & 990 & 2906 & 2214 & 447 & 66 & 31 & 12 & 10 & 9 & 9 & 6919 \\
\hline 2002 & 56 & 154 & 279 & 347 & 110 & 26 & 3 & 1 & 4 & 3 & 3 & 3 & 989 \\
\hline 2003 & 34 & 107 & 190 & 78 & 31 & 5 & 1 & 0 & 0 & 0 & 0 & 0 & 446 \\
\hline 2004 & 4 & 14 & 4 & 15 & 15 & 2 & 1 & 2 & 0 & 0 & 0 & 0 & 57 \\
\hline 2005 & 7 & 11 & 41 & 107 & 94 & 21 & 2 & 2 & 13 & 19 & 19 & 38 & 374 \\
\hline
\end{tabular}

Fonte: CVE 


\section{ANEXO 2}

Coeficiente geral de Correlação de Pearson (r) e valores de (p) comparando as variáveis de precipitação pluviométrica, temperatura, índice de infestação predial (ip) e incidência de dengue (ic), no município de São José do Rio Preto - Estado de São Paulo, entre os anos de 1990 a 2005.

\begin{tabular}{ccccccc} 
& & IP & IC & PRECIP.PLUVIO. & TEMP \\
\hline \multirow{3}{*}{ IP } & $\mathrm{r}$ & 1,000 & $-0,050$ & $0,223^{* *}$ & $0,146^{*}$ \\
& $\mathrm{p}$ & 0 & 0,491 & 0,002 & 0,044 \\
& $\mathrm{~N}$ & 192 & 192 & 192 & 192 \\
\hline \multirow{3}{*}{ IC } & $\mathrm{r}$ & $-0,050$ & 1,000 & 0,009 & 0,052 \\
& $\mathrm{p}$ & 0,491 & 0 & 0,901 & 0,475 \\
& $\mathrm{~N}$ & 192 & 192 & 192 & 192 \\
\hline \multirow{3}{*}{ PRECIP.PLUVIO } & $\mathrm{r}$ & $0,223^{* *}$ & 0,009 & 1,000 & $0,518^{* *}$ \\
& $\mathrm{p}$ & 0,002 & 0,901 & 0 & 0,001 \\
& $\mathrm{~N}$ & 192 & 192 & 192 & 192 \\
\hline \multirow{2}{*}{ TEMP } & $\mathrm{r}$ & $0,146^{*}$ & 0,052 & $0,518^{* *}$ & 1,000 \\
& $\mathrm{p}$ & 0,044 & 0,475 & 0,001 & 0 \\
& $\mathrm{~N}$ & 192 & 192 & 192 & 192 \\
\hline
\end{tabular}

**Correlação significante $(\mathrm{p}<0,01)$

*Correlação significante $(\mathrm{p}<0,05)$

Fonte: SUCEN e Secretaria da Agricultura 


\section{ANEXO 3}

\begin{tabular}{|c|c|c|c|c|c|c|c|c|c|c|c|c|c|c|c|}
\hline \multirow{2}{*}{$\begin{array}{c}\text { ÁRE } \\
\text { A }\end{array}$} & \multirow{2}{*}{$\begin{array}{c}\text { DENS. } \\
\text { DEMOGR } \\
\cdot\end{array}$} & \multirow{2}{*}{$\begin{array}{l}\text { REDE } \\
\text { DE } \\
\text { ESGOT } \\
\text { O }\end{array}$} & \multirow{2}{*}{$\begin{array}{l}\text { COLETA } \\
\text { DE LIXO }\end{array}$} & \multirow{2}{*}{$\begin{array}{c}\text { ABAS. } \\
\text { DE } \\
\text { ÁGUA }\end{array}$} & \multicolumn{5}{|c|}{ GRAU DE ESCOLARIDADE } & \multicolumn{6}{|c|}{ RENDA } \\
\hline & & & & & $\begin{array}{c}\text { Fund. } \\
\text { incomp } \\
\text {. }\end{array}$ & $\begin{array}{c}\text { Fund. } \\
\text { comp } \\
.\end{array}$ & $\begin{array}{c}\text { Seg. } \\
\text { grau } \\
\text { incomp. }\end{array}$ & $\begin{array}{c}\text { Seg. } \\
\text { grau } \\
\text { comp. }\end{array}$ & Sup. & $\begin{array}{c}<=1 \mathrm{~S} \\
\mathrm{M}\end{array}$ & $\begin{array}{c}1 \text { a } 3 S \\
M\end{array}$ & $\begin{array}{c}3 \text { a } 5 \mathrm{~S} \\
\mathrm{M}\end{array}$ & $\begin{array}{c}5 \text { a } 10 \mathrm{~S} \\
\mathrm{M}\end{array}$ & $\begin{array}{c}10 \text { a } 15 \mathrm{~S} \\
\mathrm{M}\end{array}$ & $\begin{array}{c}<15 \mathrm{~S} \\
\mathrm{M}\end{array}$ \\
\hline 1 & 24643 & 7005 & 6856 & 6278 & 1099 & 555 & 334 & 1414 & 910 & 869 & 1809 & 1687 & 1918 & 383 & 342 \\
\hline 2 & 32650 & 8458 & 8454 & 8352 & 2430 & 804 & 306 & 706 & 202 & 1891 & 3396 & 1996 & 1045 & 80 & 55 \\
\hline 3 & 26696 & 7401 & 7395 & 7349 & 1505 & 721 & 310 & 1052 & 401 & 1132 & 2454 & 1856 & 1526 & 281 & 163 \\
\hline 4 & 35950 & 9334 & 9344 & 9323 & 3519 & 1012 & 416 & 1067 & 249 & 1681 & 3766 & 2434 & 1284 & 122 & 67 \\
\hline 5 & 31790 & 8581 & 8524 & 8357 & 1489 & 726 & 373 & 1471 & 852 & 1108 & 2302 & 2021 & 2175 & 505 & 473 \\
\hline 6 & 14739 & 4140 & 4113 & 4049 & 479 & 288 & 196 & 750 & 647 & 439 & 918 & 965 & 1108 & 248 & 462 \\
\hline 7 & 26933 & 8085 & 8085 & 7869 & 816 & 455 & 299 & 1162 & 1233 & 1099 & 2238 & 1571 & 1902 & 574 & 704 \\
\hline 8 & 28024 & 8534 & 8537 & 8369 & 931 & 567 & 307 & 1365 & 1406 & 1222 & 2271 & 1733 & 1913 & 585 & 814 \\
\hline 9 & 19189 & 5332 & 5322 & 4986 & 360 & 242 & 119 & 971 & 1896 & 380 & 701 & 773 & 1382 & 648 & 1452 \\
\hline 10 & 28084 & 9009 & 8990 & 7785 & 205 & 228 & 127 & 1381 & 4699 & 417 & 662 & 887 & 2248 & 1148 & 3652 \\
\hline 11 & 21693 & 6506 & 6511 & 6432 & 461 & 329 & 162 & 971 & 1633 & 554 & 1256 & 1142 & 1669 & 667 & 1224 \\
\hline 13 & 22648 & 6631 & 6630 & 6594 & 765 & 459 & 225 & 1068 & 961 & 918 & 1630 & 1434 & 1583 & 435 & 632 \\
\hline 14 & 15671 & 4722 & 4724 & 4587 & 524 & 326 & 172 & 884 & 1246 & 441 & 884 & 918 & 1370 & 472 & 643 \\
\hline
\end{tabular}

IBGE: 2000 